\title{
Visualização de dados como ferramenta de Classificação em sistemas de Bases de Dados para Data Mining
}

\author{
Elisângela Botelho
}

Orientador:

\section{Prof. Dr. Caetano Traina Júnior}

Dissertação apresentada ao Instituto de Ciências Matemáticas e de Computação ICMC'-USP. como parte dos requisitos para obtenção do titulo de Mestre em Ciências de C'omputação e Matemática Computacional.

\author{
USP - São Carlos \\ Setembro/2002
}

\section{“VERSÃO REVISADA APÓS A DEFESA"}




\section{Agradecimentos}

A DEUS, por mais uma vez, ter permitido vencer uma importante etapa da minha vida!

Aos meus pais, Teldo e Nazaré, pelo amor, dedicação e prcocupação. Sem vocês nada seria possível! Vocês são tudo pra mim!

Aos meus irmãos, Elisson, Júnior e Natel, obrigada pelo amor c pela força de vocês! Vocês também são tudo pra mim!

Ao Prof. Dr. Caetano, não só pela excelente orientação, mas pelo exemplo maravilhoso de ser humano! Obrigada pela confiança, paciência e compreensão.

Às minhas grandes amigas de São Carlos, Camila, Daniela e Regiane, que compartilharam todos os bons e maus momentos durante esses dois anos de mestrado. Obrigada pela amizade, carinho, força, paciência e compreensão de vocês!

À Prof. Dra. Aggma e a todos os meus amigos do GBDI pela força durante este mestrado! Conviver com vocês foi muito bom e importante pra mim! Humberto, valeu pelo grande apoio técnico!

A todos os amigos que conheci nesses dois anos de São Carlos, pela amizade e pelos bons momentos compartilhados! Elaine, obrigada pelas correçóes e pela amizade, mesmo que recente.

Aos funcionários do ICMC pelo apoio lécnico e administrativo.

A FAPESP pelo apoio financeiro.

E a todos, que de alguma forma, contribuiram para essa minha vitória! Mcu muitíssimo obrigada! 


\section{Sumário}

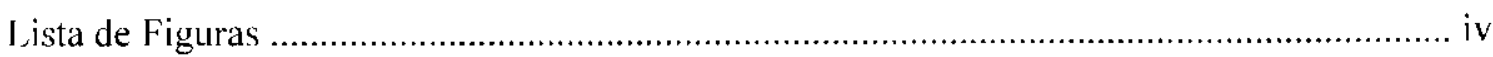

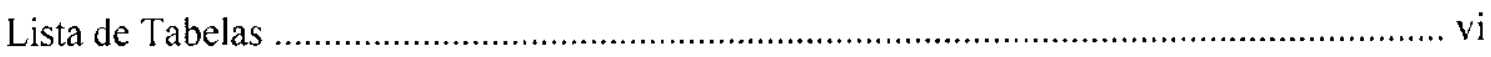

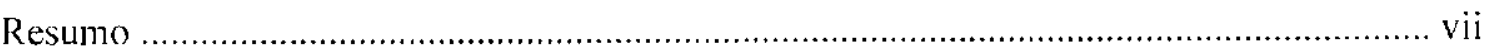

$\begin{array}{ll}\text { Capítulo } 1 \text { - Introdução } & 01\end{array}$

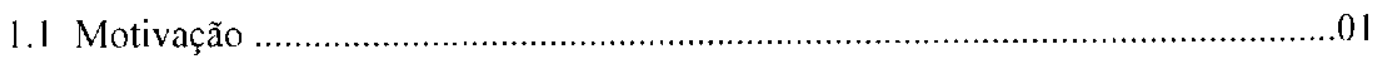

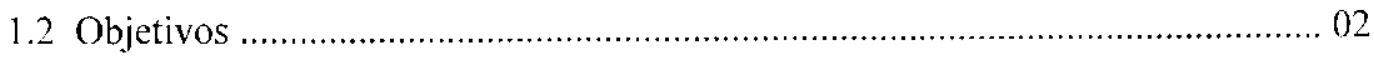

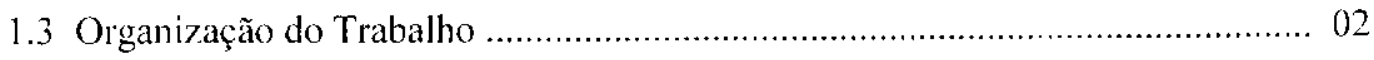

Capítulo 2 - Descoberta de Conhecimento em Bases de Dados e Mineração de Dados $\quad 04$

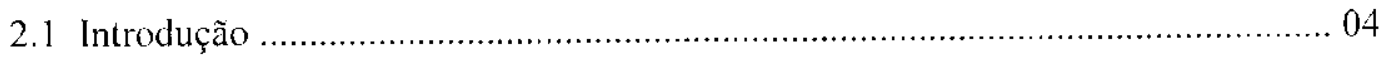

2.2 Descoberta de Conhecimento em Bases de Dados ........................................... 04

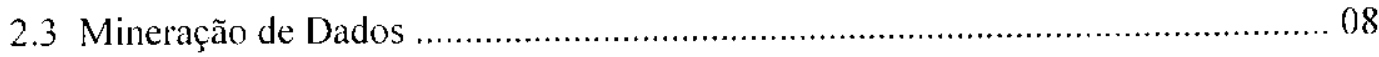

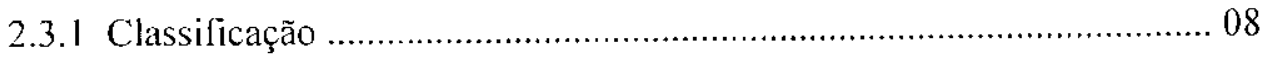

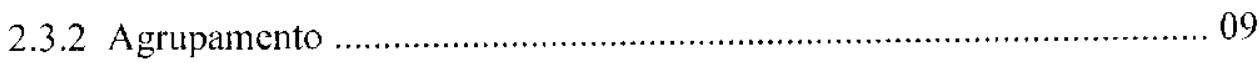

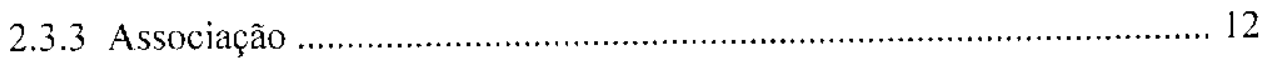

2.3.4 Tratamento de Exceções .............................................................. 13

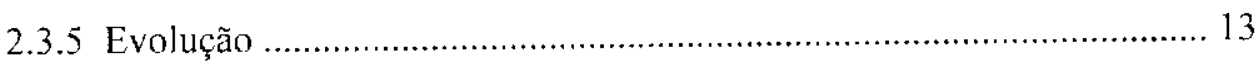

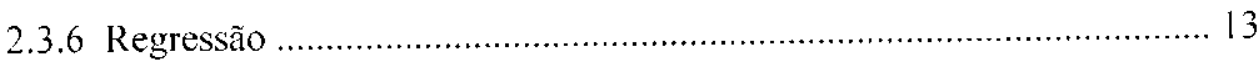

2.3.7 Redução de Dimensionalidade ................................................... 14

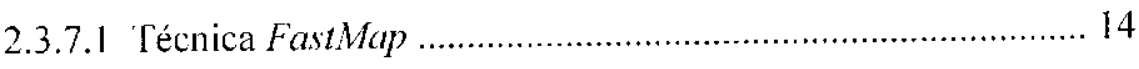

2.3.8 Mćtodos de Solıção para a Tarefa de Classificação de Dados ............. 16

2.3.8.1 Árvores de Decisão ........................................................ 16 
2.3.8.3 Classificadores Bayesianos................................................ 21

2.4 Considerações Gerais entre KDD e DM ….................................................... 25

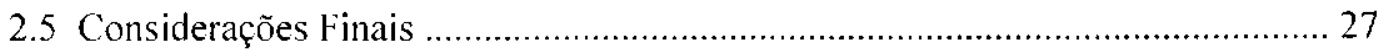

Capitulo 3 - Visualização de Dados $\quad 28$

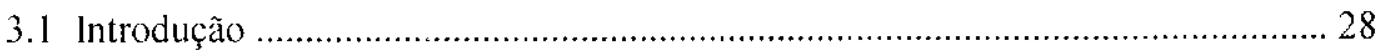

3.2 Visualização de Dados e Exploração Visual de Dados ........................................... 28

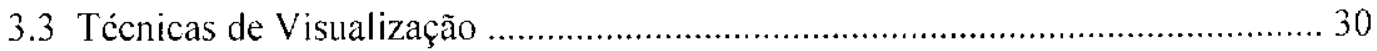

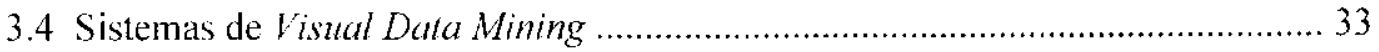

3.5 Formas de Integração das áreas de Visualização de Dados e Mineração de

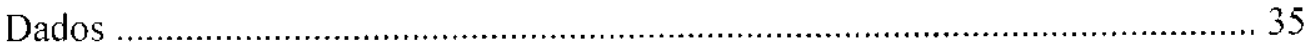

3.6 Princípios de uma Representação Gráfica ..................................................... 37

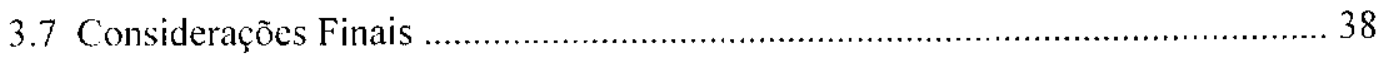

Capítulo 4 - Arquitetura do Classificador de Dados 39

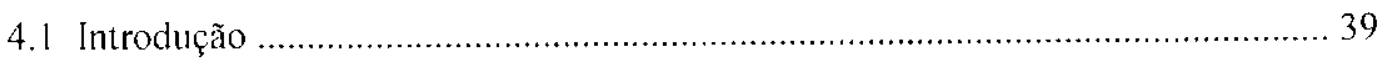

4.2 Descrição da Ferramenta FastMapDB ........................................................ 40

4.2.1 Módulo Visualizador do Fast MapDB …....................................... 43

4.3 Processo de Seleção Visual dos Dados ........................................................... 44

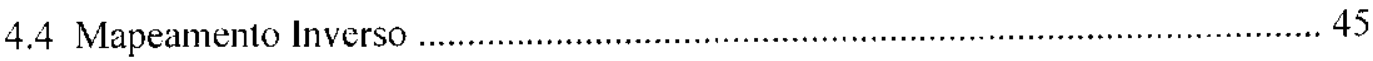

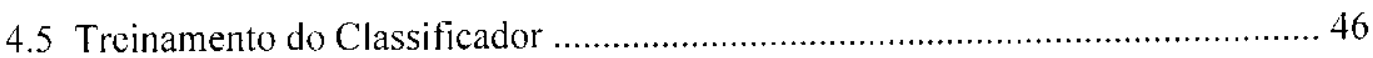

4.5.1 Tabelas do Treinamento do Classificador ........................................... 48

4.6 Processo de Classificação de Dados ...................................................................... 53

4.6.1 Fórmula de Classificação de Dados ....................................................... 56

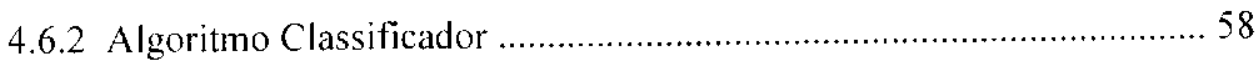


Capítulo 5 - Exemplo de Utilização do Classificador de Dados

5.1 Introdução 63

5.2 Utilização da Ferramenta FastMapDB para Classificação de Dados 63

5.2.1 Exemplo da Fase de 'Treinamento do Classificador de Dados 64

5.2.2 Exemplo do Processo de Classificação de Dados 70

5.3 Considerações Finais 77

Capítulo 6 - Conclusões 78

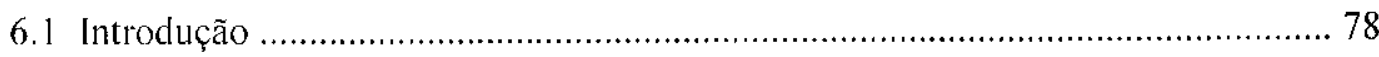

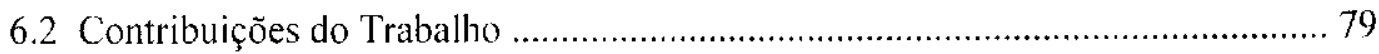

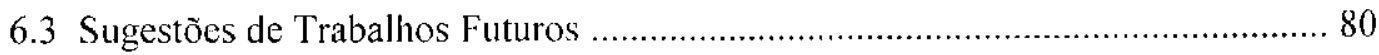

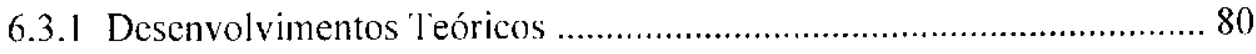

6.3.1.1 Suporte à Classificação com Análise de Vizinhança .............. 80

6.3.1.2 Suporte à Lógica Nebulosa …......................................... 81

6.3.2 Extensão da Ferramenta FastMapDB ............................................ 81

6.3.2.1 Visualização do Treinamento ........................................... 81

6.3.2.2 Suportar Diferentes Formas das Regiões ........................... 82 


\section{Lista de Figuras}

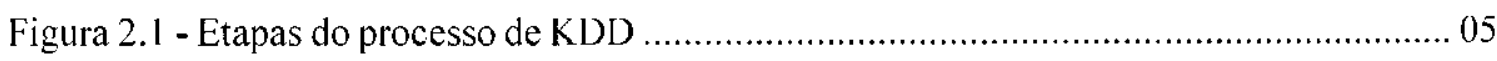

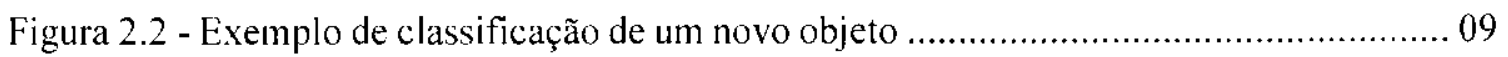

Figura 2.3 - Excmplo de agrupamento de dados ....................................................... 10

Figura 2.4 - Representação gráfica dos passos do algoritmo Fastmap ................................ 15

Figura 2.5 - Árvore de decisão para análise de risco [Felipe, 2000] ................................... 18

Figura 2.6 - Estrutura básica de uma rede neural ........................................................ 19

Figura 2.7 - Rede Neural para análise de risco cm [Felipe, 2000] ...................................... 21

Figura 3.1 - Técnica de projeção geométrica [Keim, 1997] ............................................. 31

Figura 3.2 - Técnica de apresentação icônica [Kcim, 1997] .............................................. 32

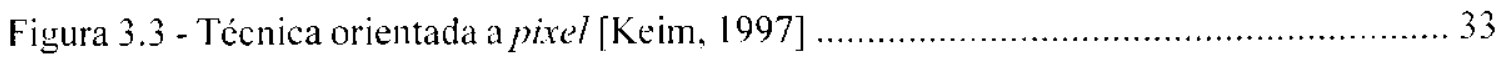

Figura 3.4 - Formas de integração de visualização de dados e DM ..................................... 36

Figura 4.1 - Tela principal da ferramenta FastMapDB …............................................. 42

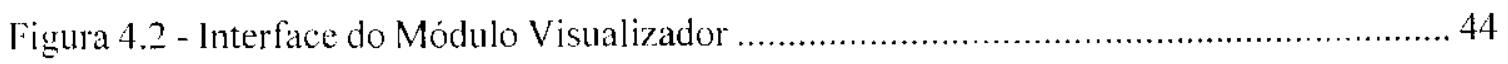

Figura 4.3 - Seleção de uma região de pontos (paralelepípedo) …..................................... 45

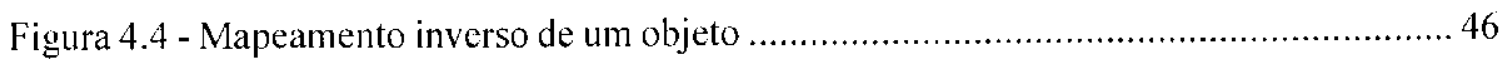

Figura 4.5 - Relacionamento entre as tabelas do treinamento do classificador ..................... 48

Figura 4.6 - Regiões selecionadas pelo usuário para o treinamento do classificador .............. 52

Figura 4.7 - Tabela criada após o processo de classificação dos dados .................................. 55

Figura 4.8 - Seleção de duas regiões na visualização dos dados ......................................... 57

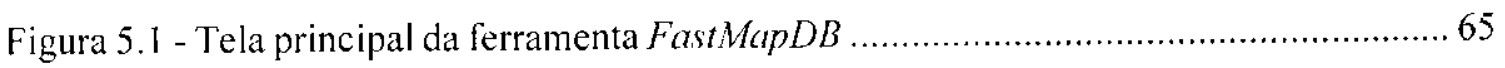

Figura 5.2 - Tela de configuração dos parâmetros dos atributos e escolha da função distância .66 
Figura 5.3 - Visualização dos dados do conjunto "Iris Plant"e seleção de uma região para o treinamento do classificador 67

Figura 5.4 - Visualização dos dados do conjunto "Iris Plant" e seleção de outra região para o treinamento do classificador 68

Figura 5.5 - Seleção da tabela a ser classificada 72 


\section{Lista de Tabelas}

Tabela 2.1 - Transações de Compras ilustrada em Felipe [Felipe, 2000] ............................. 12

Tabela 2.2 - Análise de risco para árvores de decisão em [Felipe, 2000] ............................. 17

Tabela 2.3 - Análise de risco para redes neurais em [Felipe, 2000] ................................. 20

Tabela 2.4 - Dados utilizados pelo classificador bayesiano Naive [Han \& Kamber, 2000] ... 24

Tabela 4.1 - Descrição dos atributos da tabela Visualization ............................................... 49

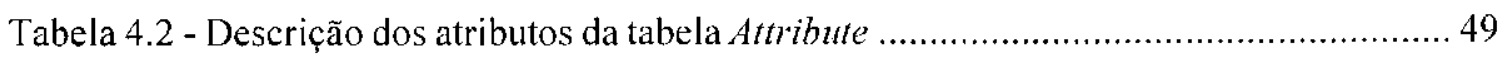

Tabela 4.3 - Descrição dos atributos da tabela Shape ……............................................... 50

Tabela 4.4 - Descrição dos atributos da tabela Counting .......................................................... 50

Tabela 4.5 - Exemplos de dados da tabela Visualization .................................................. 51

Tabela 4.6 - Exemplos de dados da tabcla Attribute ........................................................ 51

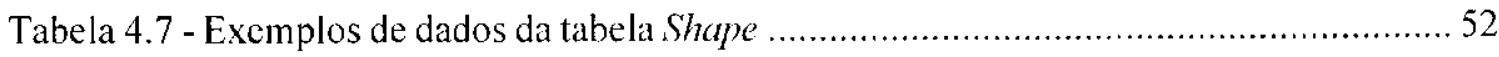

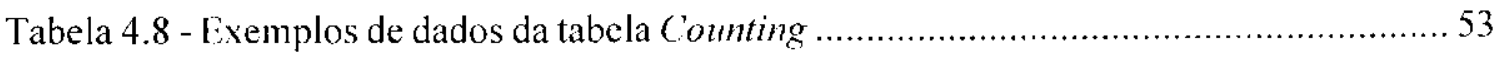

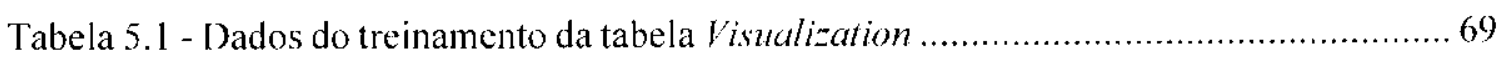

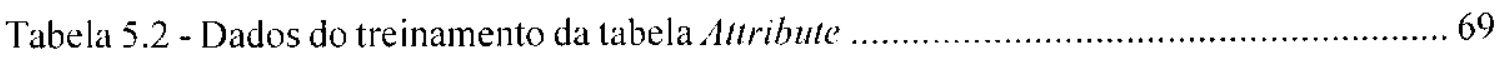

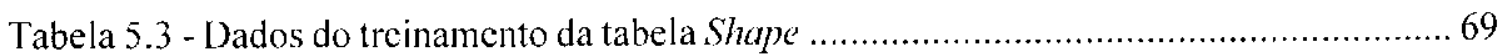

Tabela 5.4 - Dados do treinamento da tabela Counting .................................................... 70 
Botelho, E. Visualização de Dados como Ferramenta de Classificação em Sistemas de Bases de Dados para Data Mining. São Carlos, 2002. 87p. Dissertação de Mestrado - Instituto de Ciências Matemáticas c de Computação, USP.

\section{Resumo}

A automação das atividades em diversas áreas, tais como negócios, engenharia, medicina, ciência e governo, vêm aumentando a cada dia, e com isso. cresce o volume de dados armazenados nas bases de dados. É interessante usar esses dados além dos objetivos originais das operações de pura armazenagem e busca do empreendimento inicial. Em outras palavras, é desejável extrair informações úteis, não previstas inicialmentc, agregando valor ao empreendimento. Embora os gerenciadores de bases de dados forneçam ferramentas básicas para recuperação de dados em transações padrão em grandes quantidades de dados, analisar grandes volumes de dados em formato numérico ou textual, especialmente em espaços de altas dimensões, não é fácil para o ser humano. Por outro lado, o ser humano tem uma capacidade de absorver e entender informação representada de forma gráfica muito rapidamente. Dessa forma, este trabalho visa o desenvolvimento de uma nova técnica para construção visual de classificadores de dados em atividades de Data Mining, utilizando essa reconhecidamente elevada capacidade humana de análise de dados representados em formato gráfico como fator que auxilia o treinamento do classificador. Fste trabalho cstende a ferramenta $F a s t M a p D B$, que em sua versão original permitia apenas a visualização de dados e não possibilitava ao usuário interferir no processo de visualização, para permitir. não apenas essa visualização de dados, mas também, a seleção visual dos objetos mapeados c a delimitação de regiões de objetos na visualização. Com isso, a ferramenta passa a permitir a recuperação dos dados presentes na base de dados que o usuário considerar interessantes a partir da visualização, e provê à ferramenta recursos de classificação de novos objetos segundo regras visuais que o usuário possa definir no espaço mapeado de visualização. $\Lambda$ proposta deste trabalho é inédita no sentido de aplicar técnicas de visualização como fator de treinamento do classificador. As ferramentas atuais apenas mostram resultados já elaborados pelo sistema, e a continuação do processo é sempre solicitada, ou decidida manualmente, pelo usuário. Nosso sistema, ao contrário, realimenta a interpretação que o usuário pode fazer a respeito dos dados, e permite que os passos de análise seguintes utilizem automaticamente esse resultado. 


\begin{abstract}
The automation of the activities in several areas, such as business, engineering, medicine, science and government, are increasing everyday, pressing, the volume of data stored in the databases to grow exponentially. It is interesting to make use of these data beyond the original objectives of the enterprise. Moreover, it is desirable to extract uscful information not previously foreseen, aggregating value to the enterprise. Although the database management systems supply basic tools to data recovery and analysis through the standard transactions in large amounts of data, analyzing these data in numerical or textual format, especially in spaces of high dimensions, is an overwhelming job to human beings. On the other hand, human being has a great capacity to quickly absorb and understand information represented of graphical form. As classification is one of the most common analysis tasks, this work aims at the development of a new technique for the visual construction of classifiers, using this high human capacity to analyze data represented in graphical format as factor to guide the training of the classifier. This work extends the FastMapDB tool, that in its original version allowed only the visualization of data and it did not make possible the user to interfere in the visualization process, to allow not only this visualization of data, but also, the reverse identification of mapped objects and the delimitation of object regions in the visualization. This makes it possible to recover the data present in the database that the user consider interesting from the visualization, and providing to the tool visual resources for classification of the new objects according to rules that the user can define in the mapped space of visualization. The proposal of this work is new in regarding to apply visualization techniques as a factor to train the classifier. Existing tools are restricted to show results already discovered by the system. Our system, in contrast, takes advantages from the interpretation obtained from the user will through its interaction with the visualizations presented, and allows that subsequent data analysis tasks automatically use these results.
\end{abstract}




\section{Capítulo 1}

\section{Introdução}

\subsection{Motivação}

O grande progresso da tecnologia na área de hardware permitiu aos sistemas de computadores de hoje armazenarem grandes volumes de dados. E o espaço de armazenamento disponível é facilmente preenchido com dados, já que a automação das atividades em várias áreas (incluindo negócios, engenharia, medicina, ciência e govcrno, entre outras) vem aumentando a cada dia, o que acaba gerando grandes volumes de dados de fontes diversas, tais como: transações de cartão de crédito, chamadas telefônicas, pesquisa do genoma humano, etc. Geralmente, muitos parâmetros (atributos) são registrados, resultando em dados de muitas dimensões. Encontrar informação valiosa escondida nessas grandes bases de dados não é uma tarefa fácil, já que hoje cm dia essas bases de dados não podem mais ser consideradas simples repositórios de informações, mas sim, um importante patrimônio da organização.

Sabemos que os seres humanos não são "eficientes" para interpretar grandes volumes de dados em forma numérica ou textual, especialmente em espaços de altas dimensões, mas têm uma percepção muito boa quando esses dados são apresentados de forma gráfica. Por outro lado, técnicas completamente automáticas para detecção de características. classificação, agrupamentos, regressão, etc. são freqüientemente distorcidas pela incapacidade de técnicas automáticas de aproveitar outros conhecimentos que para um ser humano é lacilmente reconhecido e interpretado.

Acreditamos que para explorar grandes volumes de dados é muito proveitoso integrar essa clevada capacidade do ser humano de analisar dados em um formato gráfico juntamente com os poderosos recursos computacionais dos computadores de hoje. Isso poderá ajudar 
muito na descoberta de informação valiosa escondida nessas grandes bases de dados existentes.

\subsection{Objetivos}

O objetivo deste trabalho é o desenvolvimento de uma nova técnica para construção visual de classificadores de dados para Data Mining, utilizando a reconhecidamente elevada capacidade humana de análise de dados representados $\mathrm{cm}$ formato gráfico como fator que auxilia o treinamento do classificador. Este trabalho estende a ferramenta FastMapDB, apresentada na seção 4.2, que em sua versão original permitia apenas a visualização de dados e não possibilitava ao usuário interferir no processo de visualização, para permitir não apenas essa visualização de dados, mas também a identificação reversa dos objetos mapeados e a delimitação de regiões de objetos na visualização. Isso permite a recuperação dos dados (contidos na base de dados) que o usuário considera interessantes a partir da visualização, e provê à ferramenta recursos de classificação de novos objetos segundo regras visuais que o usuário define no espaço mapeado de visualização. Como meio de comprovar e demonstrar a viabilidade da técnica de classificação, este trabalho levou ao desenvolvimento de uma ferramenta real de classificação utilizando a nova técnica proposta.

\subsection{Organização do Trabalho}

Este trabalho é bastante interdisciplinar, pois demanda conhecimento principalmente das áreas de Knowledge Discovery in Databases, Data Mining. Banco de Dados e Visualização de dados. Dessa forma, para que ele possa ser melhor compreendido é necessário apresentar uma visão geral dos assuntos a ele relacionados. Assim, este trabalho está organizado da seguinte forma.

O Capítulo 2 explora os conceitos e as etapas do processo de Knowledge Discovery in Databases; os conceitos e as tarefas de Data Mining, bem como algumas soluções para essas tarefas.

O Capítulo 3 descreve os conceitos e técnicas relativas à Visualização de Dados. 
O Capítulo 4 apresenta a Arquitetura do Classificador de Dados desenvolvido neste trabalho de Mestrado, a fase de treinamento do classificador e o processo de classificação dos dados.

O Capítulo 5 mostra um exemplo de utilização do Classificador de Dados desenvolvido, através da utilização da ferramenta $F a s t M a p D B$, já que esse classificador foi integrado a essa ferramenta.

O Capítulo 6 apresenta as conclusões, as contribuições deste trabalho e as sugestões de trabalhos futuros. 


\section{Capítulo 2}

\section{Descoberta de Conhecimento em Bases de Dados e Mineração de Dados}

\subsection{Introdução}

Neste capítulo são abordados alguns conceitos relativos a Knowledge Discovery in Databases (KDD) e Dala Mining (DM). Sobre KDD são descritas as etapas desse processo de descoberta de conhecimento, bem como alguns excmplos de aplicações. Em DM são descritas algumas de suas tarefas, tais como: classificação, agrupamento, associação, tratamento de exceções, evolução, regressão e redução de dimensionalidade; são apresentados dois algoritmos utilizados na tarefa de agrupamentos de dados (Birch e Clarans), o algoritmo de redução de dimensionalidade - fastmap e também são discutidos alguns métodos de solução para a tarefa de classificação. $\Lambda$ presentar-sc-à também algumas considerações gerais entre KDD e DM.

\subsection{Descoberta de Conhecimento em Bases de Dados}

O termo KDD, Knowledge Discovery in Databases, que pode ser traduzido como descoberta de conhecimento em bases de dados, é o processo de identificar padrões ou modelos em um conjunto de dados que representem informação [Fayyad, 1997]:

- válida;

- inédita:

- potencialmente útil e; 
- essencialmente compreensível.

O termo data mining é usado, algumas vezes, como sinônimo de KDD. Porém, no presente trabalho será adotado o conceito de Fayyad [Fayyad, 1997] que define "KDD como o processo abrangente de descoberta de conhecimento útil a partir de dados, enquanto IDM refere-se a uma das etapas desse processo".

O processo de KDD pode ser dividido em várias etapas, como ilustrado na Figura 2.1:

- desenvolvimento do Data Warehouse;

- limpeza dos dados;

- seleção dos dados;

- transformação dos dados;

- mineração de dados;

- avaliação dos padrões e;

- apresentação do conhecimento.

DW

Seleção dos dados

Limpeza dos dados

Transformação dos dados

Mineração dos dados

Padrões

Avaliação dos padrões

Apresentação do conhecimento

Conhecimento

Figura 2.1 - Etapas do processo de KDD 
Cada uma dessas etapas possui muita interação com as demais, sendo que os resultados produzidos numa etapa podem ser utilizados para melhorar os resultados das próximas. Essas etapas são descritas a seguir:

Desenvolvimento do Data Warehouse (DW): É interessante que o processo de KDD se inicie pela construção de um DW, pois esse é um meio adequado para organizar grandes volumes de dados com a tecnologia atual. Um DW pode ser definido como uma coleção de dados orientada a assunto, integrada, não-volátil, variante no tempo, designado para ser utilizado como base para suporte à decisão e sistemas KDD [Inmon, 1996]. Um DW funciona como uma base de dados mantido separadamente das bases de dados operacionais da organização. O DW armazena todas as informações presentes e passadas da organização, o que o torna lento para o processamento das transações normais da organização, porém muito adequado à análise dos dados.

Limpeza dos dados: Nessa etapa ocorre a verificação da consistência das informações, a correção de possíveis erros e o precnchimento ou a eliminação de valores nulos e redundantcs. São, também, identificados e removidos os dados duplicados e/ou corrompidos.

Seleção dos dados: O objetivo dessa etapa é escolher apenas atributos relevantes (do conjunto de atributos da base de dados) para o objetivo da tarefa. O subconjunto selecionado é então fornecido para o algoritmo de mineração dos dados.

Transformação dos dados: Essa etapa consiste em transformar os dados para a forma apropriada para mineração utilizando, por exemplo, operações de sumarização ou agregação.

Mineração de dados: É a etapa mais importante do KDD e caracteriza-se pela aplicação de métodos, ordenadamente, a fim de que seja possível extrair, de forma eficiente, o conhecimento implícito e útil de uma base de dados (extração de padrões). 
Avaliação dos padrões: Essa etapa tem como objetivo avaliar a utilidade do conhecimento extraído, bem como remover padrões redundantes e irrelevantes.

Apresentação do conhecimento: Essa etapa utiliza técnicas de visualização e representaçâo do conhecimento para apresentar o conhecimento mincrado ao usuário.

Nos últimos anos, o leque de aplicações para KDD vem crescendo consideravelmente. Eis alguns exemplos [Felipe, 2000; Ankerst, 2000]:

- Marketing: análise de bases de dados de consumidores para identificar diferentes grupos de consumidores e fazer previsão de scus comportamentos. Outra notável aplicação de marketing é o sistema de análise market-basket, o qual encontra padrões tais como "se um consumidor compra X, cle também tenderá comprar $\mathrm{Y}$ ou Z";

- Empresas de Crédito c Seguradoras: análise de semelhança de casos e utilização de regras de indução a fim de detectar possíveis casos de fraude;

- Astronomia: descoberta de novos elementos celestes e alterações no comportamento dos mesmos, baseando-se em estudos de casos;

- Biologia Molecular: descoberta de padrões em estruturas moleculares e em dados genéticos;

- Modelagem de Alterações Climáticas: descoberta de padrões de ocorrência de fenômenos climáticos, tais como ciclones e frentes frias;

- Gerência de Informática: detcrminação de padrões de ocorrência de eventos para garantir operacionalidade e segurança de ambientes informatizados;

- Medicina: identificação de padrões de associação de terapias (bem ou mal sucedidas) para diferentes doenças. 


\subsection{Mineração de Dados}

Data Mining (DM), ou mincração de dados, é a principal etapa do processo de KDD, a qual consistc na aplicação de processos de análise de dados e algoritmos de descobrimento que produzem uma enumeração de padrões (ou modelos) particulares sobre os dados [Fayyad, 1997]. DM é, na verdade, o processo de descoberta de informações válidas e não óbvias de uma grande coleção de dados.

Os objetivos principais de DM são a previsão e a descrição. A previsão faz uso de variáveis existentes na base de dados para prever valores desconhecidos ou futuros. A descrição é voltada para a busca de padrões descrevendo os dados e a subsequiente apresentação para a interpretação do usuário.

Esses objetivos podem ser alcançados através das tarefas de DM. Cada caso de aplicação de DM possui objetivos próprios, e de acordo com esses objetivos e com a natureza dos dados a serem tratados, o caso será enquadrado $\mathrm{em}$ uma das diferentes formas de abordagem e aplicação, dependendo do tipo de tarefa que ele representa. Os lipos de tarefas de DM mais freqüentemente estudados são: classificação, agrupamento (clustering), associação, tratamento de exceções, evolução, regressão c redução de dimensionalidade. Essas tarefas são descritas nas seções seguintes.

\subsubsection{Classificação}

A classificação visa avaliar as propriedades de um objeto, ou conjunto de objetos (cm uma base de dados), e classificá-los em diferentes classes de acordo com um modelo de classificação [Chen et al., 1996], como pode ser observado na Figura 2.2. Dessa forma, a classificação de dados constitui-se de duas etapas:

- construção do modelo de classificação e;

- classificação dos dados baseado no modelo de classificação criado.

Para a construção do modelo de classificação, inicialmente é usado um conjunto de treinamento, ou seja, uma amostra de uma base de dados na qual cada registro é composto por 
um conjunto de atributos de predição e por um atributo-classe conhecido que determina a classe do registro. $O$ modelo criado é então usado para prever classes de novos registros que virão a ser incluídos na base de dados, estimando-se o valor do atributo-classe desconhecido [Chen et al., 1996; Felipe, 2000].

A classificação pode, por exemplo, classificar clientes de um banco de acordo com seu perfil, ou ainda, identificar a forma de tratamento a qual um novo paciente está mais propenso.

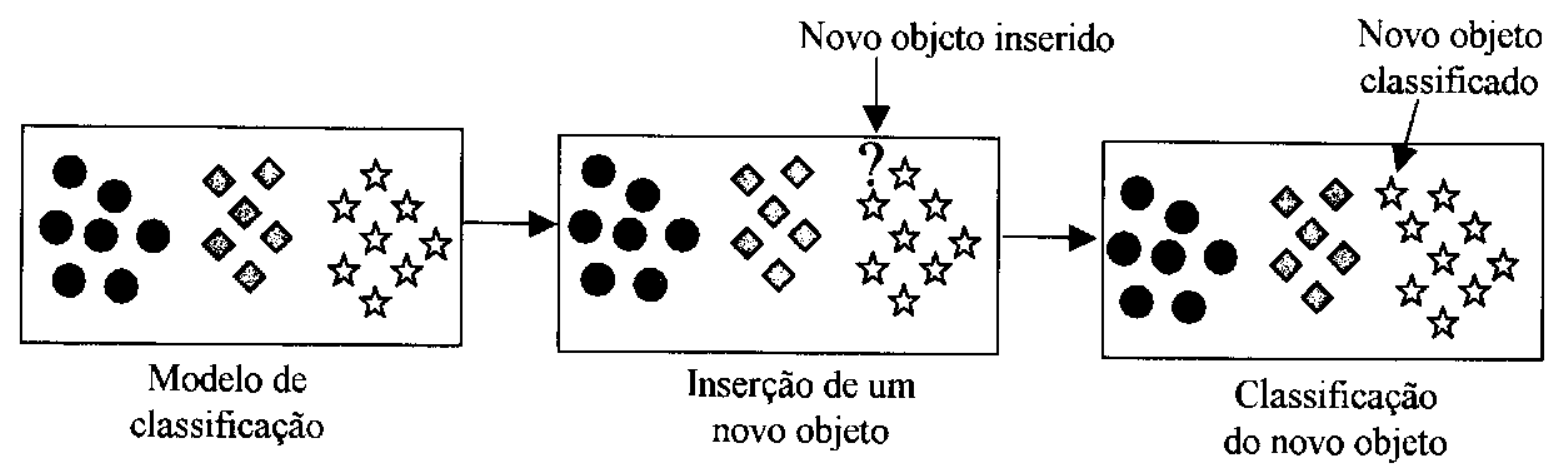

Figura 2.2 - Exemplo de classificação de um novo objeto

\subsubsection{Agrupamento}

Agrupar dados é identificar em um certo conjunto de dados, grupos diferentes, utilizando algum critério de similaridade (Figura 2.3). Esses dados não devem ter sido previamente classificados, ou seja, não deve haver um atributo que rotule os grupos de forma direta. Para diferenciar esses grupos há um princípio conceitual que deve ser seguido: máxima similaridade dentro do grupo e mínima similaridade entre os grupos. Após a formação dos grupos, é possivel aplicar métodos de classificação e associação para descobrir regras sobre seus membros [Han \& Kamber, 2000].

Segundo Felipe [Felipe, 2000], conhecendo informações sobre peso, altura e tipo de roupa preferida de um determinado universo de consumidores, pode-se executar agrupamento sobre os atributos peso e altura e depois tentar avaliar a preferência de roupa de cada grupo. 
As técnicas mais utilizadas no agrupamento são baseadas em três categorias: particionamento, agrupamento-hierárquico e localização dos dados. Nos algoritmos que trabalham com o particionamento, dado uma base de dados com $n$ objetos e sendo $k$ o número de agrupamentos a serem formados, esse algoritmo organiza os objetos dentro das $k$ partições, onde cada partição representa um agrupamento [Han \& Kamber, 2000]. Os algoritmos que efetuam o agrupamento-hierárquico dos dados decompõem a base de dados em subconjuntos menores utilizando níveis de particionamento, como numa árvore. A outra classe de algoritmos, que utiliza a localização dos dados para efetuar o agrupamento, usualmente junta elementos do conjunto de dados que são vizinhos segundo um critério de localidade [Traina, 2001].

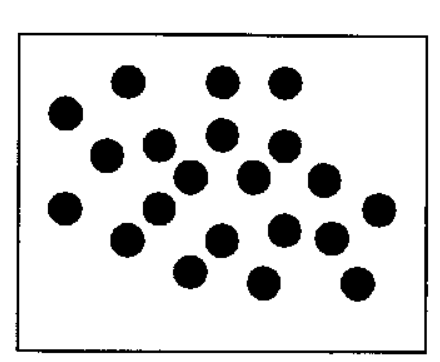

Conjunto de dados

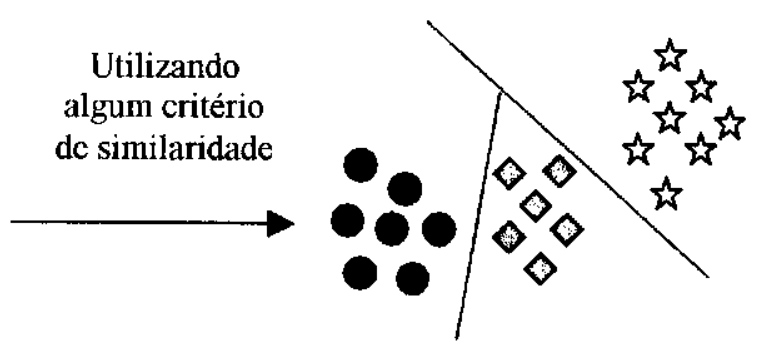

Coniunto de dados agrupados

Figura 2.3 - Exemplo de agrupamento de dados

O problema de agrupamento tem sido estudado em muitas áreas, incluindo estatística, aprendizado de máquina e biologia, mas a escalabilidade não foi um objetivo de projeto nessas aplicações. Pesquisadores sempre assumiram que o conjunto completo de dados se manteria na memória principal, e o foco estava em aperfeiçoar a qualidade do agrupamento. Conseqüentemente, esses algoritmos não são escaláveis para grandes conjuntos de dados [Ganti et al., 1999]. Recentemente, vários novos algoritmos com ênfase em escalabilidade têm sido desenvolvidos e entre eles pode-se citar o sistema Birch [Zhang et al., 1996] e o sistema Clarans [Ng \& Han, 1994] os quais utilizam algoritmos de particionamento. A seguir, é apresentada uma visão geral do Birch e do Clarans.

Birch (Balanced Iterative Reducing and Clustering using Hierarchies), de acordo com Ganti et al. [Ganti et al., 1999], pode ser visto como uma técnica de agrupamento em duas fases. Em uma primeira fase, Birch é usado para produzir uma coleção grosseira de 
agrupamentos. Numa segunda fase, outros algoritmos de agrupamento podem ser usados nessa coleção para identificar agrupamentos verdadeiros. Um agrupamento corresponde a uma região densa de objetos e Birch trata essa região coletivamente através de uma representação sumarizada chamada de cluster feature (CF). A CF de um agrupamento é uma tripla consistindo do número de pontos do agrupamento, centro e raio, com o raio do agrupamento definido como a raiz quadrática média das distâncias do centro até cada ponto do agrupamento. Quando um novo ponto é adicionado ao agrupamento, a nova CF pode ser computada a partir de uma CF antiga. Como o algoritmo Birch é incremental, ele explora essa propriedade de uma CF e mantém somente as CFs dos agrupamentos, em vez dos conjuntos de pontos, enquanto varre os dados. CFs são eficientes por duas razões: elas ocupam menos espaço do que a representação "crua" que mantém todos os objetos de um agrupamento, e elas são suficientes para calcular todas as medidas intercluster e intracluster envolvidas na decisão de agrupamento. Além disso, esses cálculos podem ser executados mais rapidamente do que usando todos os objetos dos agrupamentos.

Clarans (Clustering Large Applications based upon RANdomized Search) é também um algoritmo de agrupamento para grandes conjuntos de dados, proposto por Raymond $\mathrm{T}$. $\mathrm{Ng}$ e Jiawei Han [Ng \& Han, 1994]. Segundo Ganti et al. [Ganti et al., 1999], Clarans trata o problema do agrupamento como uma busca randômica em um grafo, sendo que cada nó representa uma partição do conjunto de dados em um número de agrupamentos especificado pelo usuário. Clarans modela o espaço solução, ou seja, todas as possíveis partições do conjunto de dados, para uma boa solução.

Para agrupamentos em domínios de dados espaciais já existem muitos estudos e várias técnicas foram desenvolvidas, como por exemplo, as propostas por Ester et al. [Ester et al., 1998] e Syed et al. [Syed et al., 1999]. Essas técnicas usam basicamente a informação de distâncias entre os objetos para definir cada agrupamento. Assim, enquanto [Ester ct al., 1998] considera estarem em um mesmo agrupamento objetos que estejam mais próximos do que uma determinada distância limiar $r$ dada, [Syed et al., 1999] considera também a distância média entre os agrupamentos já identificados para classificar cada objeto. 


\subsubsection{Associação}

Regras de associação correlacionam a presença de um conjunto de itens com outro conjunto de itens em uma relação. Dados dois conjuntos de atributos A e B de uma base de dados, a regra de associação tem a forma $\mathrm{A} \Rightarrow \mathrm{B}$, ou seja, os registros que contém $\mathrm{A}$ tendem a conter B também. [Chen et al., 1996].

$\Lambda$ análise da associação em uma base de dados pode gerar uma infinidade de regras de associação. Algumas dessas regras podem não ser interessantes por ocorrercm em baixa freqüência nos dados. Para contornar esse problema, ou seja, para eliminar regras que não aparecem freqüentemente na base de dados, foram definidos dois fatores [Agrawal \& Srikant, 1994]: suporte e confiança. Suporte é uma medida que indica a porcentagem de registros na base de dados que satisfaz a regra de associação dada, e é utilizada para eliminar as regras que não aparecem freqüentemente na base de dados. Já a confiança indica o grau de acerto da regra, dada pela porcentagem dos registros em que ocorrem A e B sobre o total de registros que possuem $\mathrm{A}$.

Um exemplo de associação pode ser observado na Tabela 2.1, onde são obtidas as seguintes regras:

$\mathrm{A} \Rightarrow \mathrm{C}$ com $50 \%$ de suporte (A e C aparecem em $50 \%$ do total de transações) c $66.6 \%$ de contiança ( $C$ aparece com $66.6 \%$ das transações que contém $A$ ).

$\mathrm{C} \Rightarrow \mathrm{A}$ com $50 \%$ de suporte (A e C aparecem $\mathrm{cm} 50 \%$ do total de transações) e 100\% de confiança ( $\Lambda$ aparece em todas as transações que contém $C$ ).

Tabela 2.1 - Transações de Compras ilustrada em Felipe [Felipe, 2000]

\begin{tabular}{|c|c|}
\hline Transação & Itens \\
\hline 1 & A, B, C \\
\hline 2 & A, C \\
\hline 3 & A, D \\
\hline 4 & B, E, F \\
\hline
\end{tabular}




\subsubsection{Tratamento de Exceções}

As demais tarefas de DM destinam-se, de alguma forma, à busca de padrões. $O$ tratamento de exceções, ao contrário, procura identificar objetos que "fogem" de qualquer padrão. Isso pode ser útil para eliminar medidas falhas que poderiam comprometer outras tarefas, ou mais importante, para identificar casos raros (exceções), por exemplo, identificar clientes em redes de supcrmercado com comportamento suspeito ou com tendência a fraudes [Aggarwal \& Yu, 2001].

\subsubsection{Evolução}

A análise da evolução dos dados descreve e modela regularidades e tendências para as mudanças no comportamento de objetos ao longo do tempo. Isso pode facilitar a aplicação de outras tarefas de DM sobre dados temporalmente relacionados [Han \& Kamber, 2000]. A evolução prevê a ocorrência de novos registros. Por exemplo, num sistema de venda de produtos, poderia ser descoberto que todo cliente que compra vídeo-cassete, volta à mesma empresa para comprar fitas de vídeo, em menos de um mês.

\subsubsection{Regressão}

A regressão prevê valores futuros de uma variável baseada em valores passados de um conjunto de variáveis, ou seja, ela auxilia a prever o futuro baseado no passado. Para isso é utilizado um conjunto de valores existentes e conhecidos. Na regressão deseja-se encontrar uma função que mapeie, com a maior precisão possível, um valor para uma variável de acordo com os valores conhecidos de outras variáveis.

Exemplos genéricos da aplicação dessa tarefa são: predizer a probabilidade de um paciente sobreviver, dados os resultados de um conjunto de exames diagnósticos; ou, dado um conjunto de dados de transações de cartão de crćdito, construir um modelo que pode predizer a probabilidade de fraude para novas transações. 


\subsubsection{Redução de Dimensionalidade}

Atualmente as bases de dados têm crescido não somente em número de tuplas, mas também em número de atributos. Assim, técnicas e algoritmos tradicionais para análise de dados podem ser eficientes para pequenos conjuntos de dados, mas quando o número de atributos envolvidos e o número de tuplas aumentam muito, essas técnicas podem não ser úteis. Sendo assim, técnicas de redução de dimensionalidade têm sido desenvolvidas e amplamente utilizadas. O objetivo da redução de dimensionalidade é apresentar o conjunto de dados com um número menor de atributos (dimensões), porém mantendo-se as características inerentes da informação armazenada. Dessa forma, busca-se definir quais são os atributos importantes ou que "concentram" a informação. Um dos marcos dentre as técnicas de redução de dimensionalidade é aquela conhecida como fastmap, que scrá descrita a seguir.

\subsubsection{Técnica Fastmap}

A técnica fastmap, de mapeamento para redução de dimensionalidade, foi proposta por Faloutsos e Lin [Faloutsos \& Lin, 1995]. O algoritmo fastmap efetua um mapeamento rápido (é de complexidade linear) de dados em espaços de altas dimensões para espaços de dimensões menores, preservando o máximo possível as distâncias entre os objetos. Ele demanda apenas três informações: o conjunto de objctos a ser mapeado, a distância métrica entre esses objetos e a dimensão $k$ do espaço destino onde os objetos serão mapeados.

$O$ conceito fundamental desse algoritmo é projetar os objetos em eixos cuidadosamente selecionados. Para fazer isso, escolhem-se $k$ pares de objetos, os quais serão considerados pivôs. A escolha desses pivôs deve recair sobre os objetos que estejam o mais distante possível, através da construção de eixos de projeção que "atravessem" todo o conjunto de dados, ou seja, considerando-se uma linha que passe através deles em um espaço $n$-dimensional. Depois de escolhidos os pivôs, calcula-se a distância de cada objeto a cada um dos pares de pivôs e realiza-se um processamento sobre essas distâncias. Com isso, têm-se as coordenadas de cada objeto mapeado. A Figura 2.4 mostra uma representação gráfica dos passos do algoritmo fastmap. 
Essa técnica pode ser utilizada para DM, análise de agrupamentos e visualização de dados em espaços de altas dimensôes. Ela é também o núcleo da ferramenta FastMapDB (vide seção 4.2) que foi a base inicial para este trabalho de Mestrado.

\section{Distância entre}

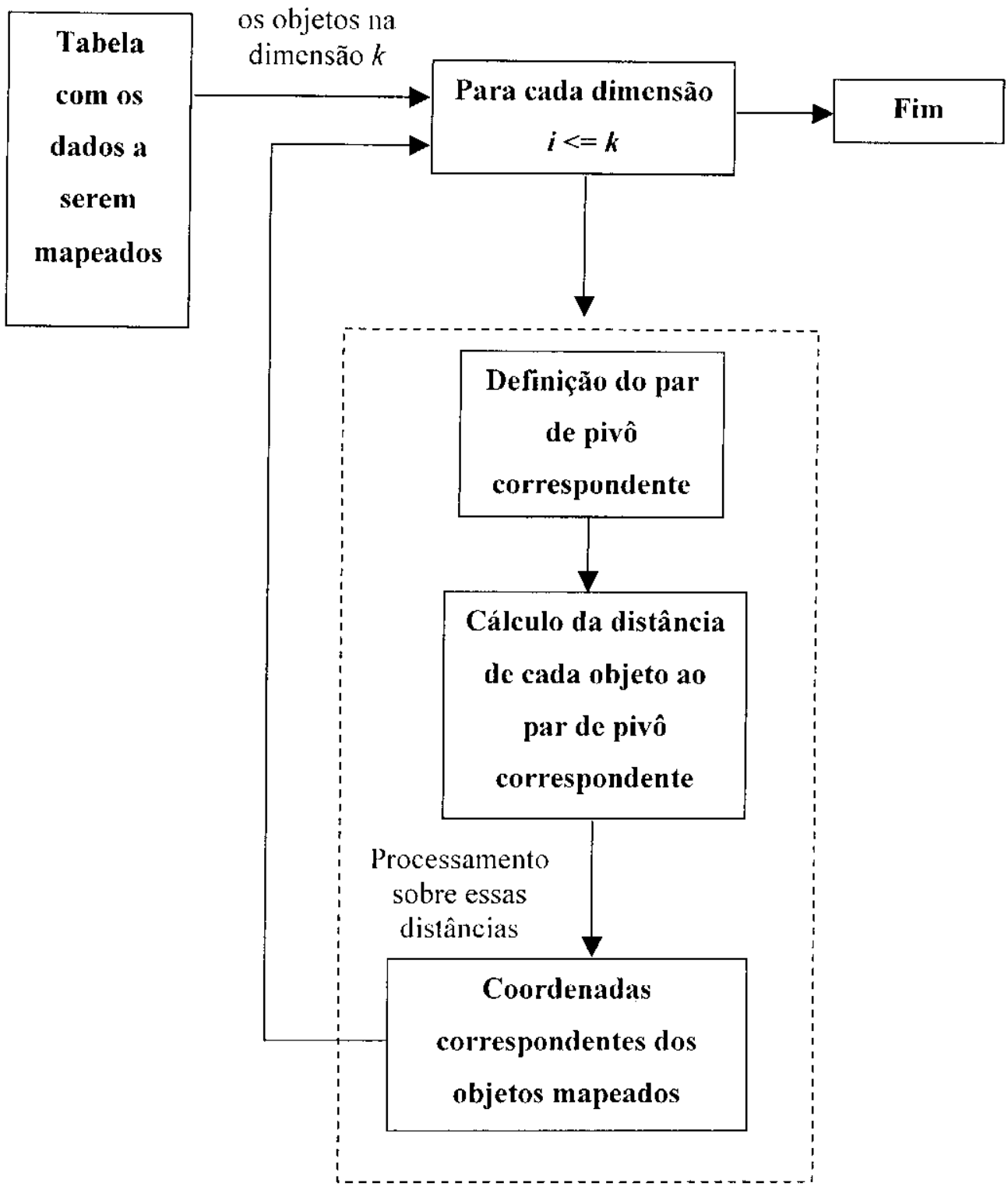

Figura 2.4 - Representação gráfica dos passos do algoritmo fastmap 


\subsubsection{Métodos de Solução para a Tarefa de Classificação}

Diversos métodos de solução podem ser utilizados de acordo com o tipo de tarefa de DM. Alguns dos métodos mais utilizados para a tarefa de classificação são: árvores de dccisão, redes neurais c classilicadores bayesianos. $\Lambda$ seguir é apresentada uma visão geral desses três métodos.

\subsubsection{1 Árvores de Decisão}

Árvores de decisão são meios de representar resultados de DM de uma forma gráfica. Sua apresentação visual torna o modelo mais fácil de entender e assimilar. Por causa disso, a árvore de decisão tornou-se um método de solução bastante popular [Felipe, 2000].

Na técnica de árvore de decisão, é escolhida uma variável que se quer avaliar e o algoritmo procura as características mais fortemente relacionadas a ela montando uma árvore com ramificações. Dado um grupo de dados com numerosas colunas e linhas, uma ferramenta de construção de árvores de decisão pede ao usuário para escolher uma das colunas como objeto de saída. A seguir, mostra o mais importante fator corrclacionado com aquele objeto de saída como o primeiro nó da árvore de decisão. Isso significa que o usuário pode rapidamente ver qual o fator que mais influencia o scu objeto de saida $\mathrm{c}$ pode cntender porque o fator foi escolhido. Uma boa ferramenta de árvore de decisão vai permitir, também, que o usuário explore a árvore de acordo com a sua vontade, do mesmo modo que ele poderá encontrar grupos alvos que lhe interessem mais.

Uma árvore de decisão é geralmente construída de maneira top-down, utilizando um algoritmo baseado na aproximação "dividir para conquistar" [Quinlan, 1993] apud [Lopes, 1999]. Inicialmente todas as tuplas que estão sendo mineradas são associadas ao nó raiz da árvore. Então o algoritmo seleciona uma partição de atributos e divide o conjunto de tuplas no nó raiz de acordo com o valor do atributo selecionado. O objetivo desse processo é separar as classes para que tuplas de classes distintas tendam a ser associadas a diferentes partições. Esse processo é recursivamente aplicado a subconjuntos de tuplas criados pelas partições, 
produzindo subconjuntos de dados cada ve $z$ menores, até que um critério de parada seja satisfeito [Lopes, 1999].

$\Lambda$ s árvores de decisão são, quase sempre, usadas em conjunto com a tecnologia de Indução de Regras [Felipe, 2000], mas são únicas no sentido de apresentar os resultados da Indução de Regras num formato com priorização, onde a regra mais importante é apresentada na árvore como o primeiro nó, e as regras menos relevantes são mostradas nos nós subseqüentes.

As principais vantagens das árvores de decisão são que elas fazem partições levando em consideração as regras que são mais relcvantes, além de screm compreensiveis para a maioria das pessoas. Ao cscolher e apresentar as regras em ordem de importancia. as árvores de decisão permitem aos usuários verem, imediatamente, quais fatores mais influenciam os seus trabalhos.

Para exemplificar o uso de árvores de decisão, considere o seguinte exemplo [Felipe, 2000]: uma instituição bancária deseja classificar seus clientes em duas categorias: os que oferecem risco de não pagar um empréstimo c os que não oferecem esse risco. A classificação deve ser baseada em três informações sobre seus clientes: se possuem débito com a instituição, o nível de renda e o estado civil. Suponha que a base de dados contenha os registros mostrados na Tabela 2.2 .

Tabela 2.2 - Análise de risco para árvores de decisão em [Felipe, 2000]

\begin{tabular}{|l|l|l|l|l|}
\hline \multicolumn{1}{|c|}{ Nome } & \multicolumn{1}{c|}{ Débito } & \multicolumn{1}{c|}{ Renda } & \multicolumn{1}{c|}{ Casado } & \multicolumn{1}{c|}{ Risco } \\
\hline Maria & Sim & Alta & Sim & Não \\
\hline José & Não & Alta & Sim & Não \\
\hline João & Não & Alta & Não & Sim \\
\hline Marta & Sim & Baixa & Sim & Sim \\
\hline Francisco & Não & Baixa & Sim & Sim \\
\hline
\end{tabular}


Para construir a árvore de decisão sobre esses dados, apresentada Figura 2.5, foi apontado como atributo-alvo o Risco. Em cada nó da árvore está calculado o número de instâncias que oferecem risco de não pagar um empréstimo e o número de instâncias que não oferecem esse risco e, ainda, o total das instâncias que chegaram até aquele nó. As instâncias no nó raiz são o total de instâncias do conjunto de treinamento: esse nó contém cinco instâncias, três das quais $(60 \%)$ oferecem risco e duas (40\%) não oferecem risco. A primeira bifurcação da árvore é determinada pelo atributo Renda, separando as instâncias de acordo com o valor desse atributo (Alta ou Baixa). A próxima bifurcação é determinada pelo atributo Casado. Quando se gera um nó que possui apenas um tipo de instância do atributo-alvo, ele passa a ser um nó terminal. A soma das instâncias de todos os nós terminais é igual ao total de instâncias do conjunto de treinamento.

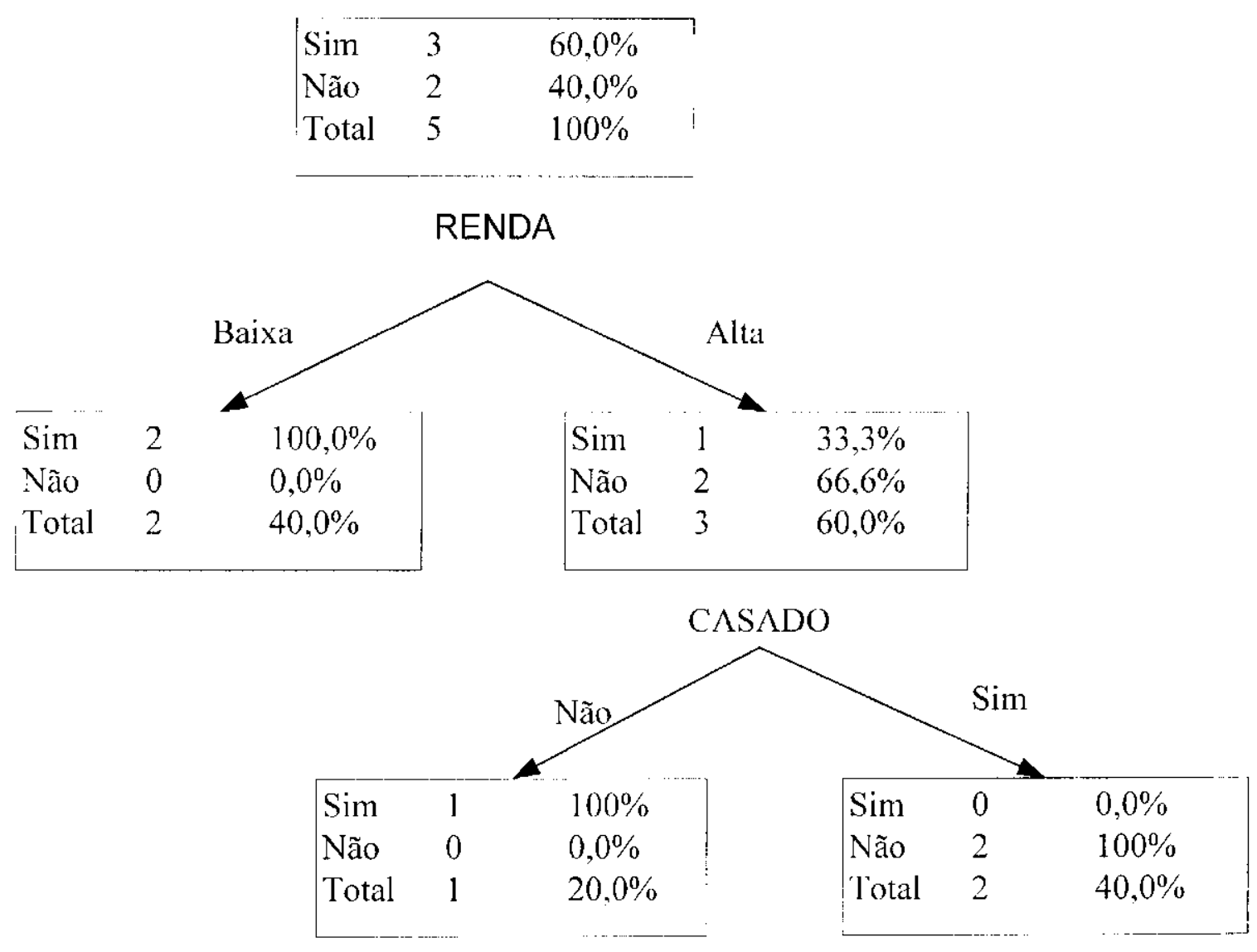

Figura 2.5 - Árvore de decisão para análise de risco [Felipe, 2000] 
Uma vez construida a árvore, é possível derivar um conjunto de regras a partir de uma árvore, uma regra para cada nó terminal, simplesmente seguindo os caminhos entre o nó raiz e cada nó terminal. Além das regras derivadas, outras informações podem também ser obtidas da análise da árvore, como as seguintes informações, relativas ao exemplo descrito nesta seção:

- existência de débito não é determinante para previsão de risco;

- clientes com renda baixa sempre geram risco positivo e;

- renda é o fator mais significativo para previsão de risco.

\subsubsection{Redes Neurais}

Redes neurais artificiais (RNA) são constituídas essencialmente por unidades de processamento simples (nós) e conexões entre esses nós, tal como ilustrado na Figura 2.6. Os nós são dispostos em uma ou mais camadas $\mathfrak{e}$ interligados por um grande número de conexões. Na maioria dos modelos de redes neurais, essas conexões estão associadas a pesos. os quais armazenam o conhecimento representado no modelo e servem para ponderar a entrada recebida por cada neurônio da rede. O funcionamento dessas redes é inspirado em uma estrutura física concebida pela natureza: o cérebro humano [Braga ct al., 2000].

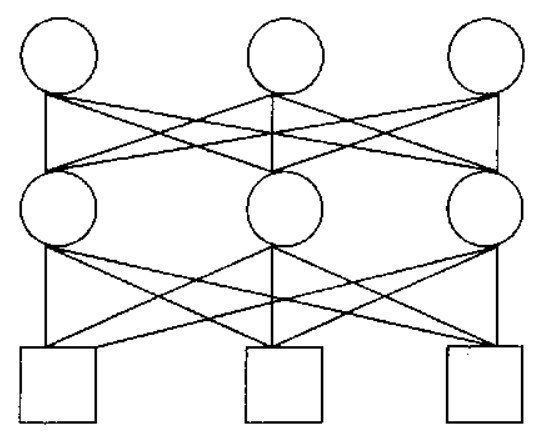

Camada de saída

Camadas intermediárias

Camada de entrada

Figura 2.6 - Estrutura básica de uma rede neural 
O procedimento usual na solução de problemas em $\mathrm{RN} \Lambda \mathrm{s}$ passa, inicialmente, por uma fase de aprendizagem, em que um conjunto de exemplos é apresentado para a rede e através de um processo de repetidas apresentações desses exemplos à rede, ou scja, por experiência, a rede extrai automaticamente as características necessárias para representar a informação fornecida. Essas características são utilizadas posteriormente para gerar respostas para o problema.

A rede neural, então, forma-se iterativamente através do ajuste dos valores dos pesos numéricos das interconexõcs, baseando-se nas informações disponíveis, por excmplo, em uma base de dados, de forma a poder determinar qual será a saída mais provável para um novo conjunto de atributos de entrada.

Para DM, as redes neurais têm sido aplicadas em tarefas de classificação e agrupamento [Han \& Kamber, 2000], mas os algoritmos de redes neurais estão entre os algoritmos mais complexos para resolução dessas tarefas. Apesar de ser demorado o processo de "treinamento" da rede, depois de determinada, ela pode realizar predições de novas classes de forma rápida e, em muitos casos, até em tempo real [Felipc, 2000].

Para exemplificar a geração de uma rede, considere o mesmo exemplo abordado na seção anterior [Felipe, 2000]. Como os algoritmos de redes neurais manipulam apenas valores 0 e 1, a Tabela 2.3 apresenta os mesmos dados da Tabela 2.2, apenas transformados para 0 e 1.

Tabela 2.3 - Análise de risco para redes neurais em [Felipe, 2000]

\begin{tabular}{|c|c|c|c|c|}
\hline Nome & Débito & Renda & Casado & Risco \\
\hline Maria & 1 & 1 & 1 & 0 \\
\hline José & 0 & 1 & 1 & 0 \\
\hline Francisco & 0 & 1 & 0 & 1 \\
\hline Marta & 1 & 0 & 1 & 1 \\
\hline João & 0 & 0 & 1 & 1 \\
\hline
\end{tabular}


Um algoritmo de rede neural, considerando como entradas os atributos Débito, Renda e Casado, e buscando classificar os clientes entre risco e não risco, geraria a rede representada na Figura 2.7. Nessa figura, o nó A representa o atributo Débito, o nó B representa o atributo Renda, o nó $\mathrm{C}$ representa o atributo Casado e o nó $\mathrm{F}$ representa o atributo Risco.

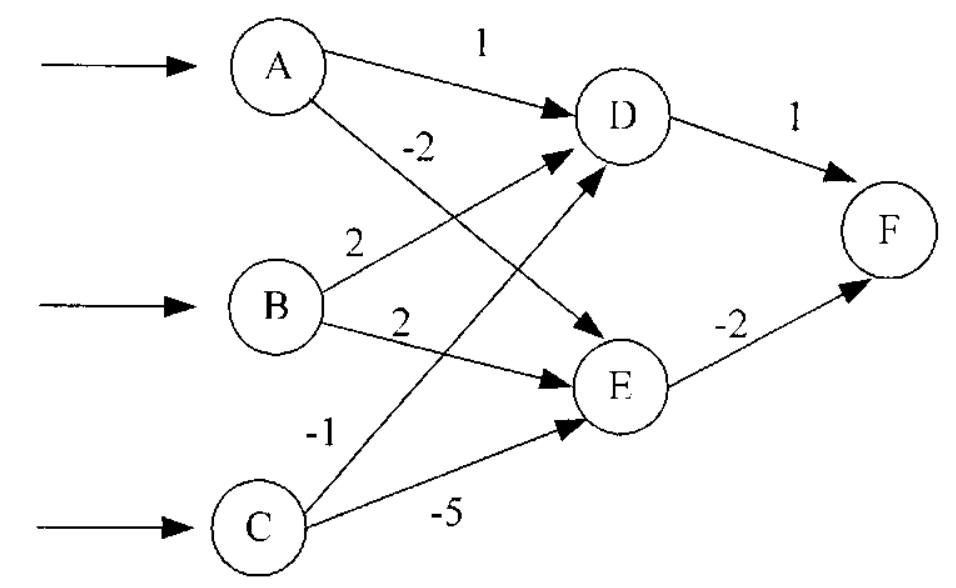

Figura 2.7 - Rede Neural para análise de risco em [Felipe, 2000]

As equações dos nós intermediários e final scriam:

D: if $(A+2 B-C)>0$ then 1 else 0

E: if $(-2 A+2 B-5 C)>0$ then 1 else 0

F: if $(D-2 E)>0$ then 0 else 1

Dessa forma, a rede prediz a classificação de risco de um novo cliente, a partir de suas informações de entrada.

\subsubsection{Classificadores Bayesianos}

Classificadores bayesianos são classificadores estatísticos, ou seja, eles podem predizer a probabilidade dos membros de uma classe, assim como a probabilidade de uma dada amostra de dados, pertencer a uma classe em particular. Esses classificadores se baseiam no tcorcma de Bayes, apresentado mais adiante nesta seção. Um classificador bayesiano pode 
ser naive (sem otimização) ou semi-naive.

O classificador bayesiano naive considera independência condicional na classe, ou seja, o valor de um atributo em uma classe independe dos valores dos demais atributos. Isso o torna simples, rápido e com um bom desempenho em grandes volumes de dados [Han \& Kamber, 2000].

\section{Teorema Baves [Itan \& Kamber, 2000]:}

Considere X um exemplo de dado onde sua classe é desconhecida e H como uma hipótese de que X pertence a uma determinada classe C. Para problemas de classificação, deseja-se detcrminar $\mathrm{P}(\mathrm{H} \mid \mathrm{X})$, ou seja, a probabilidade que o exemplo de dado $\mathrm{X}$ pertença a $\mathrm{H}$.

$\mathrm{P}(\mathrm{H} \mid \mathrm{X})$ é a probabilidade condicional de $\mathrm{H}$ condicionado a ocorrência de $\mathrm{X}$. Por exemplo, suponha que os exemplos de dados sejam sobre frutas descritas por suas cores $\mathrm{e}$ formas. Suponha que X seja vermelho e arredondado e que H é a hipótese de que X é uma maçã. Então $P(H \mid X)$ reflete a confiança que $X$ é uma maçã, dado que $X$ é vermelho c arredondado. Em contraste, $\mathrm{P}(\mathrm{H})$ é a probabilidade incondicional de H. Para esse excmplo, $\mathrm{P}(\mathrm{H})$ é a probabilidade que qualquer exemplo de dado é uma maçã, ou seja, ele é independente de X.

Similarmente, $\mathrm{P}(\mathrm{X} \mid \mathrm{H})$ é a probabilidade condicional de $\mathrm{X}$ condicionado a $\mathrm{H}$, ou seja, a probabilidade que $X$ é vermelho e arredondado, já que se sabe que $X$ é uma maçã. $P(X)$ é a probabilidade incondicional de $X$, ou seja, é a probabilidade que um exemplo de dado do conjunto de frutas seja vermelho e arredondado.

As probabilidades $\mathrm{P}(\mathrm{X}), \mathrm{P}(\mathrm{H})$ e $\mathrm{P}(\mathrm{X} \mid \mathrm{H})$ podem ser estimadas a partir de um conjunto de dados. Isso é possível através do teorema Bayes que fornece uma maneira de calcular a probabilidade condicional, $\mathrm{P}(\mathrm{H} \mid \mathrm{X})$, dado $\mathrm{P}(\mathrm{H}), \mathrm{P}(\mathrm{X})$ e $\mathrm{P}(\mathrm{X} \mid \mathrm{H})$ :

$$
P(H \mid X)=\frac{P(X \mid H) P(H)}{P(X)}
$$

Para exemplificar a fórmula acima utilizando o classificador bayesiano Naive, considere os dados da Tabela 2.4. Esses exemplos de dados são descritos pelos atributos: Idade. Rendimento, Estudante, Índice_Crédito e o atributo de classe - Compra_Computador. Considere: 
- $\mathrm{C}_{1}$ como o conjunto de tuplas onde a classe Compra_Computador = "sim" $\mathrm{c}$;

- $\mathrm{C}_{2}$ onde Compra_Computador $=$ "não".

O exemplo desconhecido que se deseja classificar é:

$\mathrm{X}=($ Idade $="<=30 "$, Rendimento $=$ "médio", Estudante $=$ "sim", Índice_Crédito $=$ "moderado")

É necessário maximizar $\mathrm{P}\left(\mathrm{X} \mid \mathrm{C}_{\mathrm{i}}\right) \mathrm{P}\left(\mathrm{C}_{\mathrm{i}}\right)$ para $\mathrm{i}=1,2 . \mathrm{P}\left(\mathrm{C}_{\mathrm{i}}\right)$, probabilidade incondicional de cada classe, pode ser computada baseada nos dados da Tabela 2.4:

$\mathrm{P}($ Compra_Computador $=$ "sim" $)=9 / 14=0.643$

$\mathrm{P}($ Compra_Computador $=$ "não" $)=5 / 14=0.357$

Para computar $\mathrm{P}\left(\mathrm{X} \mid \mathrm{C}_{\mathrm{i}}\right) \mathrm{P}\left(\mathrm{C}_{\mathrm{i}}\right)$ para $\mathrm{i}=1,2$, computa-se as seguintes probabilidades condicionais:

$\mathrm{P}($ Idade $="<30 " \mid$ Compra_Computador $="$ sim" $)=2 / 9=0.222$

$\mathrm{P}($ Idade $=$ "<30" $\mid$ Compra_Computador $=$ "não" $)=3 / 5=0.600$

$\mathrm{P}($ Rendimento $=$ "médio" $\mid$ Compra_Computador $=$ "sim" $)=4 / 9=0.444$

$\mathrm{P}($ Rendimento $=$ "médio" $\mid$ Compra_Computador $=$ "não" $)=2 / 5=0.400$

$\mathrm{P}($ Estudante $=$ "sim" $\mid$ Compra_Computador $=$ "sim" $)=6 / 9=0.667$

$\mathrm{P}($ Estudante $=$ "sim" $\mid$ Compra_Computador $=$ "não" $)=1 / 5=0.200$

P $($ Índice_Crédito $=$ "moderado" $\mid$ Compra_Computador $=$ "sim" $)=6 / 9=0.667$

$\mathrm{P}($ Índice_Crédito $=$ "moderado" $\mid$ Compra_Computador $=$ "não" $)=2 / 5=0.400$ 
Utilizando as probabilidades acima e o teorema de Bayes, pode-se obter:

$\mathrm{P}(\mathrm{X} \mid$ Compra_Computador $=" \operatorname{sim} ")=0.222 \times 0.444 \times 0.667 \times 0.667=0.044$

$\mathrm{P}(\mathrm{X} \mid$ Compra_Computador $="$ não" $)=0.600 \times 0.400 \times 0.200 \times 0.400=0.019$

$\mathrm{P}(\mathrm{X} \mid$ Compra_Computador $=$ "sim" $) \mathrm{P}($ Compra_Computador $=$ "sim" $)=0.044 \times 0.643=0.028$

$\mathrm{P}(\mathrm{X} \mid$ Compra_Computador $=$ "não" $) \mathrm{P}($ Compra_Computador $=$ "não" $)=0.019 \times 0.357=0.007$

Portanto, o classificador bayesiano naive prediz que o atributo Compra_Computador vale "sim" para o exemplo X dado acima, pois o valor da probabilidade (0.028) é maior.

Tabela 2.4 - Dados utilizados pelo classificador bayesiano Naive [Han \& Kamber, 2000]

\begin{tabular}{|c|c|c|c|c|c|}
\hline Id & Idade & Rendimento & Estudante & Índice Crédito & Compra Computador \\
\hline 1 & $<=30$ & Alto & Não & Moderado & Não \\
\hline 2 & $<=30$ & Alto & Não & Excelente & Não \\
\hline 3 & $31 \ldots 40$ & Alto & Não & Moderado & Sim \\
\hline 4 & $>40$ & Médio & Não & Moderado & Sim \\
\hline 5 & $>40$ & Baixo & Sim & Moderado & Sim \\
\hline 6 & $>40$ & Baixo & Sim & Excelente & Não \\
\hline 7 & $31 \ldots 40$ & Baixo & Sim & Excelente & Sim \\
\hline 8 & $<=30$ & Médio & Não & Moderado & Não \\
\hline 9 & $<=30$ & Baixo & Sim & Moderado & Sim \\
\hline 10 & $>40$ & Médio & Sim & Moderado & Sim \\
\hline 11 & $<=30$ & Médio & Sim & Excelente & Sim \\
\hline 12 & $31 \ldots 40$ & Médio & Não & Excelente & Sim \\
\hline 13 & $31 \ldots 40$ & Alto & Sim & Moderado & Sim \\
\hline 14 & $>40$ & Médio & Não & Excelente & Não \\
\hline
\end{tabular}




\subsection{Considerações Gerais entre KDD e DM}

Os avanços conseguidos nas áreas de hardware e software possibilitaram a criação de aplicações científicas e comerciais capazes de processar imensos volumes de dados e, também, uma grande capacidade na geração, coleta c armazenagem de dados. Os dados são freqüientemente gravados, capturados e armazenados automaticamente via sensores e sistemas de monitoração. Esses dados são processados por transações que partem do dia-dia de cada um, tal como o pagamento de comida e roupas pelo cartão de crédito, uso do telefone, etc. [Keim, 2001]. Um exemplo do grande volume de dados armazenados é o sistema usado pela empresa Wal-Mart para computar suas vendas, sendo que ele processa mais de 20 milhões de transações diariamente, produzindo muitos gigabytes ( $10^{9}$ bytes) de dados [Oliveira, 2000].

Com essa explosão do crescimento da quantidade de dados armazenados em bases de dados e da necessidade de aproveitá-los, as empresas têm buscado aumentar o uso que fazem dos dados que coletaram durante anos de processamento, pois as bases de dados não podem mais ser consideradas simples repositórios de informações, mas sim, um importante patrimônio da organização.

O volume de dados a ser analisado é imenso e, na maioria das vezes, não se sabe por onde começar o processo de extração de informação. Ou seja, todo o esforço e custo de coletar e armazenar dados pode ser "infrutífero" se não se souber recuperar os dados que respondam às consultas desejadas pelos usuários que, nesse caso, são os proprietários dessa informação. Essa quantidade de dados gerada pelos sistemas das organizações supera a capacidade humana de interpretar e compreender tanta informação.

Dessa forma, com a intensificação do uso de bases de dados e com o crescimento explosivo no tamanho dessas bases, surgc a necessidade por novas técnicas e ferramentas que possam, de forma inteligente, transformar os dados armazenados em informação e conhecimento útil [Chen et al., 1996; Fayyad et al., 1996].

Com isso, vem à tona o problema da extração de informação útil dessas bases de dados. Embora os gerenciadores de bases de dados forneçam ferramentas básicas para otimizar o armazenamento e recuperação em grandes quantidades de dados, analisar grandes volumes de dados em formato numérico ou textual, especialmente em espaços de altas 
dimensões, não é fácil para o ser humano.

Em razão dessa necessidade, uma geração nova de técnicas e ferramentas computacionais está surgindo para suportar a extração de conhecimento em grandes volumes de dados, fornecendo o conhecimento necessário para ajudar nos processos de tomada de decisão. Essas técnicas fazem parte do processo de Knowledge Discovery in Databases KDD (vide seção 2.2), que define como sendo essencial o valor do conhecimento que pode ser inferido dos dados e colocado em uso.

Dentro desse processo de descoberta de conhecimento, KDD, encontra-se um componente muito importante (scnão o mais importante) que participa desse processo: a mincração de dados, Data Mining - DM (vide seção 2.3). Um processo de DM cxtrai informações implícitas e previamente desconhecidas que são potencialmente úteis para a compreensão eficaz do conjunto de dados em análise.

Deve-se reconhecer, entretanto, que num processo de DM o objetivo da procura nem sempre é claramente definido. Por exemplo, é freqüente a busca de algum padrão no rclacionamento entre diversos atributos ou a busca de agrupamentos (clusters), mas quais atributos ou que padrão seria esse, não é conhecido à priori. Isso levanta também os problemas de identificar quão útil é, na prática, uma relação descoberta, e como interpretar os resultados.

Para ajudar na interpretação dos resultados, o processo de visualização de dados (vide Capítulo 3) auxilia na certificação e identificação de agrupamentos de objetos no conjunto de dados em análise [Ribarsky et al., 1999]. O reconhecimento de agrupamentos, bem como a classilicação de objetos no conjunto de dados, auxiliam no processo de tomada de decisão. Esses processos são comumente suportados por técnicas de DM. Entre as técnicas de classificação mais estudadas encontram-se as árvores de decisão (vide seção 2.3.7.1), redes neurais (vide seção 2.3.7.2), algoritmos genéticos e classificadores bayesianos (vide seção 2.3.7.3).

Um problema que surge é que técnicas e algoritmos de busca de dados que se mostram interessantes para conjuntos de dados pequenos podem não ser adequados quando o volume de dados é escalado para volumes que são ordens de grandeza maiores, tanto em número de atributos (dimensões) envolvidos, quanto $\mathrm{em}$ número de itens tratados. Por exemplo, algoritmos baseados em árvores de decisão, que procuram priorizar os atributos mais 
importantes num processo de classificação, operam bem com dados que possuem um número pequeno de atributos (em geral até 20). No entanto, quando o número de atributos sobe a mais de cem ou mil, esses algoritmos não são úteis porque os tempos de resposta podem subir para semanas de processamento. No entanto, muitas aplicações podem precisar desse número de atributos, como por exemplo, sistemas de armazenagem de imagens; ou de outros dados complexos, tais como estruturas genéticas, áudio, ou seqüências temporais, baseados $\mathrm{cm}$ extração de características.

\subsection{Considerações Finais}

Neste capítulo foram abordados os conceitos de KDD e os objetivos de cada uma das etapas desse processo de descoberta de conhecimento. Fm DM foram definidas e exemplificadas as principais tarefas de DM, assim como alguns métodos de solução para as mesmas.

$\dot{E}$ interessante notar que este trabalho auxilia tanto nas tarefas de agrupamento e de tratamento de exceções quanto no processo de classilicação de novos objetos. Para tarefas de agrupamento e tratamento de exceções, o sistema se comporta apenas como um sistema de visualização de dados, onde o usuário identifica os objetos visualmente e delimita o mapeamento dos agrupamentos e/ou exceções. Para tarefa de classificação, o sistema passa a utilizar a visualização como o processo determinante de treinamento na geração das regras de classificação.

Foi apresentada também a técnica fastmap, que embora concebida originalmente como uma técnica de redução de dimensionalidade, pode ser usada para visualizar dados em quaisquer dimensões, ou mesmo dados em domínios puramente métricos. Ela é o núcleo da ferramenta FastMapDB que será tratada mais à frente e intensamente utilizada na realização deste trabalho de Mestrado. Este trabalho propõe uma utilização inédita para essa técnica, além de estar criando o primeiro sistema de classificação, a partir da visualização dos dados, de que temos notícia. 


\section{Capítulo 3}

\section{Visualização de Dados}

\subsection{Introdução}

Este capítulo apresenta uma abordagem relativa a alguns tópicos da área de Visualização de Dados. São apresentados conceitos. algumas técnicas de visualização, as formas de integração das áreas de Visualização de Dados e Data Mining e alguns sistemas de Visual Data Mining.

\subsection{Visualização de Dados e Exploração Visual de Dados}

A palavra visualização, no seu sentido mais amplo, significa a geração de imagens para organização e entendimento de um conceito, idéia ou informação. Formulações alternativas relacionam essa definição de visualização a um contexto computacional [Oliveira \& Minghim. 1997]. Uma definição típica, que trata especificamente de visualização científica, é:

"Visualização é mais do que um método de computação. Visualização é o processo de transformar informação para uma forma visual, permitindo aos usuários observá-la. A apresentação visual resultante permite ao usuário perceber visualmente características que estão escondidas nos dados, mas que são necessárias para tarefas de exploração e análise" [Gershon, 1994] apud [Oliveira \& Minghim, 1997].

Atualmente um grande volume de dados tem sido gerado por diversas áreas do conhecimento humano, tais como engenharia, estatística, medicina e economia, entre outras. Para ter um aproveitamento real da informação contida neles, é necessária a utilização de 
técnicas de mapeamento de informação, cuja primeira ferramenta é a apresentação gráfica visual dos dados, ou seja, a visualização dos dados.

A visualização gráfica consiste em apresentar graficamente dados que estão sendo analisados. É centrada em mecanismos que possibilitem ao usuário a comprecnsão rápida da informação a ele apresentada e que também permitam uma interação com os mesmos.

A visualização dos dados estimula naturalmente a percepção $\mathrm{c}$ a inteligência humana, aumentando a capacidade de cntendimento e associação de novos padrões. Dessa forma, a visualização de dados utiliza a percepção humana como um primeiro método para descobrir valores [Oliveira \& Rezende, 1998]. A integração do ser humano ao processo de análise de dados pode ser muito proveitosa para explorar grandes volumes de dados. Isso permite combinar a flexibilidade, criatividade e conhecimento geral dos seres humanos com a enorme capacidade de armazenamento e poder computacional dos computadores atuais [Keim, 2002]. Em particular, as habilidades humanas de percepção permitem que usuários analisem eventos complexos $\mathrm{cm}$ um curto espaço de tempo, reconheçam informação importante $\mathrm{c}$ tomem decisões. O sistema de percepção humano processa diferentes tipos de dados de uma maneira muito flexível, automaticamente reconhecendo propriedades não usuais enquanto que, ao mesmo tempo, ignora propriedades comuns. O ser humano manipula descrições vagas e conhecimento impreciso de forma mais fácil e melhor do que os sistemas de computadores atuais e, usando conhecimentos gerais, facilmente chega a conclusões complexas [Keim \& Kriegel, 1996].

Por exemplo, tentar compreender o comportamento da evolução de vendas de uma determinada loja de uma rede de produtos alimentícios, utilizando apenas os valores numéricos em si, demanda um grande esforço. Porém, se essa informação é apresentada de forma gráfica, o processo de análise fica muito mais intuitivo e rápido para o ser humano. $\mathrm{O}$ propósito de utilizar visualização de dados é transformar grandes quantidades de dados numéricos, não processados, em representações gráficas que buscam explorar a capacidade inerente do cérebro humano de processar e inferir informações quando estas estão apresentadas de forma gráfica [Traina, 2001].

Geralmente a exploração visual de dados permite uma exploração de dados mais rápida, freqüentemente retornando melhores resultados. Ela é especialmente útil quando se conhece muito pouco sobre os dados e os objetivos da exploração são vagos. O processo de exploração visual de dados pode ser visto como um processo de geração de hipótese, através das visualizações dos dados que permitem aos usuários obter uma visão deles e surgir com 
novas hipóteses. Uma representação visual fornece um grau mais alto de confiabilidade nas conclusões da exploração do que uma representação numérica ou textual. Esse fato conduz a uma forte demanda por técnicas de visualização (seção 3.3) [Keim, 2001].

\subsection{Técnicas de Visualização}

Com o crescente aumento do volume de dados, cientistas da área de computação começaram a pesquisar formas de ver e compreender a informação que está presente nesses dados, buscando extrair mais conhecimento dos mesmos [Traina, 2001]. Dessa forma, pesquisadores reconheceram o potencial das técnicas de visualização para analisar c explorar grandes volumes de dados, e durante esses últimos anos, muitas técnicas para visualização de dados multidimensionais têm sido desenvolvidas [Keim, 2002]. As técnicas de visualização têm sido utilizadas como ferramenta para a apresentação das transformações iniciais dos dados, bem como para a navegação sobre estruturas complexas e para a exibição dos resultados das análises.

As técnicas e ferramentas para visualização de dados são instrumentos indispensáveis ao processo de descoberta de conhecimento e têm provado scus valores na exploração e análise de dados. Sendo assim, essas técnicas têm sido utilizadas nos sistemas de Visual Data Mining (VDM), ou seja, mineração visual de dados. Fm [Hinneburg et al., 1999] é apresentado um apanhado geral das técnicas utilizadas em sistemas de VDM.

As técnicas de visualização devem gerar um acesso natural e intuitivo a um mundo de informações que estão em estruturas abstratas, redes de conexão e dados em geral [Traina, 2001]. É difícil pensar em um domínio de aplicação que gera um grande volume de dados e não utiliza alguma técnica de visualização para esses dados.

Com as técnicas de visualização, grandes volumes de dados podem ser apresentados na tela ao mesmo tempo; cores permitem aos usuários reconhecerem, instantaneamente, similaridades e diferenças de milhôes de itens de dados; os itens de dados podem ser arranjados para expressar algum relacionamento entre si. Durante os últimos anos, muitas técnicas para visualização de dados multidimensionais têm sido desenvolvidas [Keim, 2002]. 
A seguir ć apresentada uma visão geral de algumas técnicas de visualização: técnicas de projeção geométrica, técnicas de apresentação icônicas, técnica baseada em codificação de forma, técnica orientada a pixel e técnica hierárquica.

Na técnica de projecão geométrica, que é uma das mais utilizadas, a idéia básica é o mapeamento de um espaço k-dimensional sobre um dispositivo de apresentação bidimensional utilizando $k$ eixos paralelos eqüidistantes a um dos eixos de apresentação dos dados. Como pode-se observar na Figura 3.1, os eixos do gráfico correspondem às dimensões c são escalados linearmente peios valores de mínimo e máximo de cada dimensão correspondente. Os objetos do conjunto de dados a serem visualizados são apresentados como poligonais que interceptam os eixos nas alturas correspondentes aos valores considerados em cada dimensão [Keim, 2002].

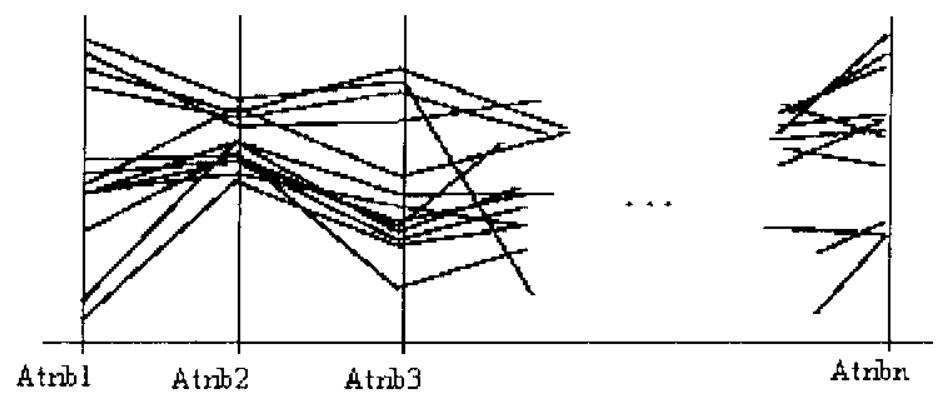

Figura 3.1 - Técnica de projeção geométrica [Keim, 1997]

A técnica de apresentação icônica é baseada em ícones, onde a idéia central é mapear cada item dos dados a un ícone (Figura 3.2). É importante notar que essa técnica limita o número de dimensões a serem apresentadas [Keim, 2002]. 


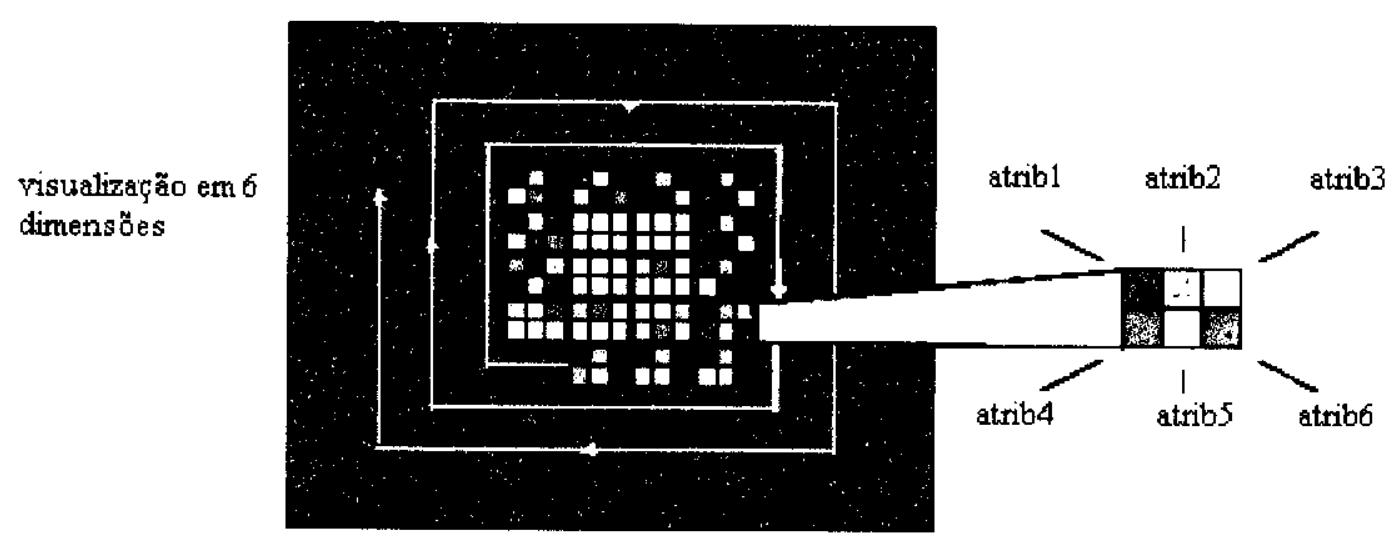

Figura 3.2 - Técnica de apresentação icônica [Keim, 1997]

A técnica baseada em codificacão de forma é uma variação mais refinada da técnica de apresentação icônica. Essa técnica permite visualizar um número arbitrário de dimensões dos dados em análise, já que ela mapeia cada dimensão a um vetor de pixels. Esse vetor de pixels é então organizado em quadrados ou retângulos e é apresentado utilizando padrão de cores ou escala em tons de cinza, onde as cores são associadas às dimensões. Os retângulos de pixels coloridos que indicam cada item de dado são apresentados alinhados na tela [Keim \& Kriegel, 1996].

Na técnica orientada a pixel, a idéia básica é mapear cada valor de dado a um pixel colorido e apresentar os valores de dados pertencentes a um atributo em janelas separadas, como ilustrado na Figura 3.3. Como essa técnica utiliza apenas um pixel da tela para cada valor de atributo da tupla, as técnicas orientadas a pixel permitem visualizar conjuntos de dados bastante grandes (foram efetuados testes para até 1 bilhão de valores de atributos). Aqui a questão crucial é como organizar os pixels na tela de forma que a informação desejada seja captada mais facilmente [Keim, 2002]. 


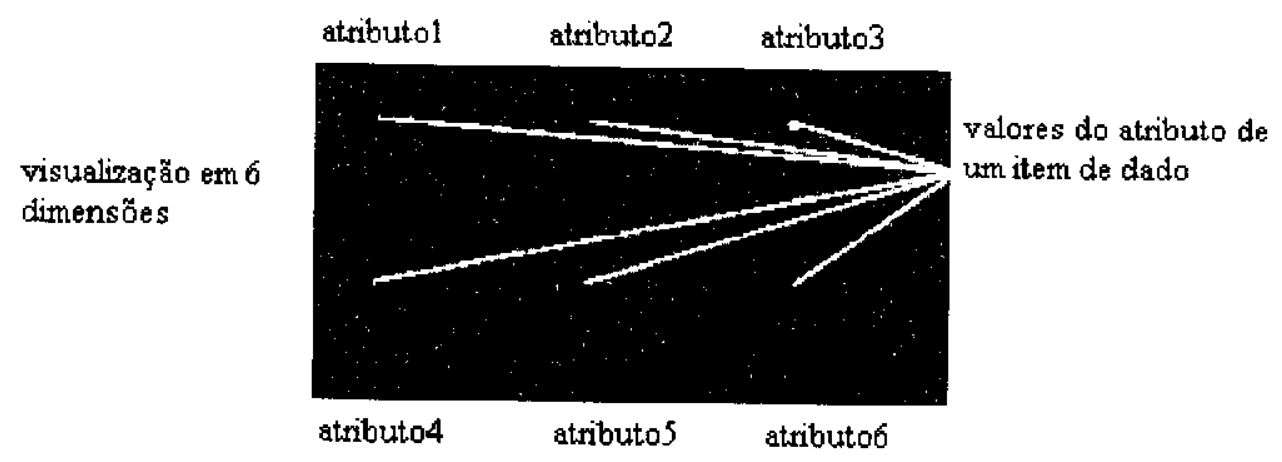

Figura 3.3 - Técnica orientada a pixel [Keim, 1997]

E, por último, a técnica hierárquica, a qual sub-divide um espaço $k$-dimensional em sub-espaços que são apresentados hierarquicamente [Keim, 2002].

$\dot{E}$ importante ressaltar que para obter uma exploração efetiva dos dados, deve-se utilizar técnicas de interação e distorção em adição aos métodos de visualização. Dessa forma, o usuário irá interagir diretamente com a visualização obtida, efetuando manipulações de mapeamento, projeção, filtragem, escalonamento, entre outras [Hinneburg et al., 1999]. A interacão do usuário com o sistema Visual Data Mining (VDM) é importante, pois permite alterações dinâmicas da visualização de forma a atingir mais efetivamente os objetivos da exploração dos dados. As técnicas de distorcão presentes nos sistemas de VDM auxiliam no processo de exploração interativa da visualização. Isto é, elas provêem meios de focalizar determinadas regiões da visualização, enquanto preserva uma visão geral do conjunto de dados. As técnicas de distorção apresentam regiões dos dados com alto grau de detalhe, enquanto outras (que não estão interessando ao usuário no momento) são mostradas com grau de detalhe muito menor [Traina, 2001].

\subsection{Sistemas de Visual Data Mining}

Os métodos analíticos utilizados nos sistemas de Data Mining (DM) geralmente não utilizam visualização, mas existem sistemas de visualização que suportam DM, os quais denominam-se Visual Data Mining (VDM). Esses sistemas de VDM podem utilizar diversas técnicas de visualização (já apresentadas na seção 3.3), sendo de grande valor na exploração e 
análise de dados, além de apresentarem um alto potencial para mineração em grandes bases de dados [Keim \& Kriegel, 1996].

Há basicamente dois enfoques para sistemas VDM:

- visualização suportando DM, na qual os resultados são apresentados de forma gráfica;

- realização de DM através de ferramentas visuais. A seção 3.5 discute tais abordagens.

Os sistemas de VDM procuram integrar a capacidade de exploração do cérebro humano com os recursos computacionais, de forma a produzir um ambiente para a descoberta de conhecimento que se vale do que há de melhor dos dois mundos: o humano e o computacional. A metodologia utilizada baseia-se, por um lado, na funcionalidade característica das estruturas internas dos dados e na exibição dos mesmos; e, por outro lado, na capacidade do ser humano em perceber padrões, exceções, tendências e relacionamentos ao analisar a representação visual dos dados de uma maneira gráfica [Wong, 1999].

As técnicas de VDM atualmente atacam três tópicos, segundo Traina [Traina, 2001]: a busca de agrupamentos, classificação de novos objetos e tratamento de elementos que são exceções no conjunto de dados. A busca por agrupamentos no conjunto de dados permite indicar quais regiões do conjunto de dados são as mais densas, além de apontar os objetos que se encontram isolados. A classificação de novos objetos visa identificar a que classe um certo objeto pertence. E, por último, o tratamento de elementos que são exceções no conjunto de dados, que permite a identificação de casos raros de ocorrência dentro desse conjunto.

Um sistema de VDM, desenvolvido recentemente na Universidade de Halle -

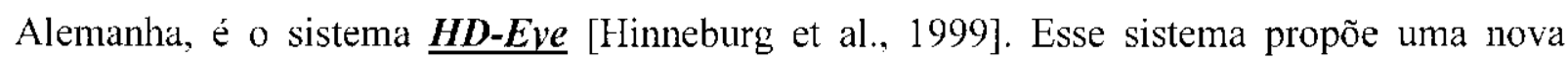
abordagem para agrupamento visual em conjunto de dados de alta dimensão. Ele utiliza um algoritmo avançado de detecção de agrupamentos, chamado OptiGrid [Hinneburg \& Keim, 1999], juntamente com novas técnicas de visualização que efetivamente suportam o processo de agrupamento, representando informação importante de forma visual. Avaliações experimentais mostram que a combinação de técnicas visual e automática melhoram efetivamente o processo de DM e propiciam uma melhor compreensão dos resultados.

\section{O sistema VisDB (Database Exploration Using Multidimensional Visualization)} também deve ser considerado [Keim \& Kriegel, 1994]. A idéia principal do VisDB é usar a capacidade do sistema de visão humano para analisar dados eficientemente $\mathrm{c}$ imediatamente 
reconhecer padrões que seriam difíceis, ou mesmo impossíveis, de serem encontrados pelos computadores. VisDB suporta o processo de cspecificação de consulta através da representação visual dos resultados. A sua interface de consulta utiliza técnicas de visualização para dar aos usuários mais feedback nos resultados de suas consultas. Esse sistema simplifica o processo de especificação de consulta. Para começar, os usuários têm que especificar uma consulta, e, guiados pelo feedhack visual, eles podem interativamente mudar a consulta de acordo com a impressão que eles tiveram através da visualização dos resultados. Nesse sistema, cada pixel representa um item da base de dados. Pixels são arrumados e coloridos para indicar os itens importantes de uma consulta do usuário e também para dar uma impressão visual do conjunto de dados resultante da consulta.

Um outro sistema a ser considerado é o Polaris [Stolte et al., 2002]. Esse sistema apresenta uma interface que permite a exploração e análise de grandes bases de dados multidimensionais. Essa interface possibilita a construção de especificações visuais a partir de representações gráficas baseadas em tabelas e habilita a geração de um conjunto preciso de consultas relacionais a partir dessas especificações.

\subsection{Formas de Integração das áreas de Visualização de Dados e Mineração de Dados}

Segundo Wong [Wong, 1999], Visualização e DM podem ter um acoplamento forte, em que a visualização e o processo analítico são integrados em uma única ferramenta, aproveitando os pontos fortes de cada uma das áreas; $\mathfrak{e}$ acoplamento fraco, em que técnicas das duas áreas são simplesmente intercaladas, possibilitando um aproveitamento apenas parcial do potencial da integração.

Um sistema de VDM visa descobrir conhecimento implícito e útil de grandes conjuntos de dados, utilizando técnicas de visualização; e pode ser visto como uma integração de duas áreas - Visualização de Dados e DM - as quais podem ser integradas das seguintes formas [Han \& Kamber, 2000; Ankerst, 2000]:

- Visualização de dados: os dados podem ser apresentados $\mathrm{em}$ vários formatos visuais. Pela interação e operação na visualização, o usuário tem controle completo na busca. Os padrões são obtidos pela exploração dos dados. Esse tipo de 
visualização ajuda os usuários a terem uma visão geral das características dos dados presentes na base de dados (Figura 3.4 a);

- Visualização do resultado de DM: é a apresentação dos resultados ou conhecimentos obtidos com DM de uma forma visual. Tais formas podem incluir regras de associação, agrupamentos, dentre outras. (Figura 3.4 b);

- Visualização do processo de extração de conhecimento: é a apresentação dos vários processos de extração de conhecimento de uma forma visual, a fim de que os usuários possam ver como os dados são extraídos e de qual base de dados são extraídos; e também, como os dados selecionados são limpos, integrados, préprocessados e minerados. Podem ser também mostrados qual método foi selecionado para DM, onde os resultados estão armazenados e como eles podem ser vistos (Figura $3.4 \mathrm{c}$ ) e;

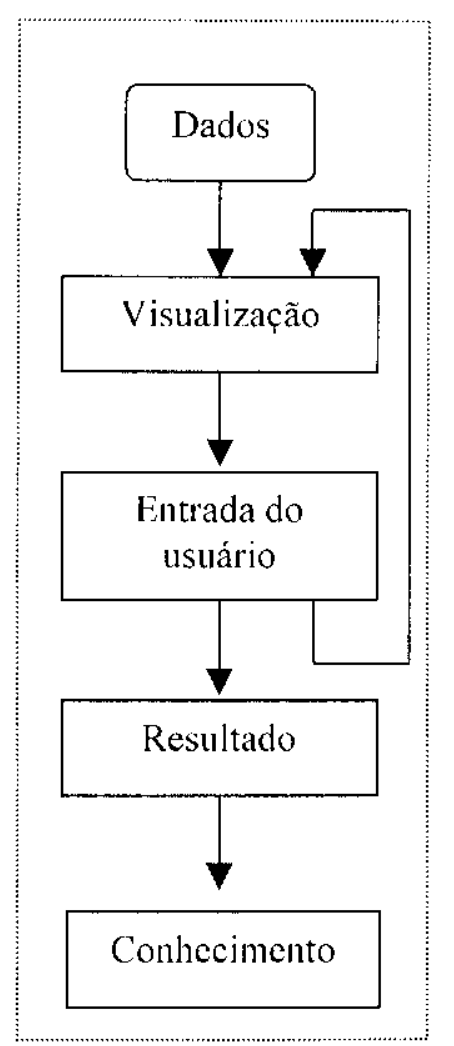

a) Visualização de
dados

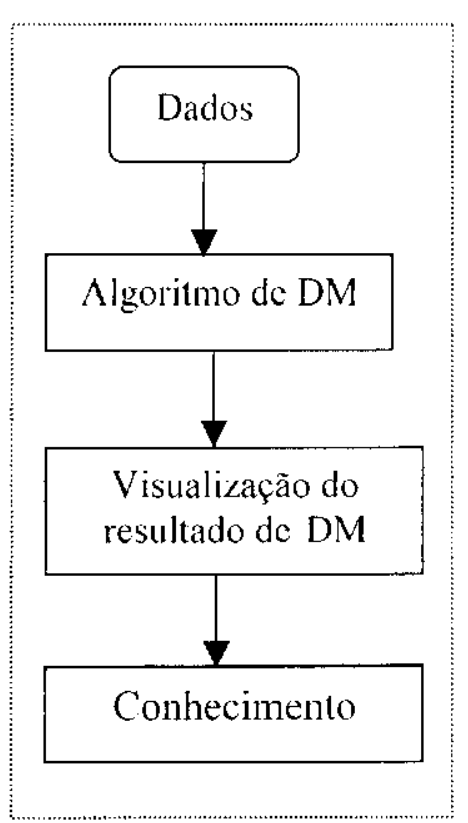

b) Visualização do resultado de DM

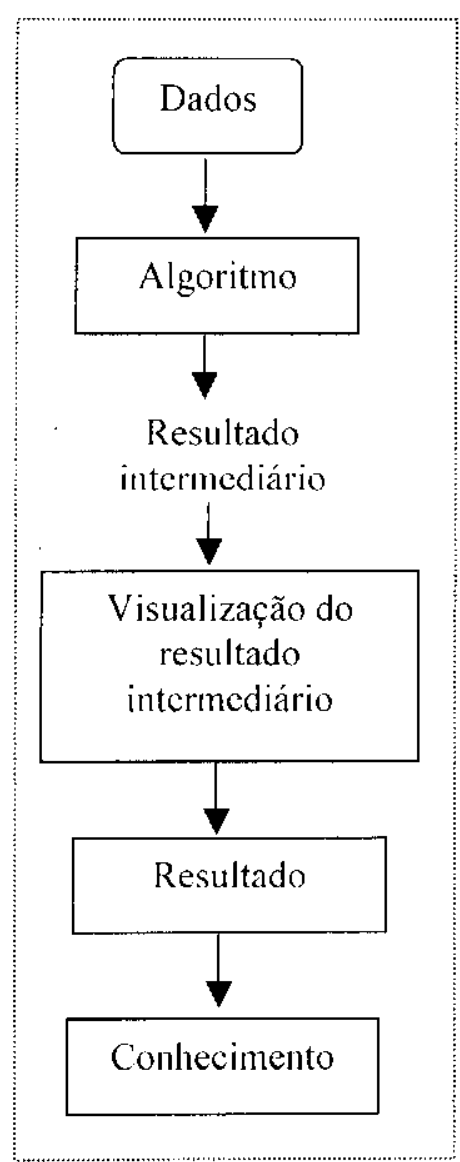

c) Visualização do processo de extração de conhecimento de DM

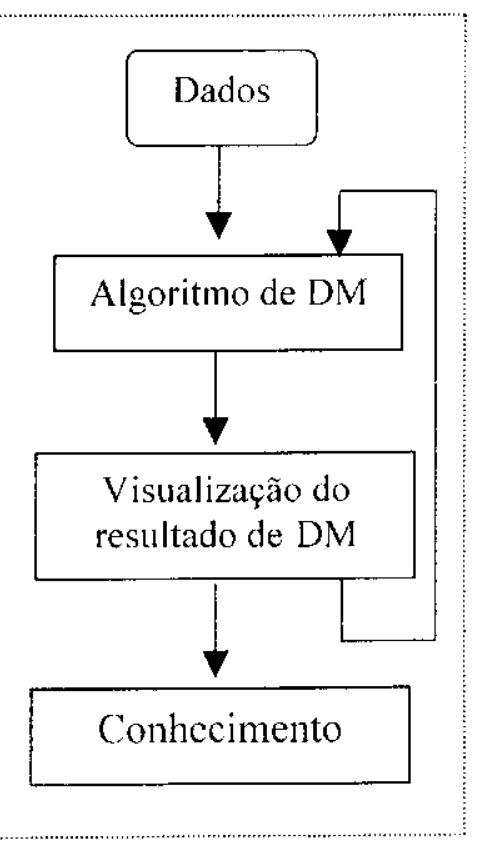

d) Visualização do DM interativa

Figura 3.4 - Formas de integração de visualização de dados e DM 
- Visualização de DM interativa: nesse caso, as ferramentas de visualização podem ser usadas no processo de DM, a fim de ajudar os usuários a tomarem decisões inteligentes de DM. Os padrões são visualizados para torná-los interpretáveis. Por exemplo, a distribuição dos dados em um conjunto de atributos pode ser exibida usando setores coloridos ou colunas. Essa exibição pode ajudar os usuários a determinarem qual setor deveria ser selecionado primeiro para classificação (Figura 3.4 d).

\subsection{Princípios de uma Representação Gráfica}

A representação gráfica proporcionada por um sistema de VDM deve seguir alguns princípios, segundo Wong [Wong, 1999]: simplicidade, confiabilidade, reusabilidade, autonomia do usuário, disponibilidade e segurança.

A simplicidade do sistema significa que ele deve ser sintaticamente simples para ser utilizado facilmente. Não significa que seus recursos sejam triviais, o que não faria sentido. $\mathrm{A}$ simplicidade desejada é no sentido de que o sistema seja de fácil aprendizado, intuitivo e use técnicas de interação amigáveis.

Em relação à confiabilidade, o sistema de VDM deve também prover informações de estimativa de erro ou precisão sobre a geração dos resultados obtidos a cada passo do processo de mineração. Através de medidas de erro desse tipo, é possível corrigir ou quantificar discrepâncias no processo de análise da visualização dos dados.

A reusabilidade do sistema de VDM refere-se à capacidade de adaptação do mesmo a uma variedade de sistemas e ambientes de forma a minimizar os efeitos de personalização e portabilidade.

Quanto à autonomia do usuário, um sistema de mineração genuíno não deve impor aos usuários um conhecimento à priori, mas guiá-los atravćs do processo de mineração, auxiliando no processo de tomada de decisão. Os usuários, então, estariam prontos a estudar as apresentações visuais e tomar as decisões apropriadas, em vez de aceitar um processo de decisão automático do sistema. 
Um sistema de VDM deve estar disponível e amplamente disseminado nos centros de geração de dados. Dessa forma, aumenta-se a comunidade de usuários do sistema e amplia-se o retorno do esforço de seu desenvolvimento.

Por fim, quanto ao princípio da segurança, é necessário tomar cuidado quanto aos aspectos de segurança e privacidade dos dados, já que muitas vezes o sistema lida com dados sigilosos. Também é importante proteger o novo conhecimento gerado pelo sistema.

\subsection{Considerações Finais}

Neste capítulo apresentou-se alguns aspectos relativos à visualização de dados e exploração visual de dados, técnicas de visualização, formas de integração das áreas de Visualização de Dados e Data Mining e alguns sistemas de Visual Data Mining (HD-Eye, VisDB e Polaris).

O sistema de classificação proposto neste trabalho difere dos sistemas de Visual Data Mining, e em particular daqueles apresentados na seção 3.4 , pois esses destinam-se a disponibilizar visualmente as informações tratadas e/ou encontradas, já o sistema proposto aqui, utiliza a téenica de visualização para a fase de treinamento do classificador, e a fase final de classificação efetiva é totalmente automática, independente da ação de um operador humano. 


\section{Capítulo 4}

\section{Arquitetura do Classificador de Dados}

\subsection{Introdução}

Este trabalho de Mestrado partiu do pressuposto que os seres humanos têm uma grande capacidade de absorver e entender rapidamente informação representada de forma gráfica. Por isso, sempre que é preciso sumarizar grandes quantidades de dados numéricos. procura-se utilizar histogramas, gráficos ou algum mecanismo de apresentação visual. Porém, quando muitas das informações que devem ser apresentadas encontram-se em espaços de altas dimensões, ou mesmo em espaços adimensionais (por exemplo, conjunto de palavras), as técnicas de visualização usuais não são as mais adequadas. Deve-se considerar, também, por um outro lado, que técnicas para detecção de características, classilicação, agrupamentos, regressão, etc., completamente automáticas, são freqüentemente distorcidas pela falta de capacidade da técnica de aproveitar outros conhecimentos que para um ser humano é facilmente reconhecido e interpretado.

Dessa forma, neste trabalho foi desenvolvida uma nova técnica para construcão visual de Classificadores de Dados, utilizando essa elevada capacidade humana para analisar dados representados de forma gráfica como fator que auxilia o treinamento do classificador. Deve-se deixar claro que o processo de classificação de dados possui duas etapas: criação do modelo de classificação (o qual é criado através do trcinamento do classificador) e a classificação dos objetos, baseado nesse modelo de classificação. A fase de treinamento do classificador é interativa. onde o usuário trabalha com a visualização do conjunto de dados disponível, e as regiões de interesse que ele definc são armazenadas juntamente com a descrição daquela visualização. Posteriormente, na fase de classificação, 
todos os parâmetros armazenados no treinamento são utilizados para a classificação dos novos objetos da base de dados.

Nestc capítulo, inicialmente, é apresentada a ferramenta FastMapDB, que foi a base inicial para a realização deste trabalho de Mestrado, e o Módulo Visualizador que foi implementado e integrado ao FastMapDB.

Depois da apresentação da ferramenta FastMapDB e do Módulo Visualizador, são descritos os resultados deste trabalho de Mestrado, os quais foram integrados ao FastMapDB.

Um dos resultados foi a realização do Processo de Seleção Visual dos Dados (presentes na visualização) que possibilita ao usuário selecionar um objeto ou regiões de objetos. Baseado nisso, foi implementada a possibilidade do usuário saber quais são esses objetos na base de dados, o que é denominado Mapeamento Inverso.

Com esses dois resultados, Processo de Seleção Visual dos Dados e Mapeamento Inverso, foi possível a realização da fase de Treinamento do Classificador. Nessa fase o usuário interage com a visualização dos dados, definindo regiões de objetos de seu interesse, que vão sendo armazenadas a fim de serem utilizadas na etapa de classificação dos dados.

O Processo de Classilicação de Dados é realizado após o Treinamento do Classificador, utilizando todos os parâmetros armazenados no treinamento.

\subsection{Descrição da Ferramenta FastMapDB}

A ferramenta FastMapDB [Traina et al., 2001] destina-se a gerar mapeamentos de dados armazenados em bases de dados relacionais, a fim de permitir a visualização dos dados em representações tri-dimensionais. O núcleo dessa ferramenta foi construído utilizando o algoritmo de mapeamento de objetos em espaços de diferentes dimensões, denominado fastmap [Faloutsos \& Lin, 1995], que já foi apresentado na seção 2.3.7.1.

Essa ferramenta foi desenvolvida, inicialmente, para disponibilizar os recursos de visualização para dados armazenados em bases de dados relacionais, utilizando resultados e algoritmos originalmente desenvolvidos para a redução de dimensionalidade ou de mapeamento de dados métricos para espaços dimensionais.

A ferramenta FastMapDB possui recursos para que o usuário crie interativamente uma função de distância vetorial, a partir de qualquer quantidade de atributos de uma tabela de 
uma base de dados conectada via ODBC (Open Database Connectivity). Com a função distância definida, o programa cscolhe os pivôs dentre os pares de tuplas mais distantes entre si, conforme explicado na seção 2.3.6.1. Com a definição dos pivôs, o sistema mapeia o conjunto de dados para uma representação tri-dimensional, que procura preservar a distância definida por essa função para os objetos do conjunto de dados no conjunto mapeado (aqui considerando a função distância cuclidiana). Os dados mapeados são, então, utilizados para visualizar a distribuição das tuplas da tabcla, mapeadas para um gráfico em três dimensōes. Os atributos utilizados pela função de distância podem ser quaisquer dados não categóricos, sejam eles numéricos, textuais (usando a função Ledit ${ }^{\prime}$ ) ou datas (considerando a contagem de dias entre as datas), e podem ser ponderados, normalizados, e/ou utilizados em escala linear ou logarítmica. Este sistema dispõe ainda do recurso de utilizar um atributo da tabela (com domínio discreto) para classificar as tuplas da tabela, permitindo a visualização de classes em diversas cores e formatos. Além disso, permite a utilização de diversos filtros para selecionar as tuplas de interesse para a visualização. $\Lambda$ tela principal do FastMapDB é apresentada na Figura 4.1.

Essa ferramenta possibilita ao usuário "ver" a distribuição dos dados sem basear-se em qualquer propriedade espacial intrínseca, possivelmente presente nos dados. Ela permite, por exemplo, verificar a existência de outliers, verificar a formação de agrupamentos (clusters) e auxiliar o usuário a escolher conjuntos reduzidos de atributos para tarefas de mineração. Para exemplificar, suponha uma base de dados que corresponda a uma coleção de exames médicos (de mesmo tipo, por exemplo, eletrocardiogramas). Se no mapeamento desses dados aparecerem aglomerados de pontos, isso deve significar que os exames que compõem cada aglomerado têm algo em comum.

Descrevendo a ferramenta de maneira sucinta, o FastMapDB permite a escolha de uma tabela em uma base de dados, a partir da qual o usuário escolhe os atributos não categóricos de interesse, bem como os critérios de seleção, os fatores de normalização e as funções a serem aplicadas ao grupo de atributos. A seguir, mapeia-se os atributos resultantes para um espaço em três dimensões, e apresenta-se o resultado em um gráfico tri-dimensional, sendo que cada objeto (tupla) da tabela é representado por um ponto no espaço mapeado.

\footnotetext{
${ }^{1}$ Função Ledit calcula o número de caracteres que devem ser inseridos, removidos ou substituídos para transformar um texto no outro.
} 


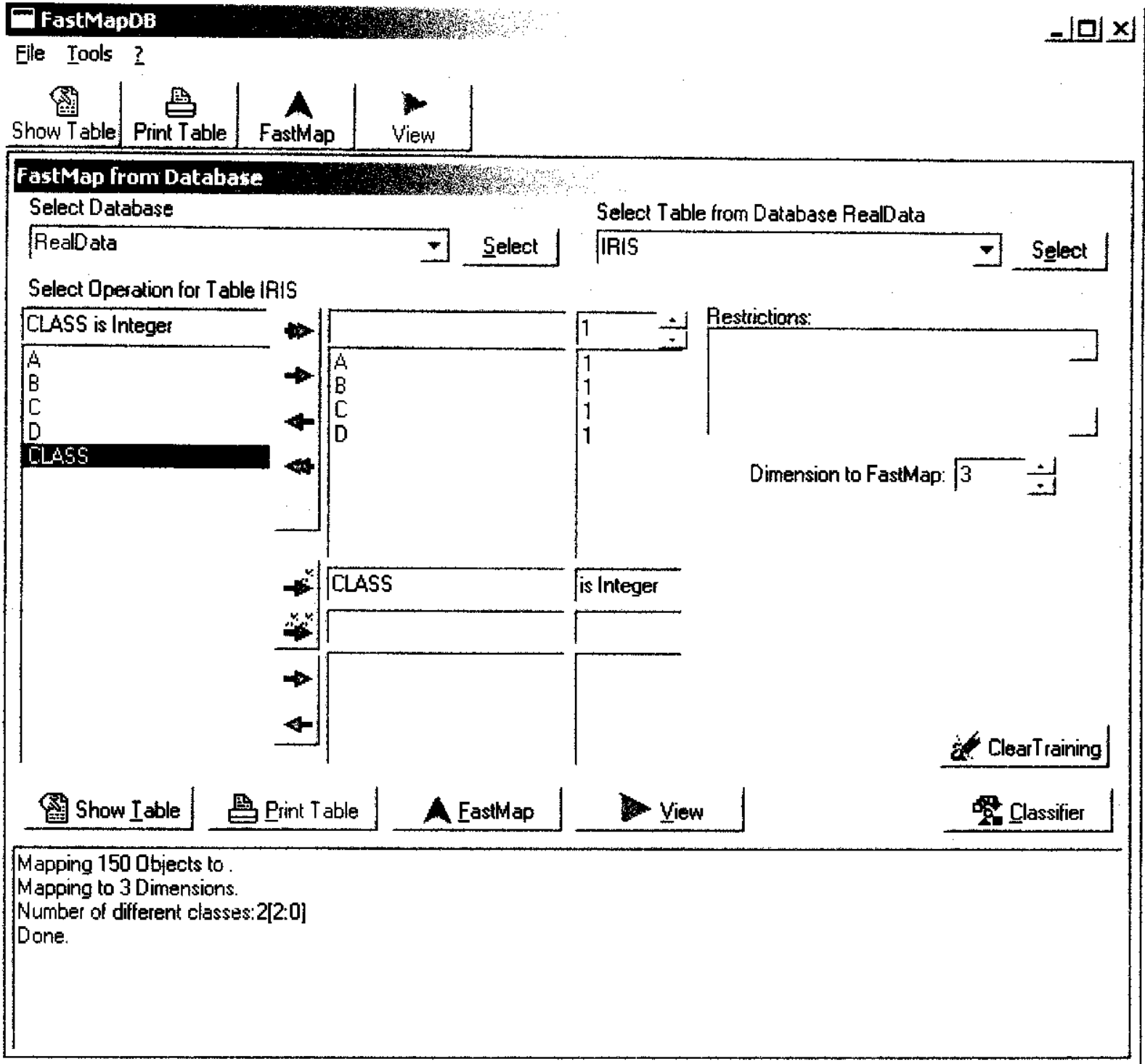

Figura 4.1 - Tela principal da ferramenta FastMapDB

O desenvolvimento da ferramenta FastMapDB foi feito em linguagem $\mathrm{C}++$ Builder, para ambiente $N T$, utilizando o $B D E$ e o protocolo $O D B C$ para conexão com os gerenciadores de bases de dados. Atualmente a ferramenta pode se conectar com gerenciadores Oracle, Sybase, MS-SQLServer e Interbase e, com algumas restrições de operações, também com o Paradox.

Essa ferramenta foi desenvolvida de forma a possibilitar que o usuário interagisse com o sistema durante as várias etapas de apresentação da informação, isto é, o controle sobre os passos de apresentação são guiados pelas preferências do usuário. No entanto, em uma versão inicial, essa ferramenta não permitia ao usuário interagir com a representação gráfica dos dados mapeados. Nessa versão inicial, as coordenadas obtidas através do mapeamento dos 
objetos eram escritas $\mathrm{cm}$ um arquivo de dados em formato texto adequado. Esse arquivo era submetido a uma ferramenta freeware de visualização $W_{g n u P l o t}{ }^{2}$, que só mostrava a visualização dos pontos, não permitindo qualquer interação do usuário com os pontos visualizados. Essa versão inicial foi criada pelos professores Dra. Agma Juci Machado Traina, Dr. Caetano Traina Júnior e Dr. Christos Faloutsos [Traina.Jr et al., 1999].

A ferramenta FastMapDB teve algumas extensões, realizadas por mim e outros membros do GBDI (Grupo de Base de Dados e Imagens) do ICMC (Instituto de Ciências Matemáticas e de Computação) da USP. Tal extensão deu origem ao Módulo Visualizador que é apresentado a seguir.

\subsubsection{Módulo Visualizador do FastMapDB}

O Módulo Visualizador, apresentado na Figura 4.2, consistiu na implementação (neste trabalho) de um módulo de visualização de dados, onde é apresentada a distribuição dos pontos mapeados (os quais representam os objetos da base de dados). Esse módulo foi integrado à ferramenta FastMapDB, dispensando, assim, o uso de qualquer outra ferramenta de visualização externa. Esse módulo permitiu uma grande interação do usuário com a visualização. onde os dados não são apenas mostrados de uma forma estática, mas são possiveis diversas operações interativas, tais como rotação, translação, escala, dentre outras.

Esse módulo implementado é composto basicamente de duas janelas:

- visualização de todos os dados mapeados (Figura 4.2a): essa janela ć fixa e apresenta um cubo 3D que delimita os pontos mapeados, os quais são visualizados na outra janela;

- visualização dos dados de interesse (Figura 4.2b): nessa janela são mostrados os dados após a interação do usuário com a visualização. Ele pode realizar operações de rotação, translação e escala sobre o cubo da outra janela. E ainda pode ter diferentes visões do cubo (e conseqücntemente dos dados): frontal (cixos x e y), esquerda (cixos z e y) e topo (eixos x e z).

\footnotetext{
${ }^{2}$ Maiores informações em http://www.gnuplot.org.
} 
As operações interativas permitem ao usuário manipular os dados da maneira que melhor lhe convier, sendo que assim ele pode observar outras disposições dos pontos e analisar os dados sob diferentes ângulos.

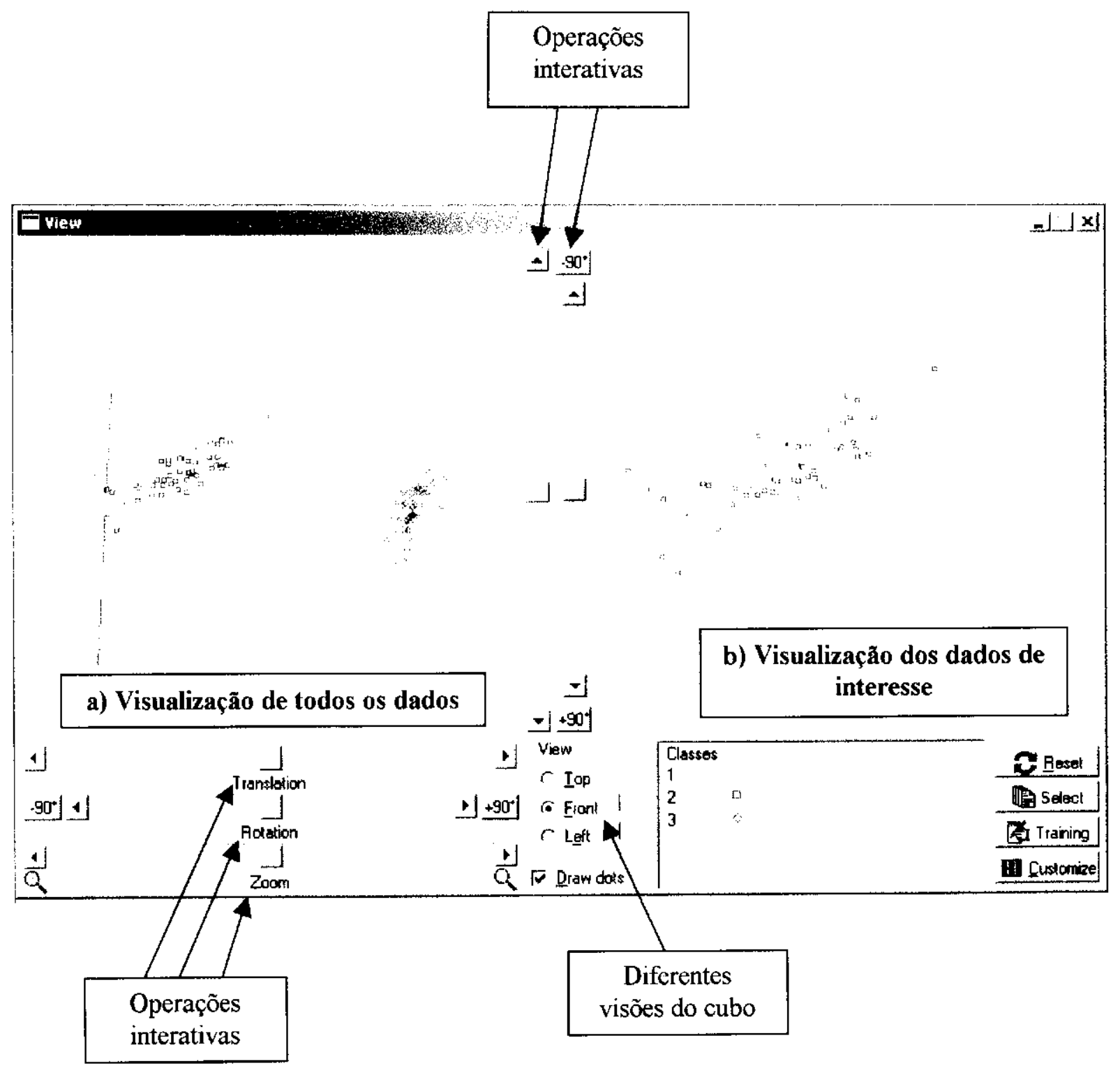

Figura 4.2 - Interface do Módulo Visualizador

\subsection{Processo de Seleção Visual dos Dados}

Baseando-se na interface gráfica de visualização dos dados criada para a ferramenta FastMapDB (Módulo Visualizador), foi desenvolvido neste trabalho o Processo de Seleção Visual dos Dados. Esse processo foi implementado de forma a possibilitar ao usuário selecionar, com o mouse, um objeto ou uma região de objetos presentes nessa visualização. 
As formas geométricas implementadas para que o usuário possa delimitar uma região pode ser um paralelepípedo ou uma esfera.

A tela da ferramenta FastMapDB referente à seleção de uma região de objetos (no caso, paralelepípedo) é apresentada na Figura 4.3. Nessa figura, na visualização à direita, o usuário seleciona a região que the interessa e, na tela à esquerda, é mostrada a região selecionada em três dimensões.

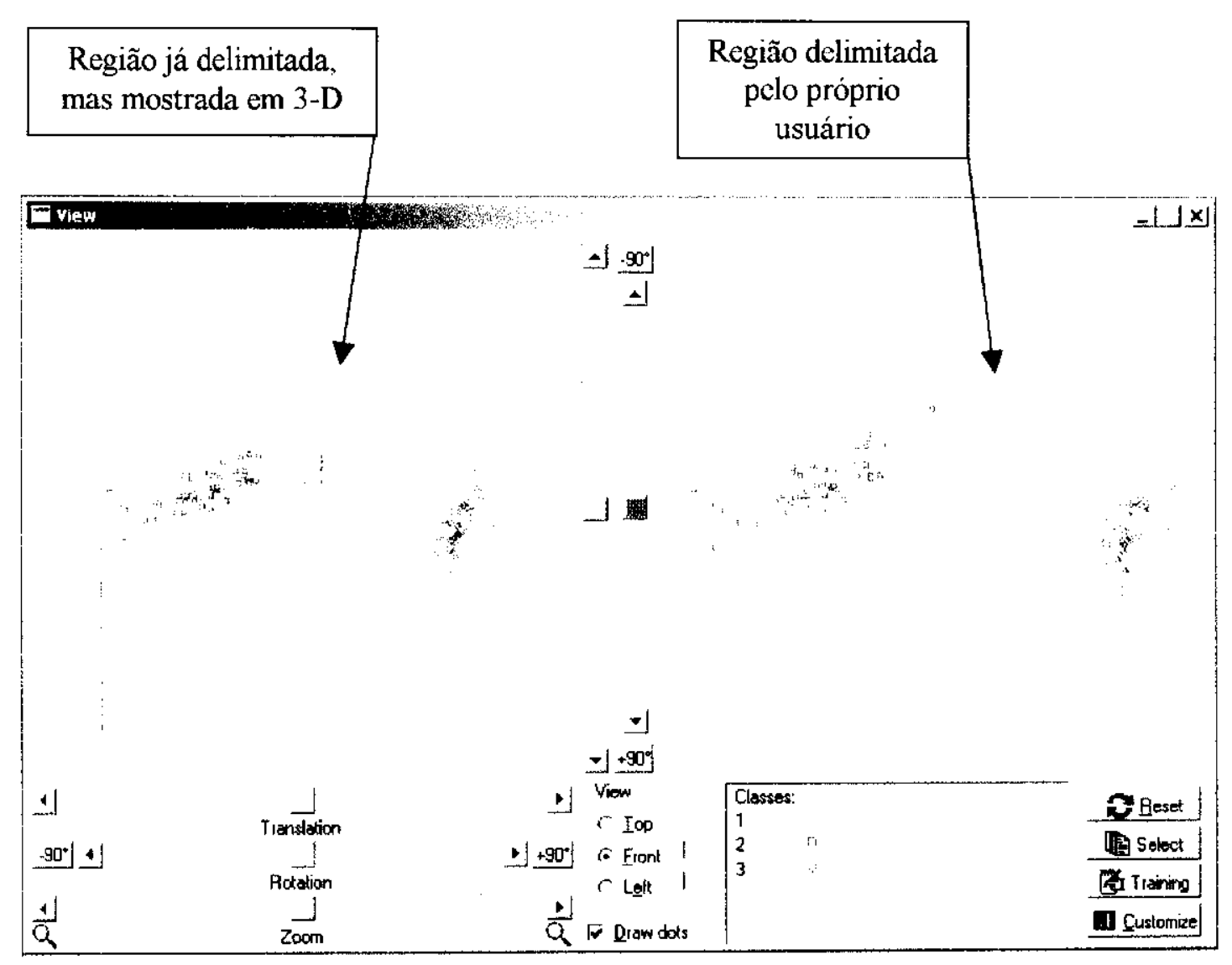

Figura 4.3 - Seleção de uma região de pontos (paralelepípedo)

\subsection{Mapeamento inverso}

Depois de criadas as formas do usuário delimitar o(s) objeto(s) que the interessa no espaço de visualização dos dados (Processo de Seleção Visual), foi implementada neste trabalho a possibilidade de se realizar o Mapeamento Inverso. O Mapeamento Inverso visa identificar pontos na visualização e fazer a correspondência com as tuplas da base de dados, o 
que pode ser observado na Figura 4.4. É criada uma nova tabela com os dados retornados, sendo que dessa forma, o usuário pode utilizar essa nova tabela para outros fins.

Com o mapeamento inverso, o usuário pode interagir com os pontos da visualização, obtendo diretamente a identificação de qual objeto (na base de dados) corresponde a um determinado ponto indicado na visualização, ou coleções de objetos cujos pontos estão incluídos em uma área da visualização que o usuário poderá indicar.

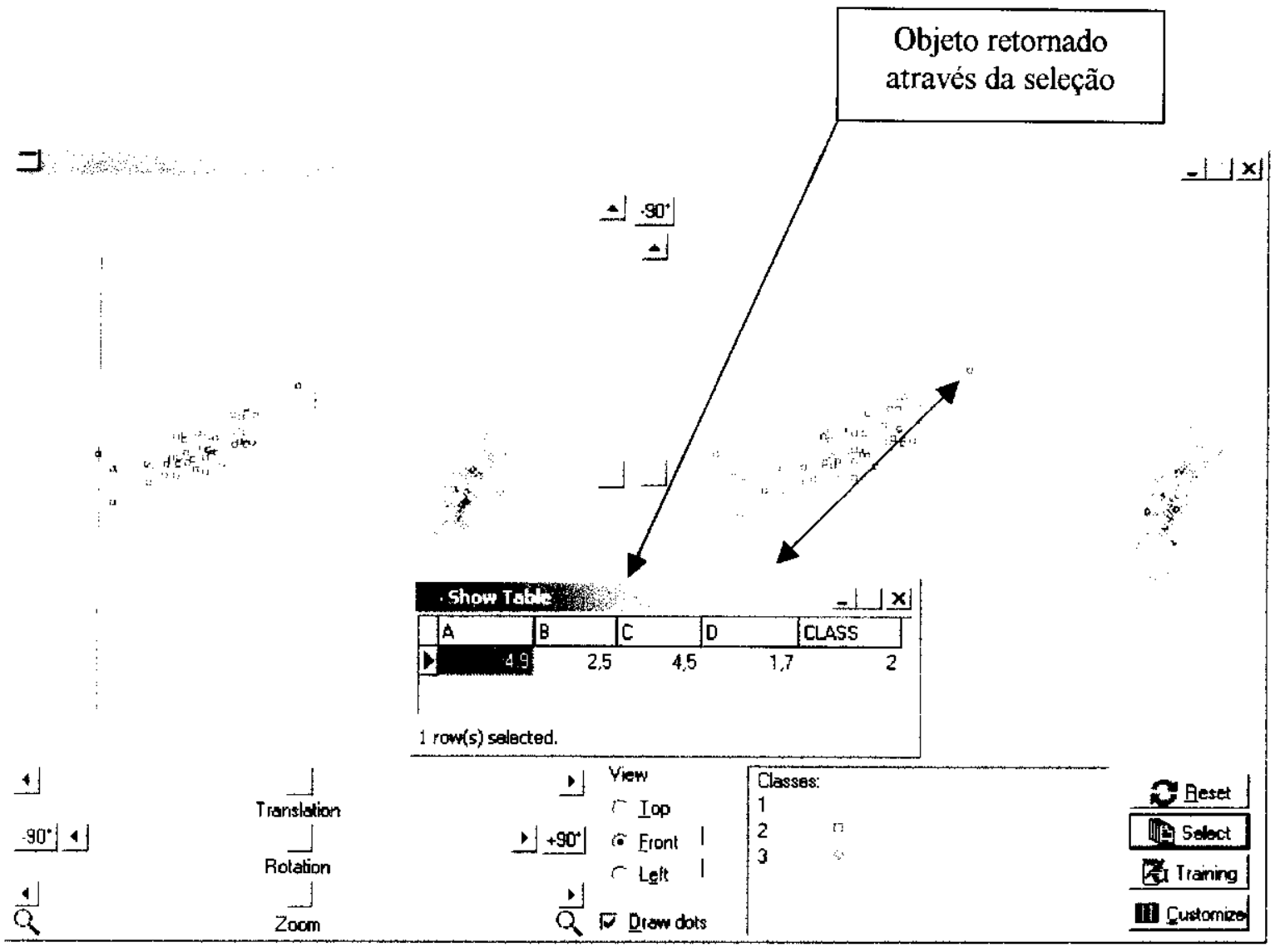

Figura 4.4 - Mapeamento inverso de um objeto

\subsection{Treinamento do Classificador}

A tarefa de classificação, conforme citado, pode ser dividida em duas fases: criação do modelo de classificação e classificação dos dados de acordo com o modelo de classificação criado. O modelo de classificação, criado neste trabalho, baseia-se no treinamento realizado pelo usuário utilizando a ferramenta FastMapDB.

$\mathrm{Na}$ fase de Treinamento do Classificador o usuário escolhe: 
- uma base de dados;

- uma tabela dessa basc de dados;

- atributos para o mapeamento que podem ser ponderados, normalizados e/ou utilizados em escala linear ou logarítmica;

- atributo classificador e;

- função distância a ser aplicada ao grupo de atributos.

Depois de selecionadas as informações acima, gera-se a visualização dos dados e, então, inicia-se a interação do usuário com a visualização.

Essa fase de treinamento do classificador é interativa, onde o usuário trabalha com a visualização do conjunto de dados disponível da maneira que desejar, utilizando o Processo de Seleção Visual e todas as operações interativas do Módulo Visualizador (rotação. translação, escala, etc.) para definir regiōes de seu interesse na visualização. Tais regiões contribuirão para a criação do modelo de classificação. O Mapeamento Inverso também pode auxiliar o usuário a escolher os objetos de interesse.

Todas as regiões definidas pelo usuário são armazenadas juntamente com a descrição da visualização corrente (que inclui dados como o nome da tabela, atributo classificador, função distância, dentre outros). Para cada região definida são guardadas várias informações: delimitação da região selecionada, transformações (operações interativas) realizadas durante a visualização, quantidade de objetos (de todas as classes) dentro e fora da região selecionada e também a quantidade de objetos de cada classe (individualmente) dentro e fora da região selecionada.

Todas as informações referentes ao treinamento realizado pelo usuário vão sendo armazenadas em tabelas, a fim de que seja possivel, na próxima etapa, gerar o classificador de dados. Na próxima seção são descritas essas tabelas do treinamento. 


\subsubsection{Tabelas do Treinamento do Classificador}

As tabelas criadas durante o treinamento do classificador são as seguintes:

- Visualization: contém informações da tabela utilizada no treinamento (nome, atributo classilicador, número de atributos e número de classes) e a função distância utilizada para o mapeamento dos objetos;

- Attribute: contém informações referentes aos atributos selccionados para mapeamento durante o treinamento;

- Shape: contém informações das regiões definidas pelo usuário e;

- Counting: contém informações sobre a contagem de objetos das regiões selecionadas pelo usuário.

O relacionamento entre as tabelas do treinamento é apresentado na Figura 4.5 , e as Tabelas 4.1 , 4.2, 4.3 e 4.4 descrevem cada um dos atributos das tabelas citadas anteriormente.

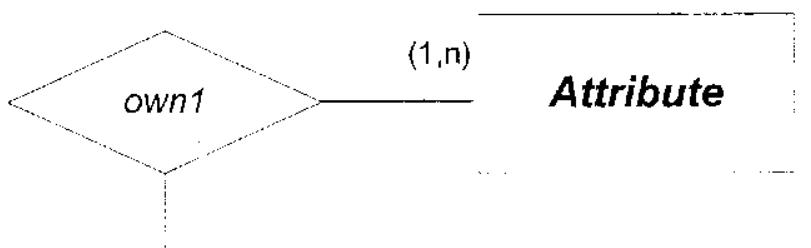

$(1,1)$

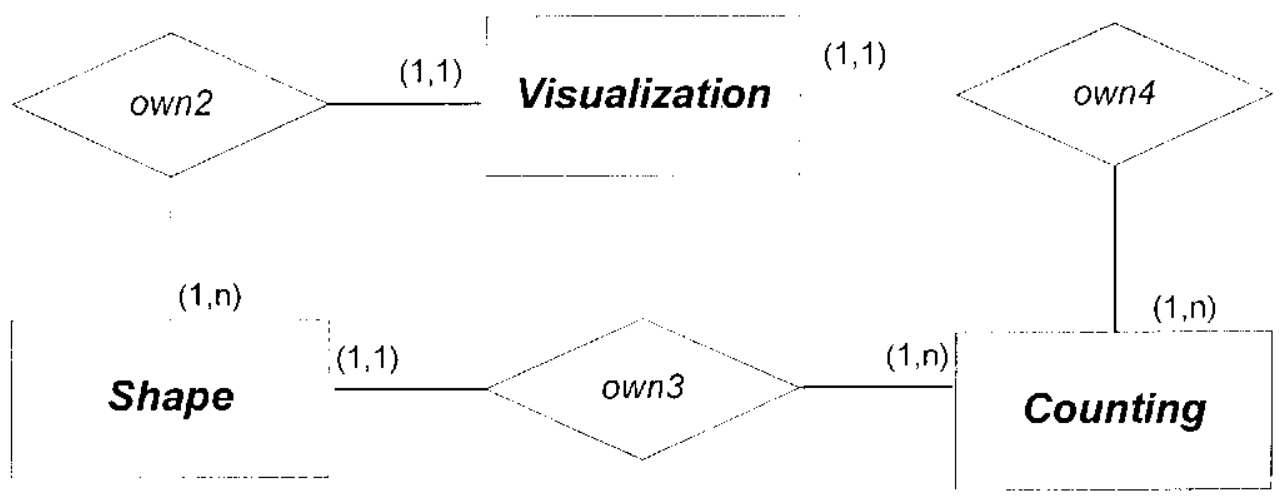

Figura 4.5 - Relacionamento entre as tabelas do treinamento do classificador 
Tabela 4.1 - Descrição dos atributos da tabela Visualization

\begin{tabular}{|l|l|}
\hline \multicolumn{1}{|c|}{ Atributo } & \multicolumn{1}{|c|}{ Descrição do Atributo } \\
\hline Oid Vis & Identificador da visualização \\
\hline Table Base & Nome da tabela selecionada na base de dados \\
\hline Attrib_Class & Nome do atributo classificador selecionado \\
\hline Nattrib & Número de atributos sclecionados para o mapeamento \\
\hline Nclass & Número de classes do atributo classificador selecionado \\
\hline F_Dist & Função distância aplicada ao grupo de atributos selecionados para o \\
& mapeamento \\
\hline
\end{tabular}

Tabela 4.2 - Descrição dos atributos da tabela Attribute

\begin{tabular}{|l|l|}
\hline \multicolumn{1}{|c|}{ Atributo } & \multicolumn{1}{|c|}{ Descrição do Atributo } \\
\hline Oid_Vis & Identificador da visualização \\
\hline Attrib & Nome do atributo \\
\hline Weight & Valor do peso atribuído ao atributo \\
\hline Log & Tratar o atributo em escala logarítmica \\
\hline AsNumber & Tratar o atributo como número \\
\hline Drop_Caracter & Desconsiderar o primeiro caractere do valor do atributo \\
\hline Kind & $\begin{array}{l}\text { Tipo de dado referente ao valor do pivô, que pode ser s(string) ou } \\
\text { d(double })\end{array}$ \\
\hline Pivoto & Valor do pivô utilizado no mapeamento para o primeiro eixo \\
\hline Pivotl & Valor do pivô utilizado no mapeamento para o primeiro eixo \\
\hline Pivot2 & Valor do pivô utilizado no mapeamento para o segundo eixo \\
\hline Pivot3 & Valor do pivô utilizado no mapeamento para o segundo eixo \\
\hline Pivot4 & Valor do pivô utilizado no mapeamento para o terceiro eixo \\
\hline Pivot5 & Valor do pivô utilizado no mapeamento para o terceiro eixo \\
\hline
\end{tabular}


Tabela 4.3 - Descrição dos atributos da tabela Shape

\begin{tabular}{|c|c|}
\hline Atributo & Descrição do Atributo \\
\hline Oid Vis & Identificador da visualização \\
\hline Oid Shape & Identificador da região sclecionada \\
\hline Form & Tipo da região sclecionada (paralelepípedo ou esfera) \\
\hline Total_Obj_Inside & Total de objetos (de todas as classes) dentro da região selecionada \\
\hline Total_Obj Outside & Total de objetos (de todas as classes) fora da região selecionada \\
\hline$X I$ & Coordenada do paralelepípedo ou do centro da esfera \\
\hline$Y I$ & Coordenada do paralelepípedo ou do centro da esfera \\
\hline$Z 1$ & Coordenada do paralelepípedo ou do centro da esfera \\
\hline$X 2$ & Coordenada do paralelepípedo \\
\hline$Y 2$ & Coordenada do paralelepípedo \\
\hline$Z 2$ & Coordenada do paralelepípedo \\
\hline Radius & Raio da esfera \\
\hline Ang_x & Ângulo de rotação em relação ao eixo x \\
\hline Ang $y$ & Ângulo de rotação cm relação ao cixo y \\
\hline $\operatorname{Ang}_{z} z$ & Ângulo de rotação em relação ao cixo z \\
\hline Disloc $x$ & Deslocamento (translação) em relação ao cixo $\mathrm{x}$ \\
\hline Disloc $y$ & Deslocamento (translação) cm relação ao eixo y \\
\hline Disloc $z$ & Deslocamento (translação) $\mathrm{cm}$ relação ao eixo $\mathrm{z}$ \\
\hline Scale & Zoom \\
\hline
\end{tabular}

Tabela 4.4 - Descrição dos atributos da tabela Counting

\begin{tabular}{|l|l|}
\hline \multicolumn{1}{|c|}{ Atributo } & \multicolumn{1}{c|}{ Descrição do Atributo } \\
\hline Oid Vis & Identificador da visualização \\
\hline Oid_Shape & Identificador da região selecionada \\
\hline Class & Nome da classe \\
\hline Num_Obj_Inside & Número de objetos de uma dada classe, dentro da região selecionada \\
\hline Num Obj_Outside & Número de objetos de uma dada classe, fora da região selecionada \\
\hline
\end{tabular}


Para exemplificar a fase de treinamento do classificador, são mostrados, a seguir, exemplos das tabelas do treinamento (Tabelas 4.5, 4.6, 4.7 e 4.8) para uma melhor compreensão dos dados armazenados nessa fase. No Capítulo 5 é apresentado, com detalhes, como é realizado o treinamento através da utilização da ferramenta FastMapDB.

1) Visualization: o atributo $F_{-}$Dist (função distância) será utilizado durante o mapeamento dos novos objetos, pelo algoritmo fastmap, no processo de classificação dos dados.

Tabela 4.5 - Exemplos de dados da tabela Visualization

\begin{tabular}{|c|c|c|c|c|c|}
\hline Oid_Vis & Table_Base & Nattrib & Attrib_Class & Nclass & F_Dist \\
\hline I & IRIS & 4 & CLASS & 3 & 2 \\
\hline
\end{tabular}

2) Attribute: todos os atributos dessa tabela serão utilizados no mapeamento dos novos objetos, pelo algoritmo fastmap, no processo de classificação dos dados.

Tabela 4.6 - Exemplos de dados da tabela Attribute

\begin{tabular}{|c|c|c|c|c|c|c|c|c|}
\hline Oit_Vis & Attrib & Weight & Log & AsNumber & Drop_Caracter & Kind & Pivoto & Pivotl \\
\hline 1 & A & 1 & 0 & 0 & 0 & d & 7,6999 & 4,5999 \\
\hline I & B & 2 & 0 & 0 & 0 & d & 2,5999 & 3,5999 \\
\hline I & C & 1 & 0 & 0 & 0 & d & 6,9000 & 1 \\
\hline 1 & D & 2 & 0 & 0 & 0 & d & 2,2999 & 0,2000 \\
\hline
\end{tabular}

\begin{tabular}{|c|c|c|c|}
\hline Pivot2 & Pivot3 & Pivot4 & Pivot5 \\
\hline 7,69999 & 5 & 5,8000 & 5,8000 \\
\hline 3,79999 & 2 & 4 & 2,7999 \\
\hline 6,69999 & 3,5 & 1,2000 & 5,0999 \\
\hline 2,20000 & 1 & 0,2000 & 2,4000 \\
\hline
\end{tabular}




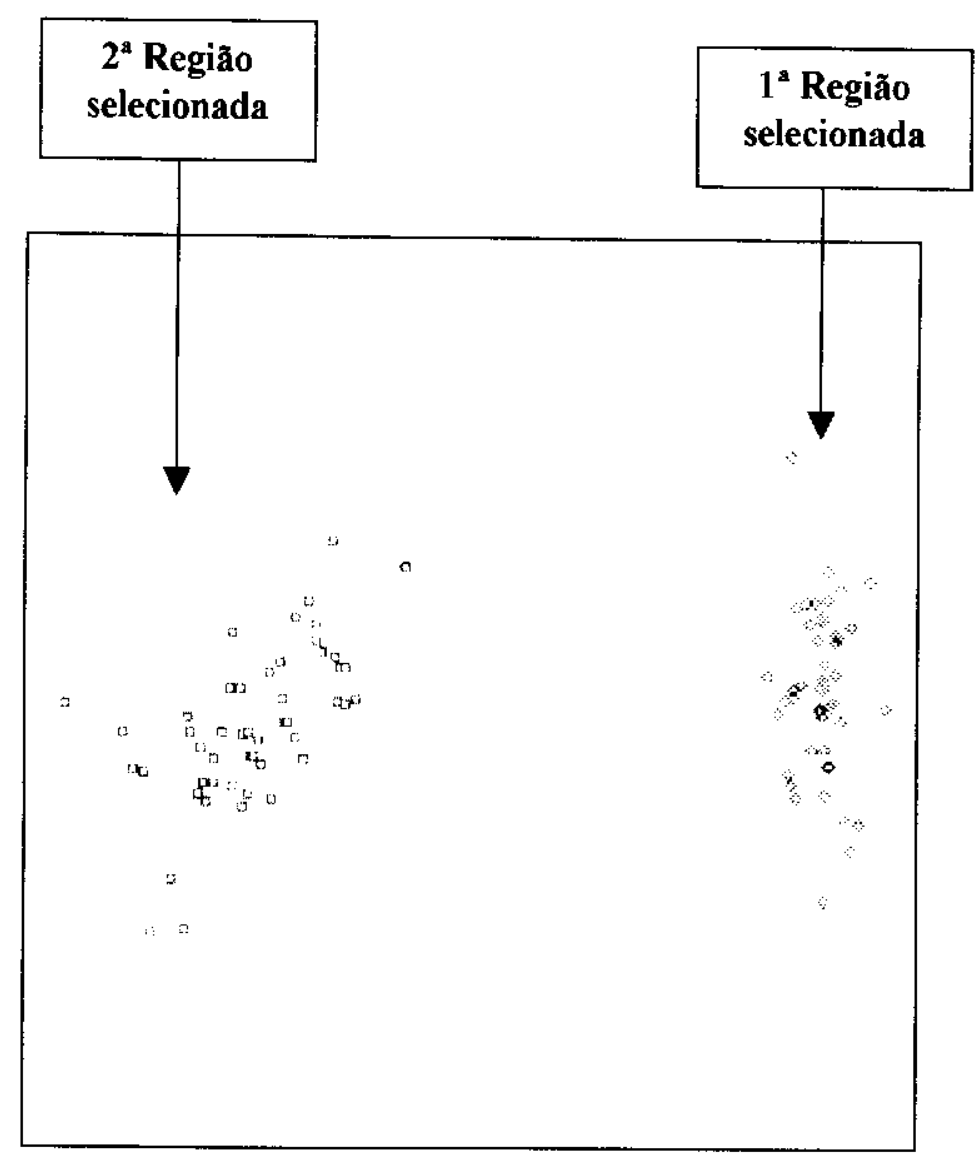

Figura 4.6 - Regiões selecionadas pelo usuário para o treinamento do classificador (classe 1 = vermelha, classe $\mathbf{2}=$ azul e classe 3 = verde)

3) Shape: os atributos Total_Obj_Inside e Total_Obj.Outside serão utilizados na fórmula de classificação, apresentada na seção 4.6.1. Os atributos Ang x, Ang $y$, Ang_z, Disloc_x, Disloc $y$, Disloc $z$ e Scale armazenam os valores relativos às transformações realizadas sobre a visualização. Esses atributos, juntamente com os atributos $X 1, X 2, Y 1, Y 2, Z 1, Z 2$ e Radius, serão utilizados para descobrir a localização de cada objeto mapeado (ponto). Dessa forma, pode-se descobrir se o objeto se encontra dentro ou fora da região selecionada. As regiões selecionadas como exemplo estão na Figura 4.6.

Tabela 4.7 - Exemplos de dados da tabela Shape

\begin{tabular}{|c|c|c|c|c|c|c|c|}
\hline Oid vis & Oid Shape & Form & Total Obi Inside & Total Obj Outside & $X 1$ & $Y 1$ & $X 2$ \\
\hline 1 & 1 & Paralelep. & 50 & 100 & 269 & 71 & 344 \\
\hline 1 & 2 & Paralelcp & 41 & 109 & 9 & 101 & 114 \\
\hline
\end{tabular}




\begin{tabular}{|c|c|c|c|c|c|c|c|c|c|c|}
\hline$Y 2$ & $Z 1$ & $Z 2$ & Radius & Any_x & Ang_y & Ang_z & Disloc_x & Disloc_y & Disloc_z & Scale \\
\hline 278 & 0 & 350 & -1 & 0 & 0 & 0 & 0 & 0 & 0 & 0,8 \\
\hline 286 & 0 & 350 & -1 & 0 & 0 & 0 & 0 & 0 & 0 & 0,8 \\
\hline
\end{tabular}

4) Counting: os atributos Num_Obj Inside e Num_Obj_Outside serão utilizados na fórmula de classificação, apresentada na seção 4.6.1. As regiões selecionadas que serão utilizadas para a contagem dos objetos se encontram no excmplo da Figura 4.6.

Tabela 4.8 - Exemplos de dados da tabela Counting

\begin{tabular}{|c|c|c|c|c|}
\hline Oid_Vis & Oid Shape & Class & Num_Obj_Inside & Num_ObjOutside \\
\hline 1 & 1 & 1 & 0 & 50 \\
\hline 1 & 1 & 2 & 0 & 50 \\
\hline 1 & 1 & 3 & 50 & 0 \\
\hline 1 & 2 & 1 & 0 & 50 \\
\hline 1 & 2 & 2 & 41 & 9 \\
\hline 1 & 2 & 3 & 0 & 50 \\
\hline
\end{tabular}

\subsection{Processo de Classificação de Dados}

O Processo de Classificação de Dados consiste na geração de um classificador para dados, baseado no conjunto de regiões definidas pelo usuário, de acordo com uma determinada tabela_base e um atributo de classificação, que são utilizados na fase de Treinamento do Classificador. O classificador utiliza as informações sobre todas as regiões definidas e as contagens de objetos (de todas as classes e de cada classe, individualmente) nas regiões selecionadas, para estimar o valor provável do atributo de classificação.

Deve-se deixar claro que todas as regiões utilizadas são de uma mesma tabela_base e de um mesmo atributo de classificação, não importando se existem vários treinamentos (visualizações) com essa tabela_base, variando-se, por exemplo, o número de atributos selecionados, os pesos atribuídos a cada um dos atributos, etc. 
Com os dados do treinamento armazenados em tabelas (as quais já foram descritas anteriormente), quaisquer novos objetos inseridos na tabela analisada podem ser classificados. O processo de classificação propriamente dito consiste na re-aplicação das mesmas operaçôes de mapeamento, projeções c delimitação das regiões armazenadas na fase de treinamento, porém efetuadas apenas internamente, sem necessidade de uma interface visual correspondente. O mapeamento desses objetos é realizado diretamente numa visualização já efetuada (de acordo com todos os seus parâmetros armazenados no treinamento), sem a necessidade de se refazer o processo de mapeamento dos demais objetos. Com os totais de contagem de objetos de cada classe nas regiões visualizadas, é possível classificar automaticamente cada novo objeto inserido na base de dados, sendo que, nessa fase. a visualização não precisa estar ativada. O algoritmo criado para a classificação é apresentado ná sç̧ão 4.6.1.

Com a integração do classificador à ferramenta FastMapDB, ela foi estendida para incluir a possibilidade de classificação de objetos a partir da definição, pelo usuário, de regiões nas visualizações. Ou seja, sobre uma mesma base de dados, diversas operações de mapeamento. possivelmente envolvendo diferentes atributos, podem criar uma coleção de regiões marcadas pelo usuário. A partir dessas coleções, é possivel definir uma fórmula, que é apresentada na seção 4.6.1, que estima a probabilidade de um objeto fazer parte de uma classe, bascada na contagem de objetos de cada classe que fica dentro/fora das regiões marcadas pelo usuário. Como o processo de mapeamento pode ser feito de maneira incremental. qualquer novo objeto a ser mapeado vai ficar dentro ou fora dessas regiões. mesmo agora que o usuário não esteja "vendo" o resultado do mapeamento. Isso permite usar essa ferramenta como um classificador. E, além disso, como os parâmetros de visualização e os pivôs de mapeamento (obtidos nos passos iniciais (que são os mais custosos) do processo de mapeamento) são armazenados na fase de treinamento, os diferentes mapeamentos já armazenados podem ser rapidamente recupcrados. mesmo que a relação tenha sofrido atualizações.

O classificador, assim criado, não é completamente automático, pois depende da capacidade humana de analisar informações representadas de maneira grálica. Essa ferramenta constitui-se numa nova forma de classificador de dados, que pode vir a proporcionar resultados adequados em muitas situações onde outras técnicas de classificação completamente automáticas ou não produzem bons resultados, ou não são práticas devido às dimensões dos dados envolvidos. Por exemplo, árvores de decisão exploram todas as 
possibilidades dentro de uma particular configuração (atributos, por exemplo), mas se o número de atributos é alto, as árvores de decisão e outros classificadores similares tornam-se impraticáveis devido ao tempo envolvido. Por outro lado, detectores de agrupamentos falham quando as nuvens de pontos geram padrões que os detectores não discriminam (embora com freqüência elas visivelmente existam). Assim, esse classificador soma-se como mais um recurso exploratório de informações $\mathrm{em}$ grandes volumes de dados armazenados em bases de dados. A força e o ineditismo deste trabalho está na participação do usuário no processo de treinamento, usando uma ferramenta gráfica, intuitiva simples de utilizar.

No final do processo de classificação dos dados, é gerada uma nova tabela com todos os dados da tabela utilizada na classificação e mais os seguintes atributos: a porcentagem referente a cada classe (de cada tupla) utilizada no treinamento e a melhor classe, ou seja, a classe com a maior porcentagem. Dessa forma, são classificados os novos objetos inseridos na tabela e reclassificados os já existentes. Um excmplo hipotético dessa nova tabela criada se encontra na Figura 4.7.

É importante salientar que com as tabelas referentes ao treinamento, esse classificador pode ser acoplado a qualquer outra ferramenta de Banco de Dados, sem a necessidade de utilizar toda a interface gráfica.

Para um melhor entendimento do processo de classificação, nas próximas seções são aprescntados: a fómula criada para a classificação dos dados (seção 4.6.1) e o algoritmo classificador implementado neste trabalho (scção 4.6.2).

\begin{tabular}{|c|c|c|c|c|c|c|}
\hline \multicolumn{4}{|c|}{$\begin{array}{l}\text { Atributos originais da tabela } \\
\text { selecionada para classificação }\end{array}$} & \multicolumn{3}{|c|}{$\begin{array}{c}\text { Novos atributos inseridos após } \\
\text { a classificação }\end{array}$} \\
\hline Attrib_l & Attrib_2 & Attrib_3 & Attrib_Class & Class_l (\%) & Class_2 (\%) & Best_Class \\
\hline 2 & 3 & 1 & 1 & 81 & 19 & 1 \\
\hline 4 & 2 & 5 & 2 & 21 & 79 & 2 \\
\hline 6 & 3 & 2 & mull & 12 & 88 & 2 \\
\hline 4 & 3 & 4 & null & 75 & 25 & 1 \\
\hline
\end{tabular}

Figura 4.7 - Tabela criada após o processo de classificação dos dados 


\subsubsection{Fórmula de Classificação de Dados}

Foi criada uma fórmula que estima qual ć a probabilidade de um objeto pertencer a cada uma das classes utilizadas no treinamento. Essa fórmula baseia-se na contagem de objetos (de cada classe) que fica dentro ou fora das regiões selecionadas pelo usuário e também do total de objetos (de todas as classes) dentro ou fora de cada região selecionada. Todas essas informaçôes estão armazenadas nas tabelas do treinamento.

A fórmula de classificação de dados é:

$\%$ ClasseN $=\frac{\sum \text { nimero_de_objetos_da_classeN_das_regiões_selecionadas }}{\sum \text { total_de_objetos_das_regiões_selecionadas }}$

O numerador dessa fórmula é o somatório do número de objetos da "classeN" de todas as regiōes selecionadas pelo usuário no treinamento. Esse valor é obtido do atributo Num Obj Inside (se o objeto a ser classificado encontra-se dentro da região selecionada) ou Num_Obj Ontside (se o objeto estiver fora da região selecionada) da tabela Counting.

O denominador é o somatório do total de objetos de todas as classes e de todas as regiões selecionadas pelo usuário durante o treinamento. Esse valor é obtido do atributo Total Obj Inside (se o objeto a ser classificado encontra-se dentro da região selecionada) ou Total_Obj_Outside (se o objeto estiver fora da região selecionada) da tabela Shape.

Considere o seguinte exemplo, baseado na Figura 4.8, a fim de ilustrar a utilização da fórmula de classificação de dados. Essa figura apresenta uma visualização de 10 objetos, sendo 5 objetos da classe losango vermelho e 5 objetos da classe estrela azul. Duas regiões foram selecionadas dessa visualização, como pode-sc obscrvar nas partes a) e b) da Figura 4.8. Suponha que se deseja saber uma possível classificação para um novo objeto inserido na base de dados, que é o objeto "?" da Figura 4.8. Os dados do treinamento para a utilização da fórmula acima. baseado nas regiões selecionadas da Figura 4.8, são os seguintes:

$1^{\text {: }}$ região selecionada (paralclcpípedo - Figura 4.8 a):

Total_Obj_Inside: 6 objetos

Total_Obj_Outside: 4 objetos 
Num Obj_Inside: classe $1=5$ objetos

$$
\text { classe } 2=1 \text { objeto }
$$

Num_Obj_Outside: classe1 $=0$ objetos

$$
\text { classe } 2=4 \text { objetos }
$$

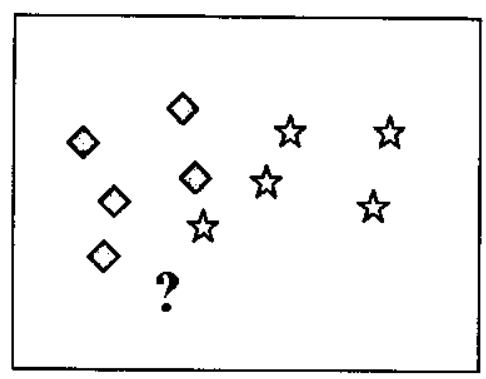

a) $1^{\mathrm{a}}$ região selecionada

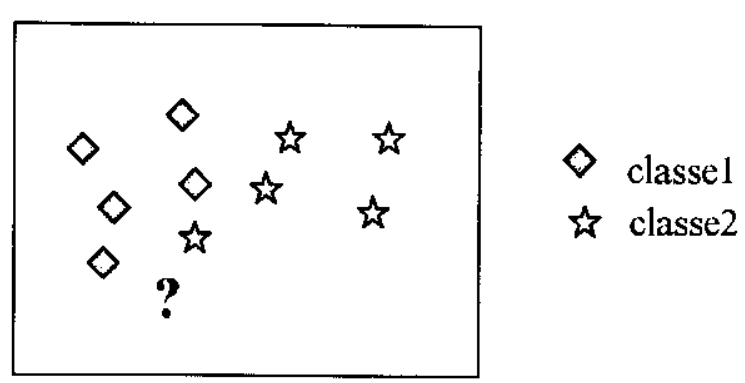

b) $2^{a}$ região selecionada

Figura 4.8 - Seleção de duas regiões na visualização dos dados

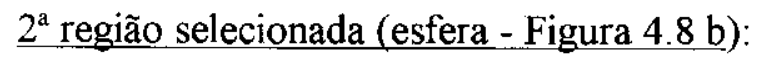

Total_Obj Inside: 5 objetos

Total_Obj_Outside: 5 objetos

Num_Obj_Inside: classe $1=2$ objetos

$$
\text { classe } 2=3 \text { objetos }
$$

Num_Obj_Outside: classe $1=3$ objetos

$$
\text { classe } 2=2 \text { objetos }
$$

Como mostrado na Figura 4.8 a), o novo objeto "?" se encontra dentro da $1^{\text {a }}$ região selecionada, logo, serão utilizadas todas as contagens de objetos dentro da região (Num_Obj_Inside e Total Obj_Inside). Na $2^{\text {a }}$ região selecionada da Figura 4.8 b), o novo objeto "?" se encontra fora da região selecionada, logo, serão utilizadas todas as contagens de objetos fora da região (Num_Obj_Outside e Total_Obj_Outside). Então, a fórmula recebe os seguintes valores: 


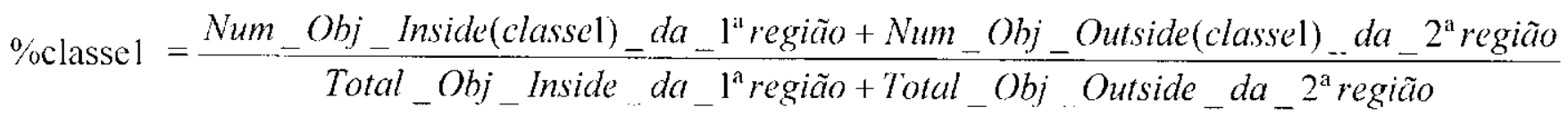

$\%$ classel $=\frac{5+3}{6+5}=0,7272727 * 100=\mathbf{7 2 , 7 2 \%}$

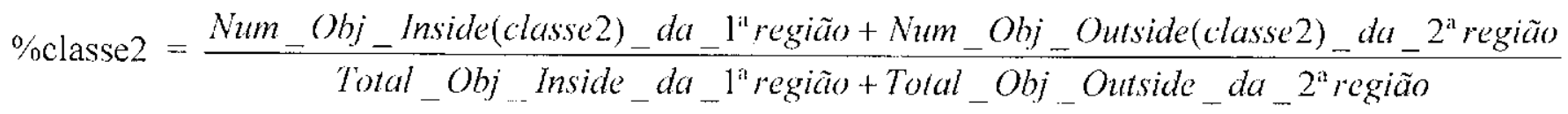

\%classe $2=\frac{1+2}{6+5}=0.2727272 * 100=\mathbf{2 7}, \mathbf{2 7} \%$

Logo, pode-se concluir que o novo ponto inserido na base de dados tem a probabilidade de $72,72 \%$ de ser da classe 1 e $27,27 \%$ de ser da classe 2 , de acordo com as regiões selecionadas pelo usuário durante o treinamento.

\subsubsection{Algoritmo Classificador}

Nesta seção é apresentado o Algoritmo Classificador cm pscudo-código, a fim de dar uma visão de como é realizado o Processo de Classificação de Dados. E, logo após, são descritos os vários passos do Algoritmo Classificador, a fím de uma melhor compreensão desse algoritmo.

\section{Algoritmo Classificador em pseudo-código:}

Considere: $(\mathrm{c} 1)=$ consulta1, $(\mathrm{c} 2)=$ consulta2,$(\mathrm{c} 3)=$ consulta3, $(\mathrm{c} 4)=$ consulta4, $(\mathrm{c} 5)=$ consulta5. Os passos declarados aqui (passol a passo9) são explicados logo após a apresentação desse pseudo-código. 


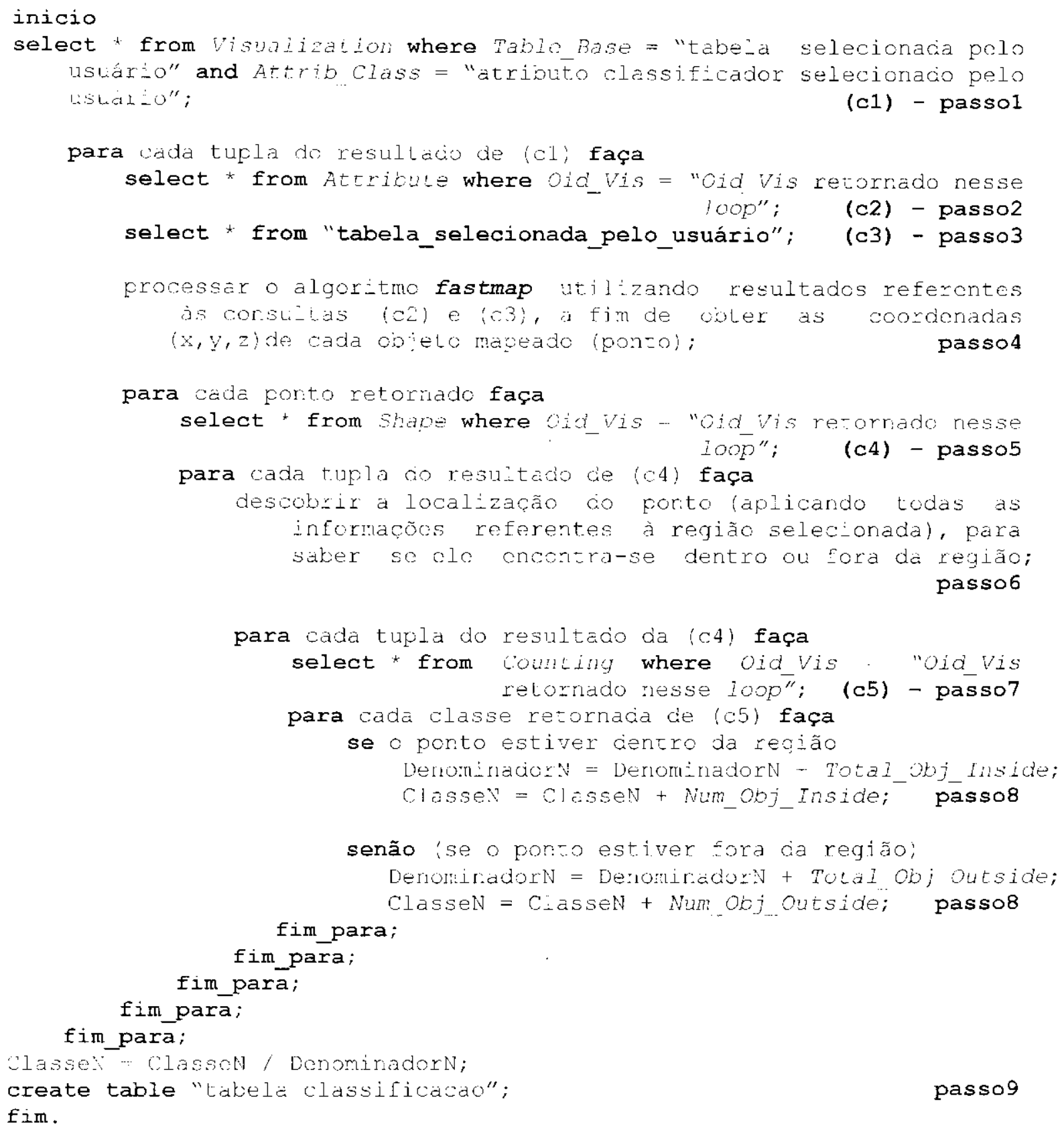

\section{Explicação do Algoritmo Classificador:}

Inicialmente, o usuário deve selecionar a tabela que deseja ser classificada, juntamente com o atributo de classificação dessa tabela. Baseado nessa tabela e nesse atributo de classificação, é que o algoritmo classificador terá início. Todas as tabelas citadas nos passos desse algoritmo são as utilizadas na Fase de Treinamento do Classificador (seção 4.5). 
Passo1: Fazer uma consulta na tabela Visualization para descobrir quais as tuplas que possuem as mesmas Table Base e Attrib_Class selecionadas pelo usuário para classificação. Devem ser retornados todos os atributos dessa tabela. Os Oid_Vis retornados dessa consulta serão utilizados em consultas subseqüentes e $F_{\text {_ }}$ Dist será utilizado no passo6 para o mapcamento de novos objetos.

Passo2: Fazer uma consulta na tabela Atribute baseado nos Oid_Vis retornados do passol. Nessa consulta devem ser retornados todos os atributos a fim de serem utilizados no passo4, para a realização do mapeamento dos objetos.

Passo3: Fazer una consulta na tabela sclecionada pelo usuário. Nessa consulta devem ser retornados todos os atributos da tabela, a lim realizar o mapeamento dos dados desejáveis dessa tabela.

Passo4: Aplicar o algoritmo fastmap (apresentado na seção 2.3.7.1) nas tuplas retornadas do passo3. Os valores resultantes da consulta do passo2 serão utilizados para o processamento do algoritmo fastmap. Esse algoritmo irá retomar as coordenadas (x,y,z) (objetos mapeados) desses novos objetos. Essas coordenadas serão utilizadas para descobrir a localização do objeto nas regiões já armazenadas na fase de treinamento.

Passo5: Fazer uma consulta na tabela Shape baseada nos Oid_Vis retornados do passol. Nessa consulta devem ser retornados todos os atributos da tabela. Esses atributos serão utilizados no passo6 para a localização dos objetos mapcados (pontos) retornados do passo4 e também serão utilizados na construção da fórmula de classificação de dados (seção 4.6.1).

Passu6: As coordenadas retornadas do passo4 serão utilizadas para se processar a localização dos pontos na visualização (sem visualizar novamente). Deve-se descobrir se o ponto se encontra dentro ou fora da região selecionada pelo usuário, sendo que essas informações sobre as regiões selecionadas são retornadas da consulta do passo5 - tabela Shape. 
Passo7: Fazer uma consulta na tabela Counting baseado nos Oid_Vis retornados do passol c nos Oid_Shape retornados do passo5. Nessa consulta devem ser retornados todos os atributos da tabela, os quais serão utilizados no passo8 para a construção da fórmula de classificação de dados.

Passo8: Cálculo da fórmula de classificação de dados (equação 1), já apresentada na seção 4.6.1. São utilizadas as informações retornadas do passo5, passo6 e passo7. Ou seja, para cada uma das regiões selecionadas durante o treinamento (referentes à tabela selecionada pelo usuário para classificação) vão sendo atribuídos à fórmula de classificação de dados os valores dos atributos: Total_Obj_Inside e Num_Obj_Inside, se o objeto mapeado estiver dentro dessa região selecionada; ou, Total_Obj_Outside e Num_Obj_Outside, se o objeto mapeado estiver dentro dessa região selecionada. Com isso, têm-se, para cada um dos objetos mapeados, as probabilidades deles fazerem parte de cada uma das classes utilizadas no treinamento.

Passo9: criação de uma nova tabela que contém todos os dados da tabela selecionada pelo usuário e mais os seguintes atributos: a porcentagem referente a cada classe (de cada tupla) utilizada no treinamento e a melhor classe, ou seja, a classe com a maior porcentagem.

\subsection{Considerações Finais}

Neste capítulo foram apresentados os resultados obtidos durante este trabalho de Mestrado, ou seja, o desenvolvimento de um Classificador de Dados utilizando a elevada capacidade visual do ser humano no treinamento do classificador, de maneira que os dados do treinamento são apresentados em uma forma visual e interativa.

Foi descrita a lerramenta FastMapDB, que foi a base inicial para a realização deste trabalho, e que permite a visualização de dados através do mapeamento desses dados para uma representação tri-dimensional. Um Módulo Visualizador de dados foi implementado e integrado ao FastMapDB, a fim de conseguir uma interação do usuário com os dados visualizados, já que isso não era possivel na versão original do FastMapDB. 
Com esse Módulo Visualizador de dados, foram implementados o Processo de Seleção Visual dos Dados e o Mapeamento Inverso. No processo de seleção visual, o usuário tem a possibilidade de selecionar, com o mouse, um objeto ou uma região de objetos de seu interesse. E, no mapcamento inverso, o usuário pode conhecer quais são esses objetos selecionados na base de dados.

$\mathrm{Na}$ fase de Treinamento do Classificador, o usuário interage com a visualização dos dados, definindo regiões de objetos de seu interesse, as quais vão sendo armazenadas nas tabelas do treinamento. Nessa fase de treinamento, o usuário utiliza o Processo de Seleção Visual dos Dados para definir as regiões e também pode utilizar o Mapeamento Inverso.

O Processo de Classificação de Dados é realizado após o treinamento realizado pelo usuário. utilizando todas as informações armazenadas nas tabelas do treinamento. Assim, o classificador utiliza as informações sobre todas as regiões definidas e as contagens de objetos nas regiões selecionadas para estimar o valor provável do atributo de classificação. 


\section{Capítulo 5}

\section{Exemplo de Utilização do Classificador de Dados}

\subsection{Introdução}

Este capítulo apresenta un exemplo de utilização do Classificador de Dados, desenvolvido neste trabalho de Mestrado, o qual foi integrado à ferramenta FastMapDB. São mostradas todas as etapas necessárias para a realização da fase de treinamento do classificador e depois a fase de classificação dos dados, através da utilização da ferramenta FastMapDB. É utilizado o conjunto de dados "Iris Plant" no exemplo.

\subsection{Utilização da Ferramenta FastMapDB para Classificação de Dados}

Fsta seção mostra todos os passos necessários à realização da fase de treinamento do classificador e a fase de classificação dos dados, utilizando a ferramenta FastMapDB. Inicialmente é utilizado o conjunto de dados "Iris Plant" para uma exemplificação bem detalhada. Esse conjunto é conhecido desde 1938 e contém dados sobre flores do gênero Íris, que são divididas em três classes: Iris setosa. Iris versicolor e Iris virginica, sendo 50 tuplas de cada classe. Esse conjunto possui quatro atributos numéricos: comprimento (atributo A) c largura (atributo $\Lambda$ ) da pétala, comprimento (atributo C) e largura (atributo D) da sépala. Ele está disponível no web site do Machine Learning Repository da Universidade da Cálifórnia em Irvine (http://www.ics.nci.edu/ mlearning/MLSumary.html). 


\subsubsection{Exemplo da Fase de Treinamento do Classificador de Dados}

Inicialmente tem que ser realizada a fase de treinamento do classificador. Nessa fase o usuário trabalha com uma tabela, sendo que todas as tuplas possuem atributo classificador, a fim de poder criar um modelo de classificação. Todos os dados que forem utilizados no treinamento vão sendo armazenados nas tabelas Visualization, Attribute, Shape e Counting, já apresentadas na seção 4.5 .

Numa primeira etapa do treinamento, o usuário deve selecionar, na tela principal da ferramenta FastMapDB, as seguintes informações (esses passos são ilustrados nas Figuras 5.1 ( 5.2):

Passo1: seleção de uma base de dados, dentre as que estão registradas (Figura 5.1). Depois de selecionada, o Fast MapDB apresenta uma lista das tabelas acessíveis nessa base de dados;

Passo2: seleção de uma das tabelas presentes na base de dados (Figura 5.1). Após a seleção dessa tabela, o FastMapDB apresenta uma lista de atributos que podem ser selecionados para mapeamento e para classificação;

Passo3: seleção dos atributos a serem mapeados, no mínimo dois atributos (Figura 5.1):

Passo4: definição dos parâmetros dos atributos para o mapeamento. Esses atributos podem ser ponderados. normalizados e/ou utilizados em escala linear ou logarítmica. Esses parâmetros são obtidos através de um clique na janela referente aos pesos de cada atributo (Figura 5.1), a qual abrirá a janela da Figura 5.2;

Passo5: seleção da função distância a ser aplicada ao grupo de atributos selecionados para mapeamento (Figura 5.2);

Passo6: seleção de um atributo para classilicação (Figura 5.1). Esse atributo de classificação faz com que as tuplas pertencentes a diferentes classes sejam representadas em diferentes cores e formatos.

Todas essas informaçõcs obtidas são armazcnadas na tabela Visualization.

$\Lambda$ tabela "IRIS" utilizada nesse exemplo é relativa aos dados do conjunto "Iris Plant", já definido no início da seção 5.2. 


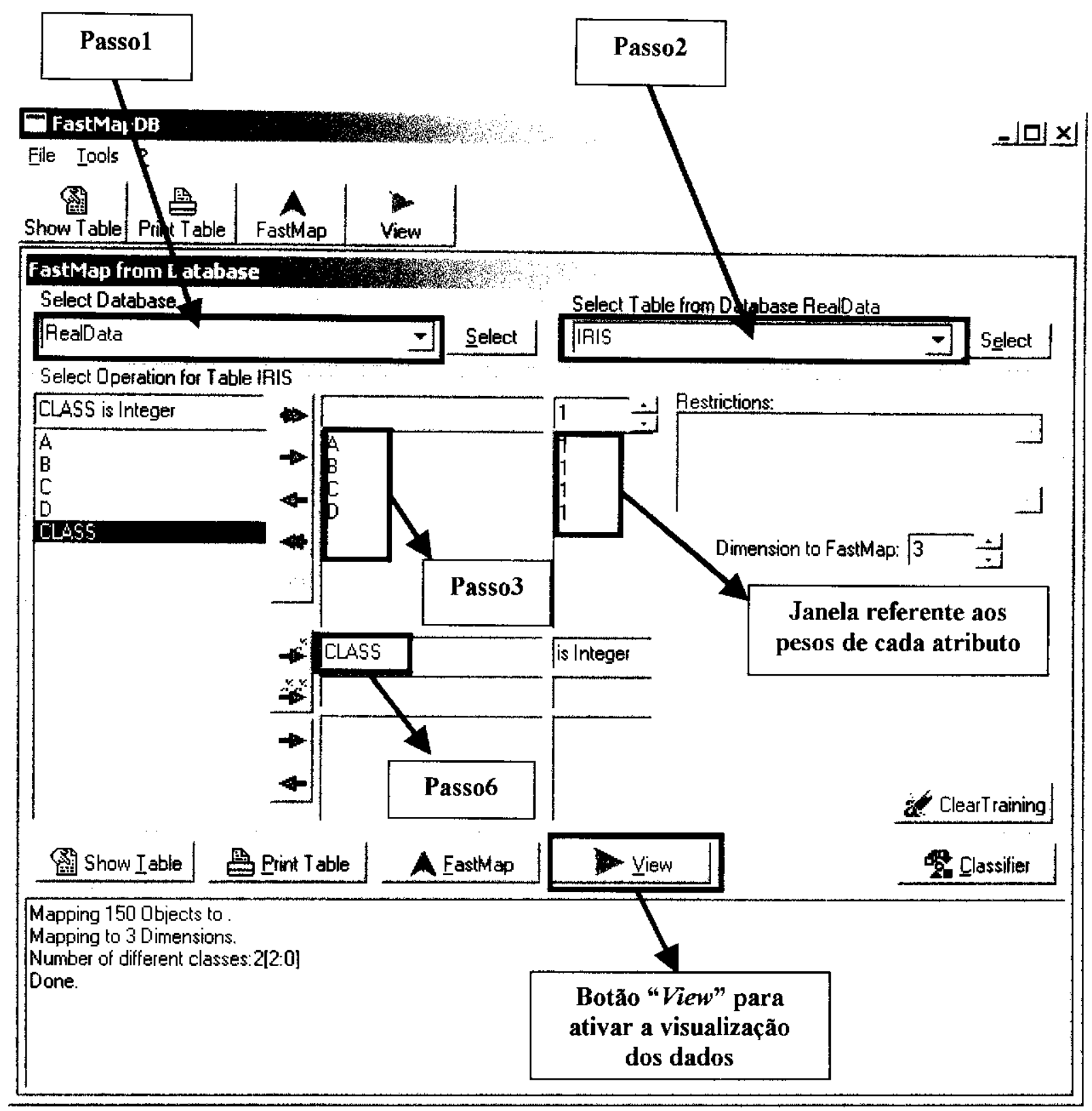

Figura 5.1 - Tela principal da ferramenta FastMapDB

Na Figura 5.1 pode-se observar que foram escolhidos todos os atributos da tabela "IRIS" (A, B, C e D) para serem mapeados e o atributo de classificação escolhido foi o CLASS. Todos os atributos do mapeamento possuem peso igual a 1 e a função distância selecionada foi a euclidiana. 


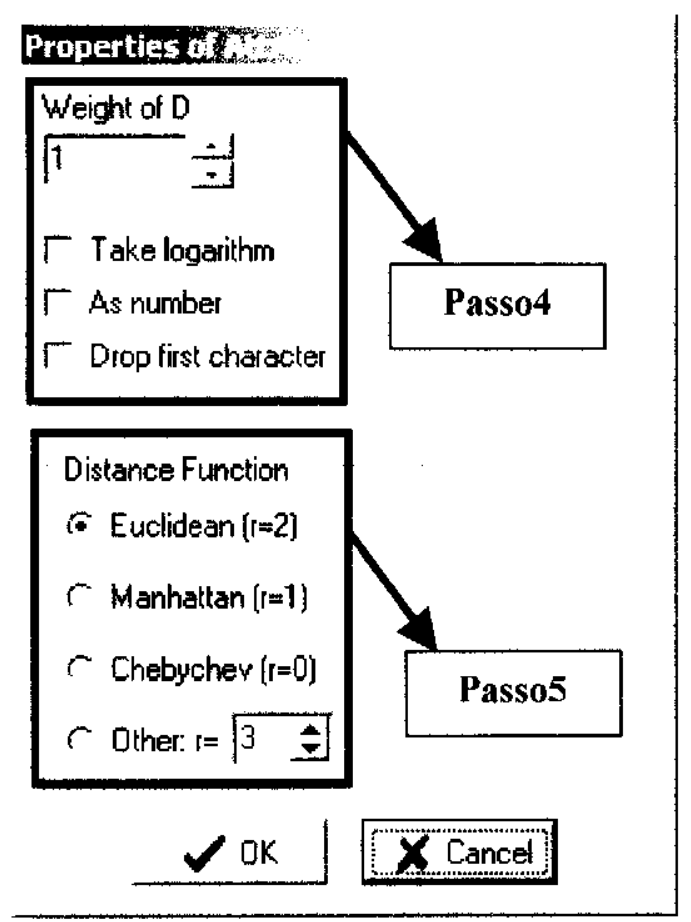

Figura 5.2 - Tela de configuração dos parâmetros dos atributos e escolha da função distância

Depois de selecionadas todas essas informações das Figuras 5.1 e 5.2, passa-se para a etapa de visualização dos dados, apenas dando um clique no botão "View" da Figura 5.1. Assim, o usuário pode iniciar a interação com os dados visualizados no Módulo Visualizador (Figura 5.3)

Essa fase de treinamento do classificador, como já comentada, é interativa, onde o usuário trabalha com a visualização dos dados da maneira que desejar, utilizando as operações interativas do Módulo Visualizador, tais como rotação, translação, escala, dentre outras. Através das transformações realizadas com essas operações interativas, ele pode observar a nova disposição dos dados, e, assim, analisá-los sob diferentes ângulos (Figura 5.3). E as regiões que ele considerar interessantes podem ser marcadas, através de formas geométricas, como paralelepípedo ou esfera, para então fazerem parte do treinamento.

Para armazenar uma região ao treinamento, após tê-la delimitada, é só clicar no botão "Training" da Figura 5.3. Procedendo dessa forma, as informações referentes à região selecionada serão armazenadas nas tabelas Shape e Counting. Essas informações referem-se à delimitação da região selecionada, transformações (operações interativas) realizadas durante a visualização, quantidade de objetos (de todas as classes) dentro e fora da região selecionada e também a quantidade de objetos de cada classe (individualmente) dentro e fora da região selecionada. 


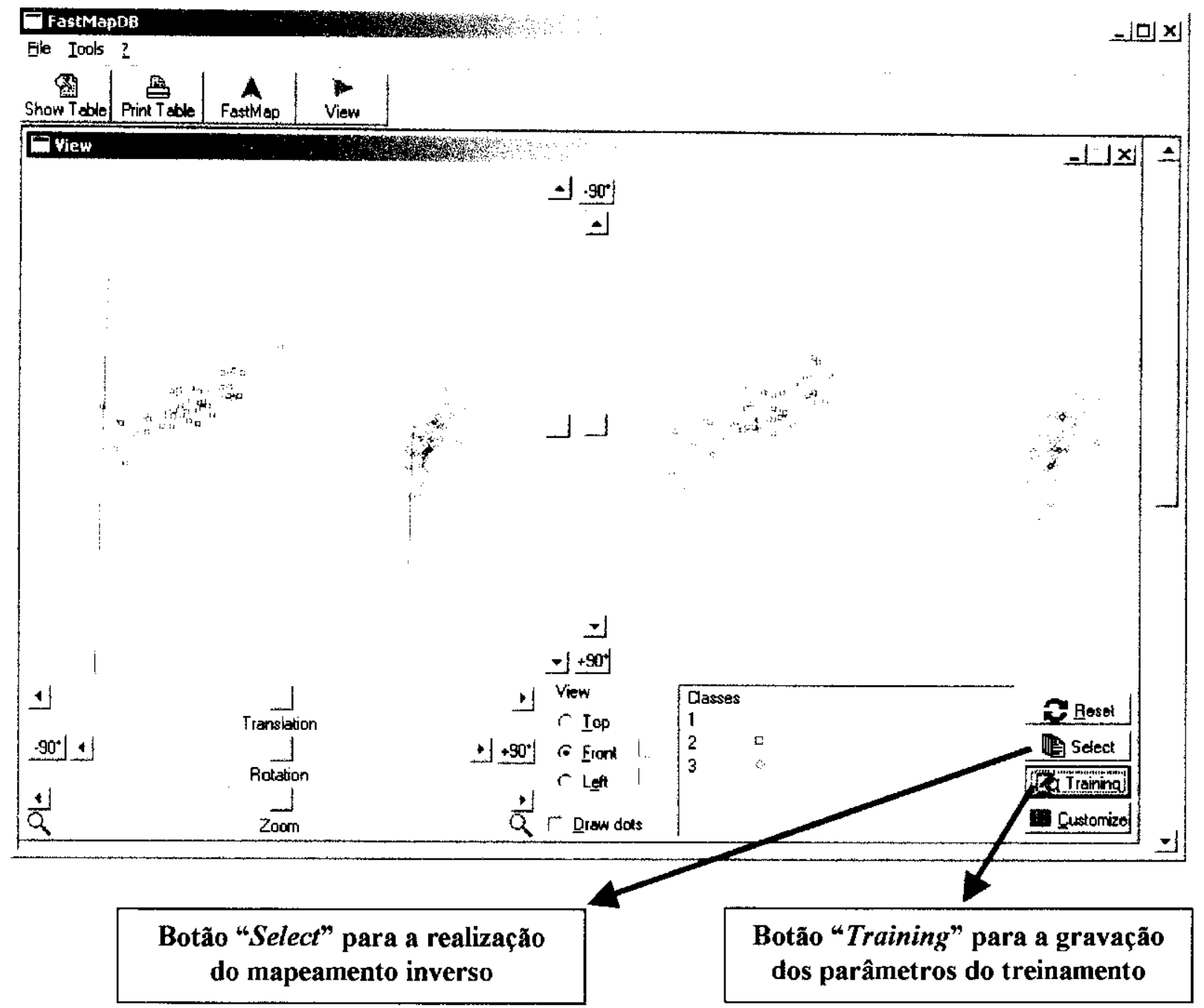

Figura 5.3 - Visualização dos dados do conjunto "Iris Plant" e seleção de uma região para o treinamento do classificador

Nesse exemplo, considerou-se que o usuário armazenou duas regiões do conjunto "Iris Plant", de uma mesma visualização (ou seja, mantendo as mesmas informações da tela principal da ferramenta - Figura 5.1), ao treinamento. Uma das regiões selecionadas é o paralelepipedo da Figura 5.3 e a outra é o paralelepipedo da Figura 5.4. 


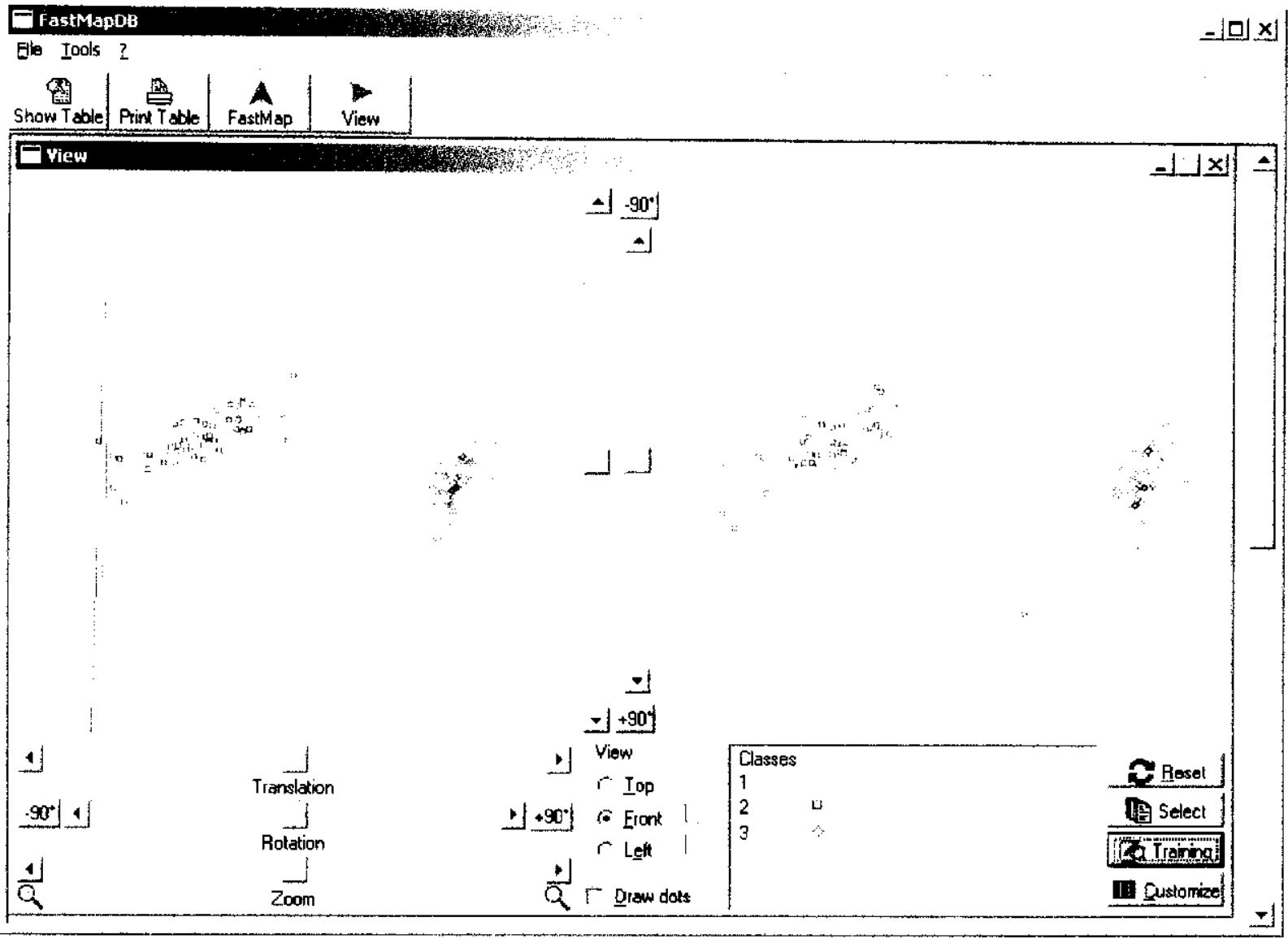

Figura 5.4 - Visualização dos dados do conjunto "Iris Plant" e seleção de outra região para o treinamento do classificador

Todas as regiões marcadas pelo usuário são armazenadas juntamente com a descrição da visualização corrente, que corresponde às informações selecionadas na tela principal do FastMapDB - Figura 5.1 (que inclui dados como o nome da tabela, atributo classificador, função distância, dentre outros). Todas as informações armazenadas nessa fase de treinamento contribuirão para a criação do modelo de classificação que será utilizado no processo de classificação dos dados.

Ainda para auxiliar no treinamento, o usuário pode desejar saber a identificação de qual objeto (na base de dados) corresponde a um determinado ponto indicado na visualização, ou coleções de objetos cujos pontos estão incluídos em uma área da visualização que o usuário poderá indicar (Mapeamento Inverso - seção 4.4). Isso pode ser feito marcando uma região de objetos e clicando no botão "Select" da Figura 5.3, que retornará quais são esses objetos na base de dados. 
Após o término do treinamento, temos os seguintes valores armazenados nas tabelas referentes do treinamento:

Tabela 5.1 - Dados do treinamento da tabela Visualization

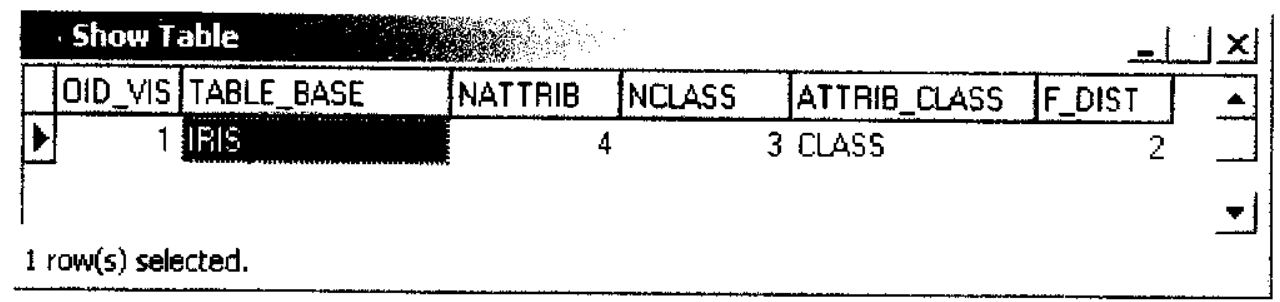

Tabela 5.2 - Dados do treinamento da tabela Attribute

\begin{tabular}{|c|c|c|c|c|c|c|c|c|c|c|c|c|}
\hline \multicolumn{13}{|l|}{ Shaw Table } \\
\hline OID VISATTRIB & IWEIGHT & LOG & ASNUMBEA & DROP_CARACTEA & A|KIND & PAVOTO & PFVOT1 & PIVDT2 & PIVTO3 & PFOT 4 & TPIVOT5 & 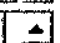 \\
\hline$1 \longdiv { A }$ & 1 & 0 & 0 & $\overrightarrow{0}$ & a d & 7,699999 & 4,3000001 & 115.6999998 & 84,900000 & & 6,30000019073486 & \\
\hline $1 \mathrm{~B}$ & 1 & 0 & 0 & 0 & $0 \mathrm{~d}$ & 2.5999996 & & 4.4001000 & 02.5 & 2,200000 & OC 3.29999995231628 & \\
\hline $1 C$ & 1 & 0 & 0 & 0 & $0 \mathrm{~d}$ & 6.9000000 & $\times 1,1000000$ & 01.5 & 4.5 & 4 & 6 & \\
\hline 10 & 1 & 0 & 0 & 0 & 09 & 22999998 & 8.1000000 & 00.4000000 & 01,7000000 & & 2.5 & \\
\hline
\end{tabular}

Tabela 5.3 - Dados do treinamento da tabela Shape

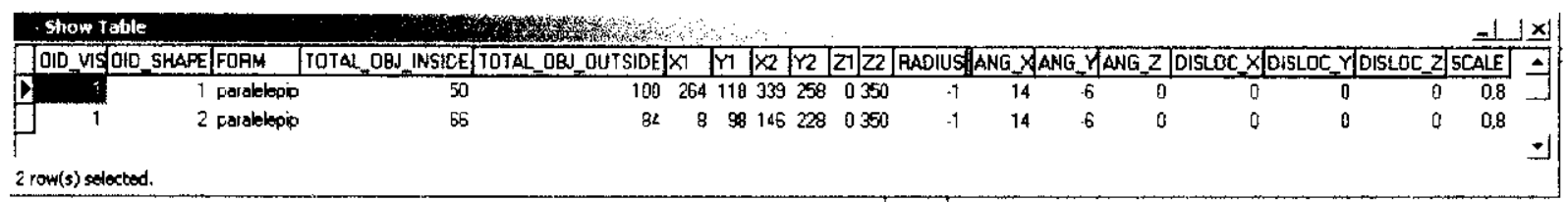


Tabela 5.4 - Dados do treinamento da tabela Counting

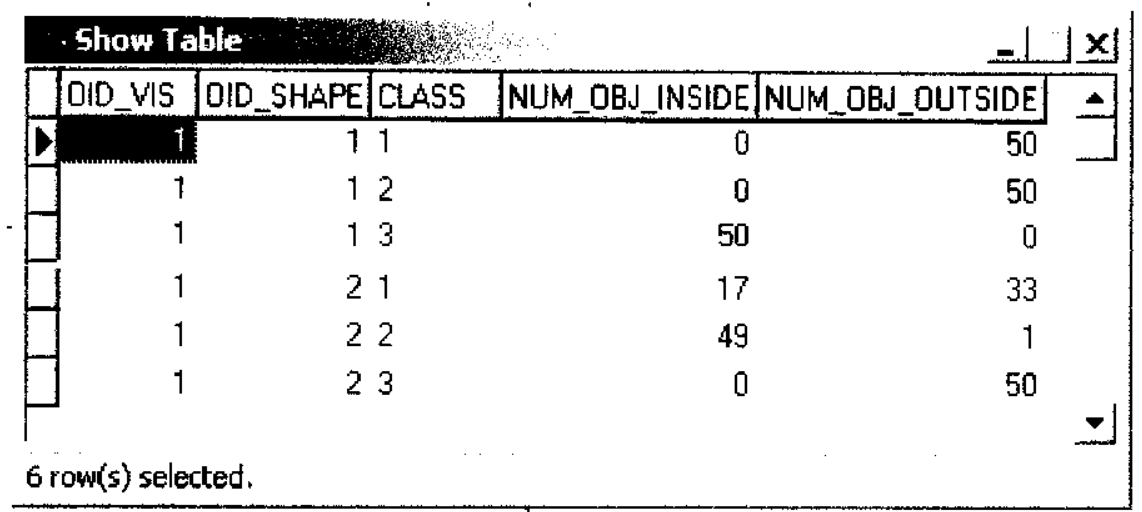

Deve-se deixar claro que aqui trabalhou-se com uma visualização somente para manter o exemplo simples. Mas o usuário poderia ter utilizado outras visualizações, variandose, por exemplo, o peso dos atributos, a quantidade de atributos, etc. E se várias visualizações referentes à tabela "IRIS" tivessem sido utilizadas no treinamento, tendo o atributo "CLASS" como atributo classificador, todas elas seriam usadas no processo de classificação.

Com todas essas informações do treinamento, ou seja, com esse modelo de classificação pronto (criado pelo usuário), podemos aplicar o Algoritmo Classificador para classificar os novos objetos inseridos na tabela "IRIS" (ou mesmo classificar os novos e reclassificar os já existentes). Isso será tratado na seção seguinte.

\subsubsection{Exemplo do Processo de Classificação de Dados}

Com o modelo de classificação criado anteriormente, pode-se iniciar o processo de classificação dos dados. De acordo com o Algoritmo Classificador, apresentado na seção 4.6.1, será mostrado, passo a passo, o processo de classificação de um objeto (escolheu-se um objeto somente para não tornar a descrição cansativa, pois tudo que é feito para um vale para todos os objetos).

Considere a seguinte tupla da tabela "IRIS" sem atributo classificador, ou seja, a tupla do objeto a ser classificado:

\begin{tabular}{|c|c|c|c|c|}
\hline A & B & C & D & Class \\
\hline 5 & 2 & 4 & 1 & Null \\
\hline
\end{tabular}


Como pode-se observar os dados da tabela Visualization na Tabela 5.1, tem-se uma tupla relativa ao treinamento da tabela "IRIS". Baseado no Oid Vis da tabela Visualization são realizadas consultas nas tabelas: Attribute (Tabela 5.2) para realizar o mapeamento dos objetos c Shape (Tabela 5.3) para saber a localização do ponto baseado nas regiões selecionadas pelo usuário. Posteriormente, baseado no Oid Shape da tabela Shape, é realizada uma consulta na tabcla Counting (Tabela 5.4) para poder calcular a fórmula de classificação. Os passos realizados no algoritmo classificador são os seguintes:

1. Inicialmente o usuário deverá entrar na tela principal da ferramenta FastMapI)B (Figura 5.5) e selecionar: a base de dados, a tabela "IRIS" e o atributo de classificação dessa tabcla "CLASS". Depois disso, ele deve clicar no botão "(Kassifier" (Figura 5.5), que automaticamente iniciará todo o processo de classificação dos dados. Desse ponto $\mathrm{cm}$ diante tudo é feito internamente, sem a intervenção do usuário, e utilizando todos os dados armazenados durante o treinamento. A única intervenção do usuário ocorre quando o programa pergunta qual o nome da nova tabela que retornará as porcentagens das classes. Essa tabela é gerada a partir dos dados da tabcla utilizada na classificação e mais os seguintes atributos: a porcentagem referente a cada classe (de cada tupla) utilizada no treinamento e a melhor classe, ou seja, a classe com a maior porcentagem. 


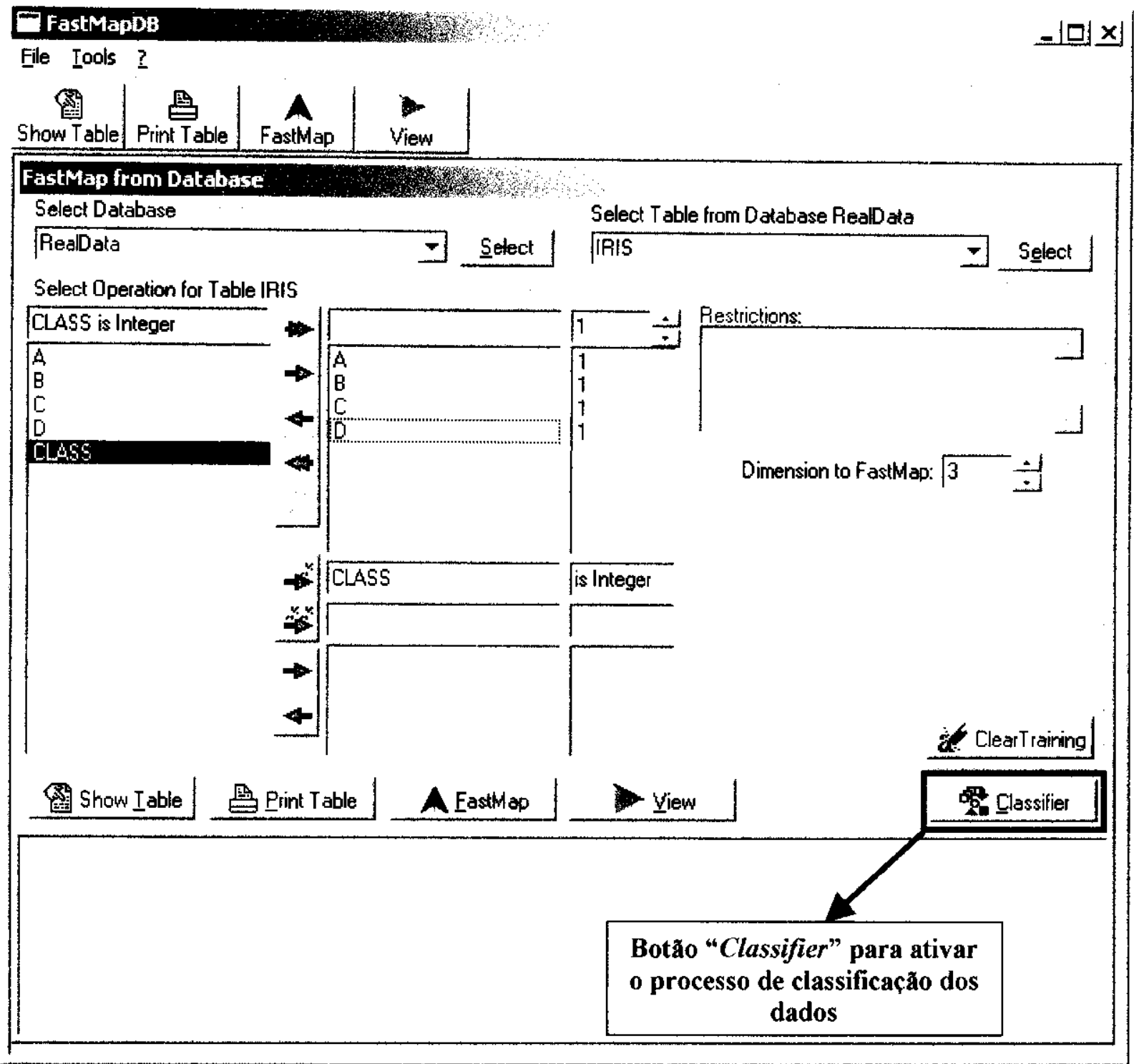

Figura 5.5 - Seleção da tabela a ser classificada

2. Realizar uma consulta na tabela Visualization para descobrir se existe treinamento referente à tabela "IRIS" e ao atributo de classificação selecionado - Class.

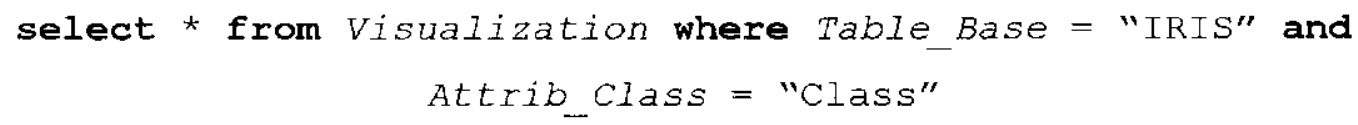

Essa consulta irá retornar os seguintes valores:

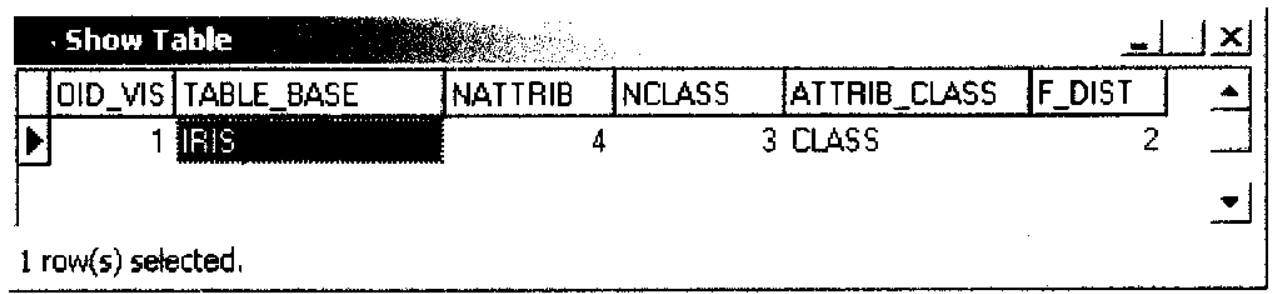


3. Realizar uma consulta na tabela Attribute, de acordo com o valor do Oid Vis retornado da consulta anterior, para obter as informações necessárias à realização do processamento do algoritmo fastmap (apresentado na seção 2.3.6.1).

select * from Attribute where oid Vis $=01$

Essa consulta irá retornar os seguintes valores:

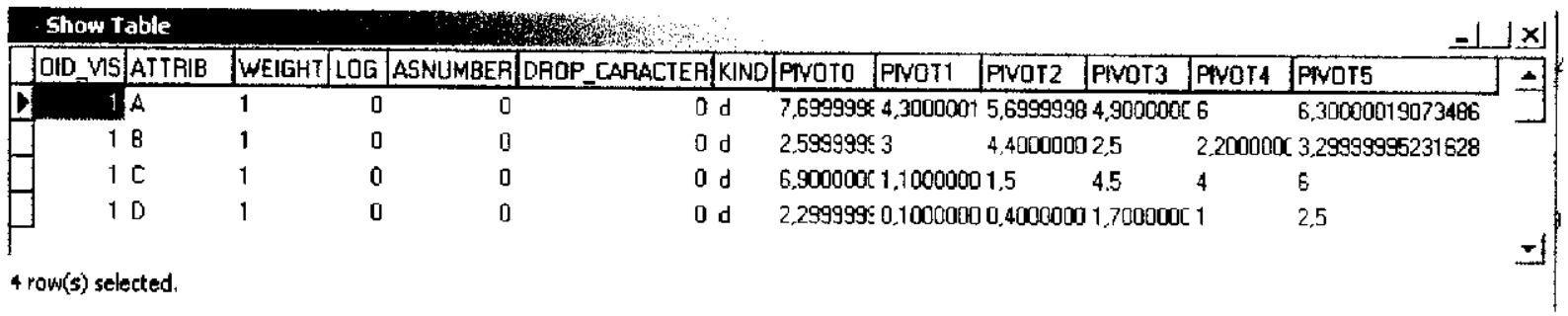

4. Processamento do algoritmo fastmap que realiza o mapeamento de objetos, retornando suas coordenadas $(x, y, z)$ no espaço tri-dimensional. Ele utiliza os valores dos pivôs, os pesos dos atributos e se foi utilizado o logaritmo do atributo, sendo todas essas informações retornadas da consulta anterior. Fastmap utiliza também a função distância retornada da consulta na tabela Visualization.

Como aqui está sendo exemplificada somente a classificação de um objeto, o resultado do algoritmo fastmap retornaria a coordenada $(300,107.52,102.46)$. Esse ponto será utilizado para descobrir a localização do objeto nas regiões armazenadas na fase de treinamento.

5. Realizar uma consulta na tabela Shape, de acordo com o valor do Oid Vis retornado da consulta na tabela Visualization, para obter as informações necessárias às regiões selecionadas no treinamento, e, então, descobrir a localização do objeto mapeado anteriormente, baseado nessas regiões selecionadas pelo usuário.

select * from Shape where Oid Vis $=01$

Essa consulta irá retornar os seguintes valores:

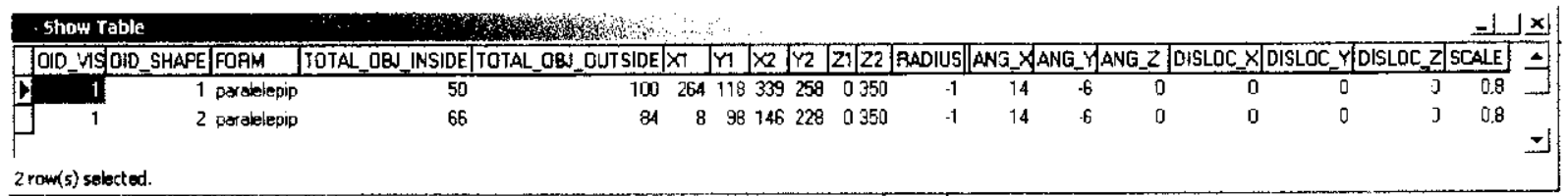


Será analisada, inicialmente, a primeira região selecionada onde Oid_Shape $=1$. É realizado um processamento no ponto $(300,107.52,102.46)$ para descobrir se ele se encontra dentro ou fora dessa região, utilizando todas as transformações realizadas na visualização durante o treinamento (Ang_x, Ang y, Ang_z, Disloc_x, Disloc y, Disloc_z, e Scale). Com esse processamento tem-se a posição desse ponto - $(320,67,92)$. Agora, compara-se esse ponto transformado com os valores das delimitações do paralelepípedo $(X 1, Y 1, X 2, Y 2, Z 1$, $Z 2$ ), para descobrir se ele se encontra dentro ou fora do paralelepípedo. Se esse ponto se encontrar dentro, usa-se o total de objetos (de todas as classes) dentro dessa região Total_Obj Inside, caso contrário, usa-se Total Obj_Outside. Como o ponto se encontra fora, guarda-se o valor de Total_Obj_Outside que é 100, o qual será utilizado posteriormente na fórmula de classificação.

Agora será analisada a segunda região selecionada onde Oid Shape $=2$. É realizado o mesmo processamento no ponto $(300,107.52,102.46)$ para descobrir se ele se encontra dentro ou fora dessa região, utilizando todas as transformações realizadas na visualização durante o treinamento, como já citadas na primeira região selecionada. Com esse processamento tem-se a posição desse ponto - $(320,67,92)$. Agora, compara-se esse ponto transformado com os valores das delimitações do paralelepípedo para descobrir se ele se encontra dentro ou fora do paralelepípedo. Como o ponto se encontra fora, usa-se o valor de Total Obj_Outside que é 84, o qual também será utilizado posteriormente na fórmula de classificação.

5. Realizar uma consulta na tabela Counting, de acordo com os valores dos Oid Shape retornados da consulta na tabela Shape, para obter as informações sobre a quantidade de objetos, de cada classe, presentes dentro e fora das regiões selecionadas.

Analisando a primeira região selecionada da tabela Shape, onde Oid Shape $=01$ select * from Counting where Oid_Vis $=01$ and Oid Shape $=01$

Os dados retornados são:

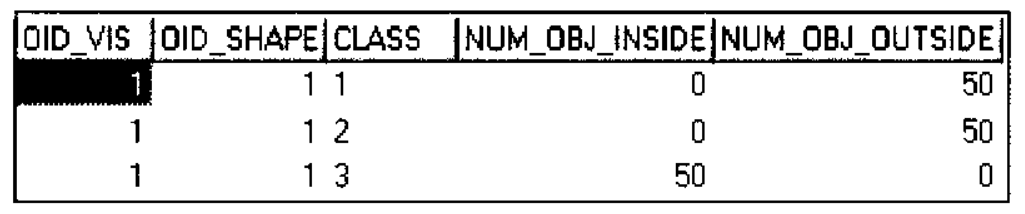


Com essas informações, inicia-se a construção da fórmula de classificação dos dados, usada na equação (1), a qual já foi apresentada na seção 4.6.1. Logo, utilizando os valores retornados da consulta anterior, têm-se:

Num_Obj_Outside (classeI)_da_I ${ }^{a}$ região $=50$

Total_Obj Outside_da_l ${ }^{a}$ região $=100$

Num Obj_Outside (classe2)_da_I ${ }^{a}$ região $=50$

Total_Obj_Outside_da_l ${ }^{a}$ região $=100$

Num_Obj_Outside (classe3)_da_1 ${ }^{a}$ região $=0$

Total_Obj_Outside_da_1 $1^{a}$ região $=100$

Agora, analisando a segunda região selecionada da tabela Shape, onde Oid Shape $=02$

select * from Counting where Oid_Vis $=01$ and Oid_Shape $=02$

Os dados retornados são:

\begin{tabular}{|c|c|c|c|}
\hline OID_VIS & OID_SHAPE CLASS & NUM_OBJ_INSIDE & NUM_OBJ_OUTSIOE \\
\hline 1 & 21 & 17 & 33 \\
\hline 1 & 22 & 49 & 1 \\
\hline 1 & 23 & 0 & 50 \\
\hline
\end{tabular}

Com as informações dessa nova região, a fórmula de classificação dos dados vai sendo complementada. Mas como não existem mais regiões selecionadas e nem novas visualizações dessa tabela no treinamento, aqui já é finalizado o processo de classificação do objeto, computando a porcentagem do objeto fazer parte de cada uma das classes:

Num_Obj_Outside (classe1)_da_2 ${ }^{a}$ região $=33$

Tolal Obj_Outside_da_2 ${ }^{a}$ região $=84$ 
Num Obj Outside (classe2) da $2^{\prime \prime}$ região $=1$

Total_Obj_Outside_da_2"regiõo $\cdots 84$

Num_Obj_Outside (classe3) da_2"região $=50$

Total Obj Ontside da_2"região $=84$

Com os valores referentes às duas regiões utilizadas no treinamento, têm-se os seguintes valores para a fórmula de classificação dos dados:

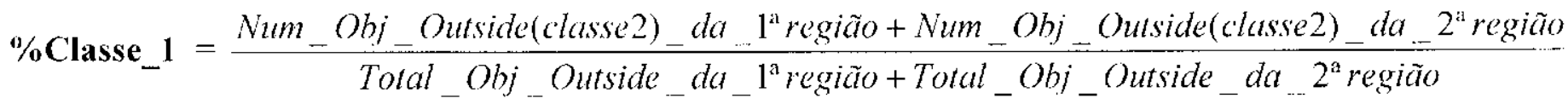

$\%$ Classe_I $=\frac{50+33}{100+84}=0.451086 * 100=\mathbf{4 5 , 1 1 \%}$

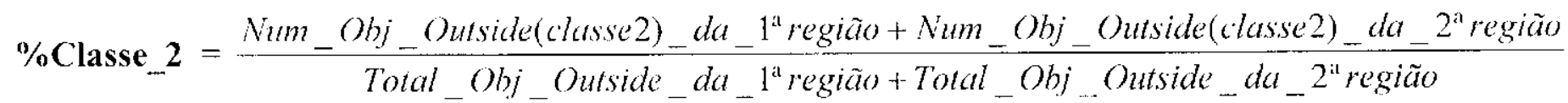

$\%$ Classe_2 $=\frac{50+1}{100+84}=0.277173 * 100=\mathbf{2 7 , 7 2 \%}$

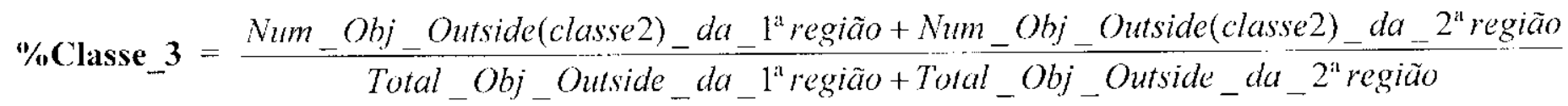

\%Classe_3 $=\frac{0+50}{100+84}=0,271739 * 100=\mathbf{2 7 , 1 7 \%}$

Logo, pode-se concluir que o objeto a ser classificado tem a maior probabilidade $(45,11 \%)$ de fazer parte da Classe "1". Deve-se salientar que essa classificação é baseada nas regiões selecionadas pelo usuário, então para que o objeto seja bem classilicado, o usuário tem que ter escolhido, adequadamente, as regiões significativas que ele "vê". 
A nova tabela, que é criada após a classificação do objeto, está ilustrada a seguir:

\begin{tabular}{|c|c|c|c|c|c|c|c|c|}
\hline A & B & C & D & Class & Class_1 (\%) & Class_2 (\%) & Class_3 (\%) & Best_Class \\
\hline 5 & 2 & 4 & 1 & Null & 45,11 & 27,72 & 27,17 & 1 \\
\hline
\end{tabular}

\subsection{Considerações Finais}

Neste capítulo foi apresentado um exemplo de utilização do Classificador Visual de Dados, desenvolvido neste trabalho de Mestrado, através da utilização da ferramenta FastMapDB. Com isso, loi possível exemplificar cada passo da lase de treinamento do classificador e também cada etapa do processo de classificação dos dados. 


\section{Capítulo 6}

\section{Conclusões}

\subsection{Introdução}

Este trabalho de Mcstrado desenvolveu uma nova técnica para construcão visual de Classificadores de Dados. utilizando a elevada capacidade humana para analisar dados representados de forma gráfica como fator que auxilia o treinamento do classificador.

Dessa forma, criamos o primeiro sistema de apoio à criação visual de um classificador de que temos notícia, pois os sistemas Visual Data Mining, existentes atualmente, destinam-se apenas a disponibilizar visualmente as informações tratadas e/ou encontradas. Já o nosso sistema utiliza a visualização na fase de trcinamento do classificador, e a fase final de classificação efetiva é totalmente automática, independente da ação de um operador humano.

Os resultados práticos obtidos com o desenvolvimento dessa nova técnica para construção visual de classificadores de dados para Data Mining foram incorporados à ferramenta FastMapDB, através de uma extensão da mesma. $\Lambda$ ssim, essa ferramenta passou a ser utilizada também para classificação de dados.

A força c o ineditismo deste trabalho está na participação do usuário no processo de treinamento do classificador, usando uma ferramenta grálica, e que, ainda acreditamos, ser agradável de se utilizar.

É importante ressaltar que este trabalho pode auxiliar também nas tarefas de agrupamento e de tratamento de exceções. Para tarefas de agrupamento e tratamento de exceções, o sistema se comporta apenas como um sistema de visualização de dados, onde o usuário identifica visualmente e delimita o mapeamento dos agrupamentos e/ou exceções. 
Para a tarefa de classificação, o sistema passa a utilizar a visualização como o processo determinante de treinamento na geração das regras de classificação.

\subsection{Contribuições do Trabalho}

As contribuiçôes deste trabalho são:

1) Implementação de uma interface gráfica de visualização de dados, Módulo Visualizador, que foi integrado ao Fast MapDB;

2) Definição do Processo de Seleção Visual dos Dados que possibilita ao usuário selecionar um objeto ou regiǒes de objetos, baseado na visualização dos dados;

3) Desenvolvimento do processo de Mapeamento Inverso que possibilita ao usuário saber quais são os objetos na base de dados, de acordo com uma região selecionada na visualização;

4) Implementação do algoritmo de Mapeamento Inverso:

5) Desenvolvimento da fase de Treinamento Visual do Classificador. Nessa fase o usuário interage com a visualização dos dados, definindo regiões de objetos de scu interesse, que vão sendo armazenadas em tabelas, a fim de serem utilizadas na etapa de classificação dos dados;

6) Implementação da fase de Treinamento Visual do Classificador;

7) Descnvolvimento do Processo de Classificação de Dados que é realizado após a fase de treinamento do Classificador, e onde são utilizados todos os parâmetros armazenados no treinamento. Foi desenvolvido um Algoritmo Classificador e uma Fórmula para Classificação dos Dados: 
8) Implementação do Processo de Classificação de Dados.

\subsection{Sugestões de Trabalhos Futuros}

Este trabalho pode ter prosseguimento em duas frentes de trabalho: desenvolvimentos teóricos e extensão da ferramenta FastMapDB. A seguir, as sugestões de trabalhos futuros nessas duas frentes de trabalho são descritas.

\subsubsection{Desenvolvimentos Teóricos}

\subsubsection{Suporte à Classificação com Análise de Vizinhança}

O uso do classificador visual opera efetuando a contagem de objetos de cada classe que estão dentro da região delimitada no espaço pelo usuário. Objetos que estejam fora de uma determinada região são contabilizados como fora dá região, c não importa se estejam próximos ou distantes da região. todos recebem a mesma classificação. No entanto, a maioria dos classificadores existentes, e em particular muitos dos mais bem sucedidos classificadores existentes. são baseados nas medidas de distância desde os objetos que fazem parte de uma classe até os objetos externos (ou que devem ainda ser classificados). Portanto, a incorporação de meios para considerar a distância dos objetos que estão fora de uma região demarcada pelo usuário até essa região pode ser interessante. Várias opções devem ser estudadas, considerando-se tanto a adequação de cada opção quanto a eficiência e unicidade dos resultados que podem ser obtidos. Dentre essas opções é possível antever e considerar: a distância de um objeto externo ao objeto interno mais próximo; a distância de um objeto externo à região demarcada; a distância de um objeto externo ao centro representativo da classe. o qual pode ser o centro de massa do conjunto de objetos internos ou o centro geométrico da região delimitada e; funções de distância lineares entre os objetos externos, ou baseadas em comportamentos representados por curvas de distribuição. Essas mesmas opções podem ser igualmente consideradas para ponderar objetos internos, permitindo a criação de uma função híbrida entre o classificador bascado apenas na pertinência de um objeto às várias 
regiões delimitadas num modelo de classificação e um classificador baseado apenas na distância entre os objetos c as classes delimitadas através de uma dada opção.

\subsubsection{Suporte à Lógica Nebulosa}

A tabela resultado gerada pela segunda fase do processo de classificação inclui todos os dados da tabela original, mais as probabilidades de cada objeto pertencerem a cada classe existente, e a indicação de qual a classe mais provável. Esse último atributo é útil em situações onde se pretende "classificar" o objeto pela classe mais provável, mas outras aplicações podem se beneficiar das probabilidades que foram calculadas para cada classe. Uma das aplicações onde isso pode ser útil é quando mais de um atributo classificador é utilizado. Por exemplo, pode-se classificar uma imagem pelas obras arquitetônicas que nela aparecem (prédios, pontes, casas, arquibancadas, calçadas, etc.) e também pelo tipo de vegetação (grama, árvores, arbustos, etc.), mobília, etc. Assim, poder-se-ia procurar um cstádio de futebol em figuras com grande probabilidade de ter grama e arquibancadas, ou um campo de basquete como tendo arquibancadas e calçadas. Aplicações assim poderiam utilizar lógica nebulosa, envolvendo diversos atributos. em que cada atributo classificador pode ter vários valores, cada qual com diferentes probabilidades de ocorrência. O resultado produzido pelo classificador hoje pode ser estendido para suportar esse tipo de aplicação.

\subsubsection{Extensão da Ferramenta FastMapDB}

\subsubsection{Visualização do Treinamento}

Tal como está implementada hoje, o processo de treinamento de um classificador é realizado como uma sequiência continua, incremental, de operações de parametrizações da visualização e delimilação de regiões. Após a finalização de uma seção de treinamento não é possível "refinar" o modelo de classilicação obtido, a menos que um novo classificador seja treinado desde o início. No entanto, essa é uma restrição imposta pela implementação atual da ferramenta, a qual foi feita com o objetivo imediato de demonstrar a aplicabilidade dos conceitos desenvolvidos nesta dissertação. Evidentemente, a usabilidade da ferramenta pode 
ser bastante aumentada com a implementação de uma interface com o usuário que inclua mais opções de interação. Dentre clas. uma que certamente seria bem-vinda corresponde à possibilidade de se visualizar simultaneamente as várias regiões que interceptem a janela de visualização corrente, mesmo que oriundos de parametrizações distintas (tal como rotação, translação e escala). Igualmente atraente scria, nesse caso, a utilização de métodos de síntese de imagem para a visualização das regiões não apenas através de seus "wire frames" tal como é feito atualmente, mas utilizando uma visualização mais intuitiva.

\subsubsection{Suportar Diferentes Formas das Regiões}

Atualmente a ferramenta suporta a delimitação de paralelepípedos e esferas. A cxtensão da quantidade de tipos de regiões (por exemplo, cones e elipses), é também uma sugestão que pode ser bastante interessante para a utilização prática da ferramenta no dia a dia. No entanto, nos cxperimentos realizados, notou-se que a delimitação de regiões resultantes da intersecção de outros volumes pode apresentar resultados interessantes. Isso ocorre, por exemplo, quando duas classes de objetos visivelmente se interceptam. Da maneira como a ferramenta está implementada, essa separação deve ser feita delimitando-se cada classe scparadamente em duas regiões, e a região de interceptação como uma terceira região. No entanto, o reconhecimento automático de operações como soma e subtração de sólidos poderia aumentar a usabilidade e capacidade classificatória da ferramenta. 


\section{Referências Bibliográficas}

[Agrawal \& Srikant, 1994]

[Aggarwal \& Yu, 2001$]$

[Ankerst, 2000]

[Braga et al., 2000]

[Chen et al.. 1996]

[Ester et al., 1998]

[Faloutsos \& Lin, 1995]
AGRAWAL, R.; SRIKANT, R. Fast algorithms for mining association rules. In: Internacional Conference Very Large Databases (VLDB'94), Santiago, Chile, p.487-499, 1994.

AGGARWAL, C. C.; YU, P. S. Outlier Detection for High Dimensional Data. SIGMOD/PODS, Santa Barbara. USA, May, 2001.

ANKERST, M.. Visual Data Mining. Dissertação de Mestrado. Disponível na URL: http://www.disscrtation.de/englisch/index.php3. Consultado em 20 de fevereiro de 2002.

BRAGA, A. de P.; LUDEMIR, T. B.; CARVAlHO, A. C. P. de L. F. Redes Neurais - Teoria e Aplicações. 1. ed. Rio de Janeiro: LTC - Livros Técnicos e Científicos Editora S.A., 2000. cap.1, p.1-14.

CHEN. M.; HAN, J.; YU, P. S. Data Mining: an Overview from Database Perspective. IEEE Transactions on Knowledge and Data Engineering, v.8, n.6. p. 866-863, 1996.

ESTER, M; FROMMELT, A.; KRIEGEL, H.-P.; SANDER, J. Algorithms for Characterization and Trend Detection in Spatial Databases. In: International Conference on Knowledge Discovery and Data Mining. 4., New York, USA, 1998. Proceedings. $\Lambda$ AI Press, 1998, p. 44-50.

FALOUTSOS, C.; LIN, K.-I. FastMap: A Fast Algorithm for Indexing, Data-Mining and Visualization of Traditional and Multimedia Datasets. $A C M$ SIGMOD, v.24, n.2, p.163-174, 1995. 
[Fayyad, 1997]

[Fayyad et al., 1996]

[Felipe, 2000]

[Ganti et al., 1999]

[Gershon, 1994]

[Han \& Kamper. 2000]

[Hinneburg et al., 1999]

[Hinneburg \& Keim, 1999]

[Inmon. 1996]
FAYYAD, U. Mining Databases: Towards Algorithms for Knowledge Discovery. Bulletin of the IEEE Technical committee on Data Engineering. v. 21, p. 39-48, 1997.

FAYYAD, U.: SHAPIRO, G. P. and SMYTH, P. The KDD Process for Extracting Useful Knowledge from Volumes of Data. COMMUNICATIONS OF THE ACM, v.39, n.11, p.2734, 1996.

FELIPE, J. C. Extração de Conhecimento sobre Metadados de Aplicações Multimídia em um Ambiente Multidimensional Orientado a Objetos. São Carlos, 2000. Dissertação de Mestrado, Centro de Ciências Exatas e de Tecnologia, Universidade Federal de São Carlos, 137 p.

GANTI, V.; GEHRKE, J.; RAMAKRISHN $\Lambda$ N, R. Mining Very Large Databases. IEEE Computer, v. 32, p. 38-45, 1999.

GERSHON, N. From Perception to Visualization. In: Rosemblum, L. et al. (eds.) - Scientific Visualization, Advances and Challenges. Academic Press, 1994.

HAN, J.; KAMPER, M. Data Mining - Concepts and Techniques. 1. ed. New York: Morgan Kaufmann, 2000, 550 p.

IIINNEBURG, A.; KEIM, D. $\Lambda$ : WAWRYNIUK, M. HD-Eyc: Visual Mining of High-Dimensional Data. IEEE Computer Graphics and Applications, v. 19, p. 22-30, 1999.

HINNEBURG, A.; KEIM, D. A. Optimal Grid-Clustering: Towards Breaking the Curse of Dimensionality in HighDimensional Clustering. In: International Conference on Very Large Databases, 25., Edinburgh, Escócia, 1999. Proceedings. Morgan Kaufmann, p. 506-517.

INMON, W. H. Como Construir um Data Warchouse, Traduçăo. Rio de Janeiro:Editora Campus Ltda., $2^{a}$ edição, 1996. 
[Keim, 1996]

[Keim, 1997$]$

[Keim, 2001]

[Keim, 2002]

[Keim \& Kriegel, 1994]

[Keim \& Kriegel, 1996]

[Lopes, 1999]

[Ng \& Han, 1994$]$

[Oliveira, 2000]
KEIM, D. A. Pixel-oriented Database Visualization. S/GMOD RECORD, v. 25, n. 4, p. 35-39, 1996.

KEIM. D. A. Tutorial "Visual Data Mining" on VLDB'97. Disponível na URI: $\underline{\text { http://www.informatik.uni- }}$ halle.de/ keim/tutorials.html. Consultado em 17 de abril de 2002.

KEIM, D. A. Visual Exploration of Large Data Sets. Communications of the ACM. v. 44. n. 8, p. 39-44, 2001.

KEIM, D. A. Information Visualization and Visual Data Mining. IEEE Transactions on Visualization and Computer Graphics, v.8, n.1 2002.

KEIM, D. A.; KRIEGEL, H. -P. VisDB: Database Exploration Using Multidimensional Visualization. IEEE Computer Graphics and Applications, v. 14, p. 40-49, 1994.

KEIM, D. A. KRIEGEL, H. -P. Visualization Techniques for Mining Large Databases: A Comparison. IEEE Transactions on Knowledge and Data Engineering, v.8, n. 6, p. 923-938. 1996.

LOPES, C. H. P. Classificação de Registros em Bunco de Dados por Evolução de Regras de Associaçăo Utilizando Algorimos Généticos. Rio de Janeiro, 1999. Dissertação de Mestrado. Pontifícia Universidade Católica do Rio de Janeiro, $145 \mathrm{p}$.

NG, R. T.; IIAN: J. Ffficient and Effective Clustering Methods for Spatial Data Mining. In: International Conference on Very Large Data Bases, 20., Santiago, Chile, 1994. Proccedings. Morgan Kaufmann, 1994, p. 144-155.

OLIVEIRA, R. B. T. O Processo de Extração de Conhecimento de Base de Dados Apoiado por Agentes de Softrucare. São Carlos, 2000. Dissertação de Mestrado, Instituto de Ciências Matemáticas e de Computação, Universidade de São Paulo, 104 p. 
[Oliveira \& Minghim, 1997] OLIVEIRA, M. C. F.; MINGHIM, R. Uma Introdução à Visualização Computacional. In: Jornada de Atualização em Informática, 16., Brasília, Brasil, 1997. Anais. SBC, 1997, p. 85-131.

[Oliveira \& Rezende, 1998$]$

OLIVEIRA, R. B. T.; RFZENDE, S. O. Ferramentas de Visualização de Dados do MineSet. Relatório Técnico, n.71. Instituto de Ciências Matemáticas e de Computação, USP, 1998.

[Quinlan. 1993]

QUINLAN, J. R. C4.5: Programs for Machine Learning. San Mateo, CA: Morgan Kaufmann, 1993.

[Ribarsky et al., 1999]

RIBARSKY, W.; KAT\%, J.; JIANG, F.; HOLIAND, A. Discovery Visualization Using Fast Clustering. IEEE Computer Graphics and Applications, v. 19, p. 32-39, 1999.

[Stolte et al., 2002]

[Stolte et al., 2002] STOLTE, C.; TANG, D.; HANRAHAN, P. Polaris: A System for Query, Analysis, and Visualization of Multidimensional Relational Databases. IEEE Transactions on Visualization and Computer Graphics, v. 8, n. 1, p. 52-65. 2002.

[Syed el al., 1999]

SYED, N. A.; LIU. H.; SUNG, K. K. A Study of Support Vectors on Model Independent Example Selection. In: International Conference on Knowledge Discovery and Data Mining, 5., San Diego, USA, 1999. Proceedings. AAAI Press, 1999, p. 272-276.

[Traina, 2001]

TRAINA. A. J. M. Suporte à Visualização de Consultas por Similaridade em Imagens Médicas através de Estrutura de Indexação Métrica. Tese Livre-Docente em Computação. ICMC - USP, São Carlos, 2001, 104 p.

['TrainaJr et al., 1999]

TRAINAJR, C.; TRAINA, A. I. M.; FALOUTSOS, C. FastMapDB User's Manual. Carnegie Mellon University School of Computer Science, 1999, 8 p.

['Traina et al., 2001]

TRAINA, A. J. M.; TRAINAJR, C.; BOTELHO, E.; BARJONI, M. C. N.; BUENO, R. Visualização de Dados em 
Sistemas de Bases de Dados Relacionais. In: Simpósio Brasileiro de Banco de Dados, 16., Rio de Janeiro, Brasil. 2001. Anais. s. ed., 2001, p. 95-109.

[Wong, 1999]

WONG. P. C. Visual Data Mining. IEEE Computer Graphics and Applications, v. 19, p. 20-21, 1999.

[7hang et al.. 1996]

ZHANG T.; RAMAKRISHNAN, R.; LIVNY, M. BIRCH: An Efficient Data Clustering Method for Very Large Databases. In: International Conference on Management of Data, Montreal, Canada, 1996. Proceedings. ACM Press, 1996, p. 103-114. 